\title{
Uma Técnica por Transformada para Compressão de Imagens
}

\author{
Ana Cristina dos Santos
}

Orientador: Messias Meneguette Júnior

Dissertação apresentada ao Instituto de Ciências Matemáticas de São Carlos - USP, como parte dos requisitos para a obtenção do Título de Mestre em Ciências - área: Ciências de Computação e Matemática Computacional.

São Carlos 
Aos meus pais, José e Antonia, a minha irmã, Neide, ao Alexandre, pela compreensão, carinho e incentivo. 


\section{Agradecimentos}

Ao Messias, pelo apoio dado desde minha vinda ao ICMSC, pela orientação e por toda sua dedicação nos momentos em que foi necessária sua presença em São Carlos.

À Agma, pela concessão de algumas imagens, pela atenção e incentivo.

À Edméa e Marcinha, pela grande amizade nascida neste Instituto.

Ao José Hilton, meu grande amigo, pela força e incentivo dispensado em momentos importantes de minha vida.

Aos amigos da FATEC-Taquaritinga, pelo carinho e companheirismo.

A todas as pessoas que de alguma forma contribuíram para a realização deste trabalho.

A CAPES, pelo auxílio financeiro concedido. 


\section{Resumo}

A representação digital de imagens exige um número muito grande de bits, ocupando muito espaço de memória. A fim de reduzir o custo de transmissão ou armazenagem, preservando a qualidade da imagem, recorre-se às técnicas de codificação e compressão.

Este trabalho apresenta um módulo "adaptativo" de compressão baseado na transformada discreta do co-seno (DCT), onde a quantização é feita utilizando duas matrizes atribuiçôes de bits geradas a partir das variâncias dos blocos de coeficientes transformados; e o código de Huffman é utilizado para associar aos coeficientes quantizados uma palavra de código de comprimento variável. 


\begin{abstract}
The digital representation of an image requires a very large amount of bits, i.e. too much storage space. In order to reduce transmission/storage costs, as well as preserving quality, one uses compactation and compression techniques.

This work presents an "adaptative" image compression module based on discrete cosine transform (DCT), where quantization is done through two matrices of bits obtained from the coefficient variance; Huffman algorithm is used to associate - quantized coefficients to a variable length word.
\end{abstract}




\section{Conteúdo}

Introdução 1

1 Fundamentos de Compressão de Imagens 3

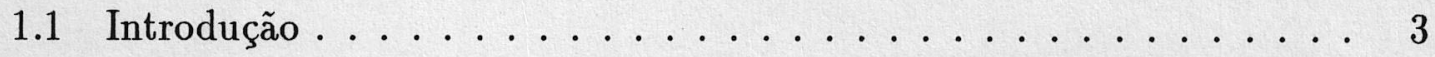

1.2 Psico-Física da Visão . . . . . . . . . . . . . . . 4

1.2 .1 O Olho Humano $\ldots \ldots \ldots \ldots \ldots \ldots \ldots \ldots \ldots \ldots \ldots \ldots$

1.2 .2 Limiar Visual . . . . . . . . . . . . 6

1.3 Redundâncias Estatísticas . . . . . . . . . . . . 7

1.3.1 Redundâncias nos Dados Amostrados - Teoria de Informação 7

1.3.2 Codificação com Aproximação - Teoria Razão de Distorção . . 14

1.3.3 Modelos Estatísticos . . . . . . . . . . . . . 16

2 Técnicas de Compressão de Imagens 22

2.1 Introdução . . . . . . . . . . . . . . . . . . . 22

2.2 Técnicas Básicas de Compressão . . . . . . . . . . . . . . 23

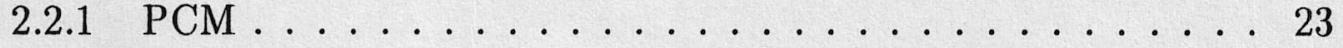

2.2.2 Quantização por Contraste . . . . . . . . . . 25

2.2.3 Quantização por Ruído Pseudo-Aleatório ......... 25

2.2 .4 Codificação Run-Length . . . . . . . . . . 26

2.3 Codificação Preditiva . . . . . . . . . . . . . . . 28

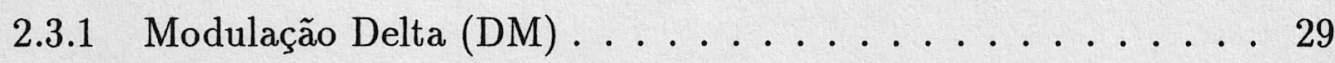

2.3 .2 Codificação DPCM . . . . . . . . . . . . 31

2.4 Codificação Híbrida . . . . . . . . . . . . . . . . . . 37 
2.5 Codificação por Blocos de Imagens . . . . . . . . . . . 38

2.5.1 Codificação por Truncamento de Blocos (BTC) . . . . . 40

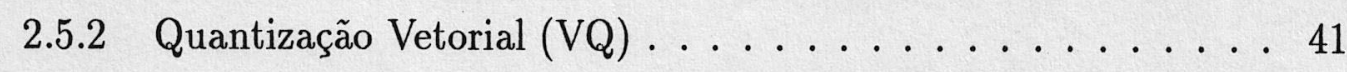

3 Codificação de Imagens por Transformada 43

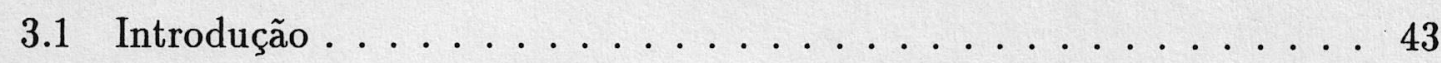

3.2 Transformada Ótima de Karhunen-Loève (KLT) . . . . . . . . 44

3.3 Algoritmo Rápido para a Transformada Discreta do Co-Seno . . . . 46

3.3.1 Transformada Discreta do Co-Seno 2-D . . . . . . . . . 46

3.3.2 Transformada Rápida Discreta do Co-Seno 2-D (FDCT) . . . 49

3.3.3 Transformada Rápida Inversa do Co-Seno - FDCT Inversa . . 50

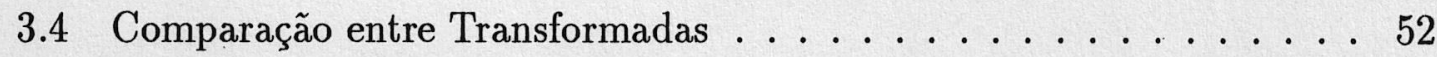

3.4.1 Eficiência em Compactar Energia $\eta_{E} \ldots \ldots \ldots \ldots \ldots$

3.4.2 Eficiência na Decorrelação $\eta_{c} \ldots \ldots \ldots \ldots \ldots \ldots$

3.5 JPEG $\ldots \ldots \ldots \ldots \ldots \ldots \ldots \ldots \ldots \ldots \ldots \ldots \ldots$

3.6 Seleção e Quantização de Coeficientes . . . . . . . . . . . 59

3.6 .1 Seleção de Coeficientes . . . . . . . . . . . . . . 59

3.6 .2 Atribuição de Bits . . . . . . . . . . . . 61

4 Resultados Experimentais $\quad 65$

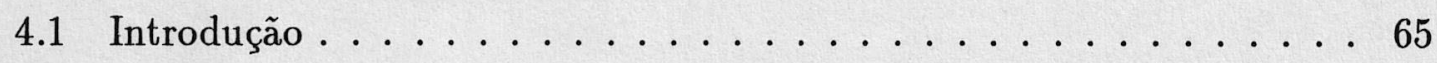

4.2 O Processo de Compressão e Descompressão . . . . . . . . . . 66

4.3 Imagens Originais . . . . . . . . . . . 70

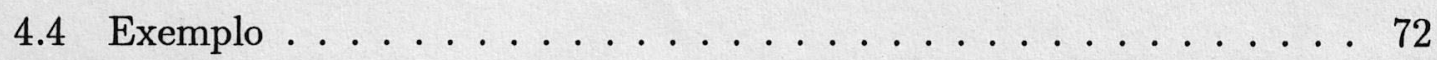

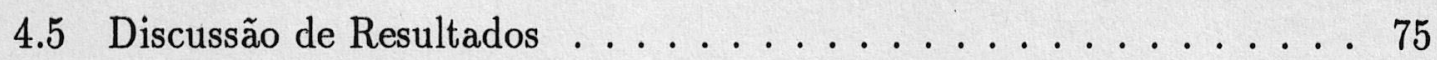

4.6 Conclusões e Trabalhos Futuros $\ldots \ldots \ldots \ldots \ldots \ldots \ldots$

$\begin{array}{ll}\text { Bibliografia } & 82\end{array}$ 


\section{Lista de Figuras}

1.1 Construção de um código de Huffman binário - Procedimento da di-

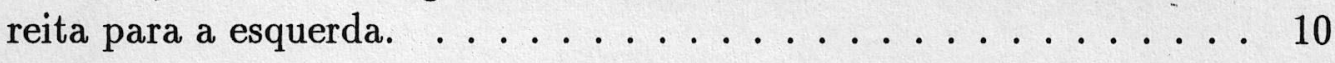

1.2 Construção de um código de Huffman binário - Procedimento de codificação da esquerda para a direita. . . . . . . . . . . 11

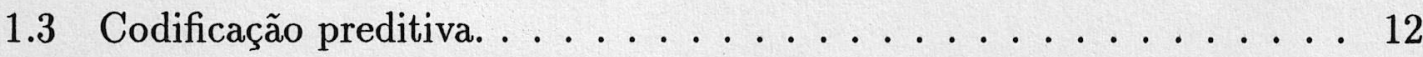

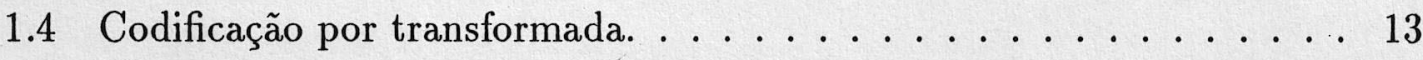

1.5 Representação de um sistema clássico de comunicação. . . . . . . . 14

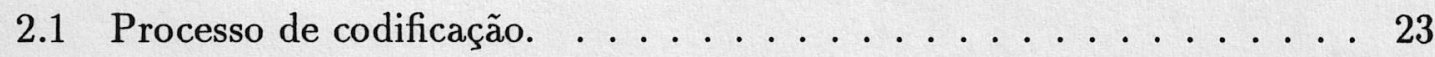

2.2 Codificação PCM. (a) Componentes de um codificador PCM. (b) Representação binária de 4 bits de níveis de amplitude entre 0 e 15 . . 24

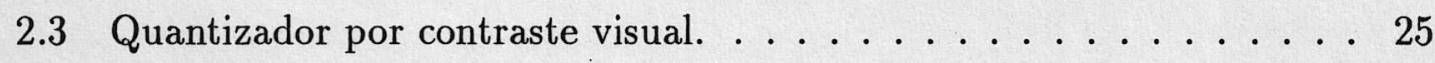

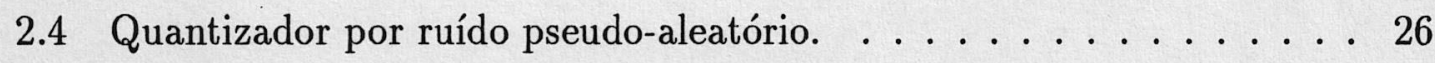

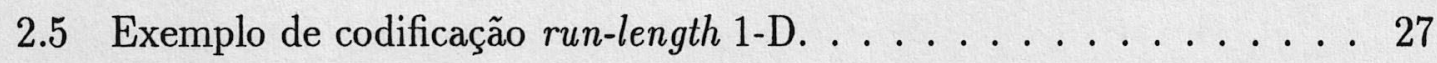

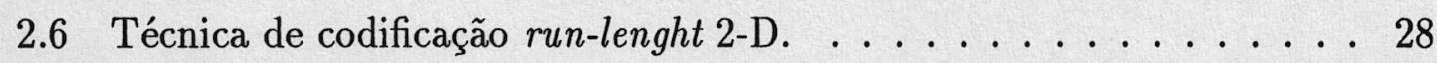

2.7 Diagrama de blocos de um codificador e decodificador preditivo. . . 29

2.8 Diagrama de blocos do sistema de modulação delta. . . . . . . . 30

2.9 Uma classificação intuitiva de distorção na quantização devido a codificação DPCM. Três classes de ruídos são identificadas: ruído granular, sobrecarga e edge busyness. . . . . . . . . . . . 32

2.10 Características de um quantizador. $x$ é a entrada e $y$ é a saída. $t_{i}$ e $l_{i}$ são níveis de decisão e reconstrução, respectivamente. Entradas entre $t_{i}$ e $t_{i+1}$ são representadas por $l_{i+1} \ldots \ldots \ldots \ldots \ldots \ldots 33$

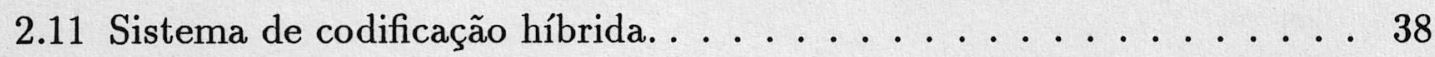

2.12 Codificação com palavra de comp. variável de n pixels. Para quantização de $K$ bits, $2^{n K}$ palavras de códigos são exigidas. . . . . . 39 
2.13 Exemplo de codificação BTC. . . . . . . . . . . . . . . 41

2.14 Quantização Vetorial Simples. . . . . . . . . . . . . . . 42

3.1 Sistema de Codificação por Transformada. . . . . . . . . . . 44

3.2 Exemplo de uma seqüência 2-D com $\left(N_{1} \times N_{2}\right)$ pontos e suas extensões

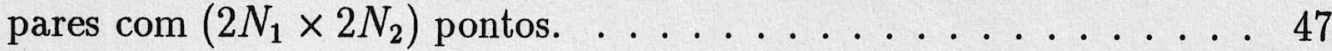

3.3 Eficiência em compactar energia $\eta_{E}(N=8$, com 4 coeficientes conservados) em função do coeficiente de correlação. (a) DCT, (b) KLT $(0.36)$ e (c) DFT. . . . . . . . . . . . . . . . . . . . 54

3.4 Variância do coeficiente transformado $\sigma_{p}^{2}$ em função da ordem $p$ do coeficiente; $\rho=0.91 ; N=16$. (a) DCT, (b) DFT e (c) DST. . . . . 55

3.5 Eficiência na decorrelação $\eta_{c}(N=8)$ em função do coeficiente de correlação (a) DCT, (b) DST, (c) KLT e (d) KLT (0.36). . . . . . . . 56

3.6 Eficiência na decorrelação $\eta_{c}$ em função do tamanho do bloco da transformada, $\rho=0.91$. (a) DCT, (b) Slant, (c) WHT, (d) Haar, (e) KLT,

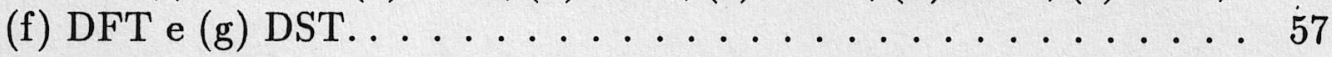

3.7 Exemplos de regiões usadas para amostragem por zona para a DCT. . 60

4.1 Processo "Adaptativo" de Codificação e Decodificação por Transformada Utilizado. . . . . . . . . . . . . . . . . . 67

4.2 Caminho da seqüência "zig-zag", colocando coeficientes com freqüências mais baixas antes dos coeficientes com freqüências mais altas. . . . 68

4.3 Imagens Originais Utilizadas. (a) Imagem jor256s; (b) Imagem agmat3; (c) Imagem cps5 e (d) Imagem brasília . . . . . . . . . . . 71

4.4 Resultados da compressão da imagem jor256s para as seguintes razões médias: (a) $p_{1}=2.0$ e $p_{2}=2.5$; (b) $p_{1}=1.5$ e $p_{2}=2.0$; (c) $p_{1}=1.0$

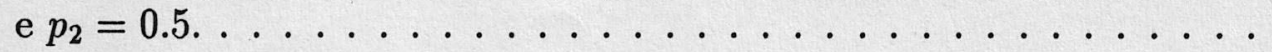

4.5 Resultados da compressão da imagem agmat3 para as seguintes razões médias: (a) $p_{1}=2.0$ e $p_{2}=2.5$; (b) $p_{1}=1.5$ e $p_{2}=2.0 ; \quad$ (c) $p_{1}=1.0$ e $p_{2}=0.5 \ldots \ldots \ldots \ldots \ldots \ldots \ldots \ldots \ldots \ldots \ldots \ldots$

4.6 Resultados da compressão da imagem cps 5 para as seguintes razões médias: (a) $p_{1}=2.0$ e $p_{2}=2.5 ; \quad$ (b) $p_{1}=1.5$ e $p_{2}=2.0$; (c) $p_{1}=1.0$ e $p_{2}=0.5 \ldots \ldots \ldots \ldots \ldots \ldots \ldots \ldots \ldots \ldots \ldots$

4.7 Resultados da compressão da imagem brasilia para as seguintes razões médias: (a) $p_{1}=2.0$ e $p_{2}=2.5 ; \quad$ (b) $p_{1}=1.5$ e $p_{2}=2.0 ; \quad$ (c) $p_{1}=1.0$

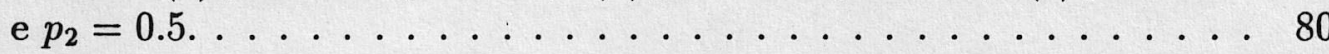




\section{Lista de Tabelas}

1.1 Classificação de qualidade e diminuição mais usadas. . . . . . . . 4

1.2 Exemplo de algumas probabilidades e suas correspondentes entropias

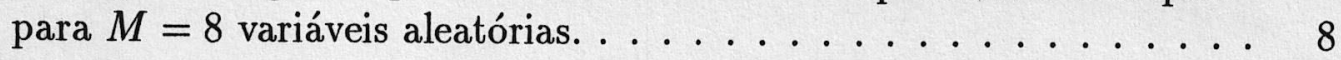

2.1 Um código de comprimento variável para um sinal do codificador DPCM com 16 níveis de quantização. . . . . . . . . . . 36

4.1 Imagens Originais com suas Estatísticas. . . . . . . . . 70

4.2 Resultados do MSE e SNR para as imagens em estudo. . . . . . . 76

4.3 Resultados da razão de compressão, em bits/pixel, para as imagens

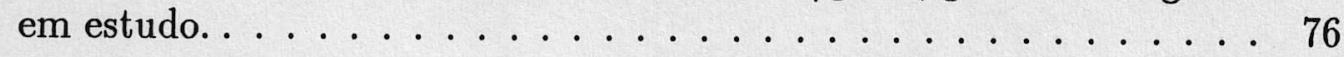




\section{Introdução}

Processamento de Imagens é a ciência de modificar e analisar imagens digitais. É uma área que vem se desenvolvendo rapidamente nos últimos 20 anos juntamente com a evolução dos computadores, tornando-se uma ferramenta interdisciplinar muito importante em diversos campos da ciência e tecnologia, tais como medicina, engenharia, ciência de computação, astronomia, física, sensoriamento remoto etc.

O interesse em métodos de processamento digital de imagens cresceu a partir de duas principais áreas de aplicação: a de melhorar a informação visual da imagem para interpretação humana e a de processamento dos dados de uma cena para percepção de máquina.

Mais comumente, o processamento computacional objetiva a melhoria da - informação visual de cada imagem para facilitar sua análise. No caso de percepção de máquina, objetiva-se extrair informações que permitam manipulação automática das imagens, por exemplo, classsificações estatísticas, armazenamento mais econômico através de transformadas etc.

Um dos principais problemas em processamento de imagens tem sido a exigência de um número muito grande de bits para representar uma imagem. Por exemplo, uma imagem de $512 \times 512$ pixels com 256 níveis de cinza exige 256 Kbytes para armazenagem.

Assim, dentre os vários aspectos de processamento de imagens tais como realce, restauração, segmentação, uma área de crescente interesse é a de compressão de dados, que visa a redução na quantia de bit trazendo, portanto, grandes vantagens para a transmissão e armazenagem das imagens.

Dependendo do tipo de imagem é interessante, em alguns casos, obter uma taxa de compressão maior em função de alguma distorção, podendo ser usadas técnicas aproximadas. Já em outros casos, como por exemplo em imagens médicas, é preciso que não haja perda visual de informação, ocorrendo geralmente taxas de compressão menores. 
O principal objetivo deste trabalho é estudar técnicas eficientes de compressão de imagens. Esta área é muito abrangente, com resultados espalhados na literatura. Procurou-se, então, dar ao conteúdo deste trabalho uma forma mais uniforme e didática. 0 trabalho foi escrito tendo por base as referências $[15,21,24,27]$, para compressão, além das citadas durante a descrição do trabalho.

O trabalho está dividido da seguinte forma:

No Cap. 1 são discutidos dois aspectos de fundamental importância para codificação de imagens: propriedades do sistema visual humano, com a finalidade de representar, transmitir e exibir a informação visual com uma exatidão mínima exigida pelo olho humano; e redundâncias estatísticas existentes na imagem.

No Cap. 2 são dadas as principais técnicas de compressão de imagens, indo de técnicas básicas como PCM e Run-Lenght, passando pelas preditivas e indo aos métodos híbridos. Além de uma breve descrição dos métodos de codificação por truncamento de blocos e quantização vetorial.

Em virtude do interesse especial pelas técnicas por transformada, o capítulo 3 trata especificamente desta técnica iniciando com a descrição da transformada ótima Karhunen-Loéve (KLT) e, em seguida, a transformada discreta do co-seno (DCT), onde faz-se um estudo de um algoritmo que utiliza a transformada discreta de fourier (DFT) para obtenção da DCT.

Ainda no capítulo 3 faz-se uma comparação geral entre as transformadas - mais usadas do ponto de vista de sua eficiência em compactar energia e decorrelacionar os dados, de forma a justificar a opção feita pela DCT. Além disso, trata-se do padrão de compressão JPEG. Discute-se também as estratégias usadas para determinar quais coeficientes serão codificados e um algoritmo para se obter a atribuição de bit ótima para os coeficientes, ou seja, como associar um número fixo de bit para os coeficientes de maneira que a fidelidade no domínio espacial seja maximizada.

O capítulo 4 consta basicamente de informações a respeito da implementação, de testes de simulação e conclusões a respeito do desempenho do módulo de compressão estudado. 


\section{Capítulo 1}

\section{Fundamentos de Compressão de Imagens}

\subsection{Introdução}

Os métodos de codificação de imagens baseiam-se tanto nas limitações do sistema visual humano quanto nas redundâncias existentes nas imagens. Quando representa-se uma imagem por uma quantia finita de dados, esta representação pode conter uma soma considerável de informações supérfluas. Essas informações podem ser divididas em dois tipos:

- Redundância Subjetiva: é uma característica que está relacionada com os dados que podem ser removidos sem queixa do observador humano. Sua remoção é irreversível.

- Redundância Estatística: é uma característica que está relacionada com similaridades, correlação e predição dos dados. Com a remoção de informações supérfluas deste tipo é possível a recuperação dos dados originais.

A fim de estudar essas duas espécies de redundância, precisa-se conhecer as características da visão humana, bem como as estatísticas da imagem, [24]. 


\subsection{Psico-Física da Visão}

A principal preocupação em qualquer sistema de comunicação visual é que somente deve-se representar, transmitir e exibir informação que o olho humano possa ver. Assim, deve-se representar e trabalhar com imagens dentro da exatidão mínima exigida pelo olho humano.

Devido a complexidade do sistema visual e a falta de um modelo simples e poderoso que possa ser usado para otimizar sistemas de codificação, geralmente recorre-se a testes subjetivos para avaliar a qualidade de uma imagem. Existem duas técnicas para se medir a qualidade de imagens:

\section{Medidas primárias ou explícitas.}

Nesta técnica um grupo de pessoas examina um conjunto de imagens e toma decisões subjetivas a respeito de sua qualidade. Esses métodos primários são mais úteis se as distorções introduzidas pelo processamento são mais complexas em aparência. Avaliações primárias podem ser de dois tipos: métodos opinião por categoria ou escala de classificação e métodos de comparação.

- No método escala de classificação a pessoa observa uma seqüência de imagens sob condições naturais e associa cada imagem (ou seqüência) a uma das várias categorias dadas. Essas categorias podem ser sobre a qualidade geral, como na Tabela (1.1(a)) ou pode ser sobre uma escala de "diminuição", como na Tabela $(1.1(\mathrm{~b}))$.

Tabela 1.1: Classificação de qualidade e diminuição mais usadas.

\begin{tabular}{|l|l|l|}
\hline \hline \multicolumn{1}{|c|}{$(\mathrm{a})$} & \multicolumn{1}{c|}{$(\mathrm{c})$} & \multicolumn{1}{c|}{$(\mathrm{c})$} \\
\hline \hline 5. excelente & 5. imperceptível & 3. muito melhor \\
4. bom & 4. perceptível, mas tolerável & 2. melhor \\
3. regular & 3. ligeiramente não tolerável & 1. ligeiramente melhor \\
2. inferior & 2. quase não tolerável & 0. igual \\
1. péssimo & 1. não tolerável & -1. ligeiramente pior \\
& & -2. pior \\
& & -3. muito pior \\
\hline \hline
\end{tabular}

Os resultados de uma classificação dependem de muitos fatores tais como a experiência e motivação das pessoas, as condições sob as quais a imagem é 
vista (ou seja, iluminação do ambiente, tamanho da imagem, distância do observador). Estes resultados são normalmente apresentados calculando-se um score médio de opinião (SOM).

$$
S O M=\frac{\sum_{i=1}^{k} n_{i} C_{i}}{\sum_{i=1}^{k} n_{i}}
$$

onde: $C_{i}$ é o valor numérico correspondente a categoria $i, n_{i}$ é o número de opiniões naquela categoria e $k$ é o número de categorias na escala.

- No método de comparação a pessoa compara uma imagem teste distorcida ou prejudicada com uma imagem referência. Uma variação deste método é onde a pessoa usa uma escala de classificação e comparação (1.1(c)).

\section{Medidas secundárias ou implícitas.}

Nesta técnica características de formas de onda padronizadas são medidas e os resultados são, então, convertidos para medidas de qualidade. Embora esta técnica seja adequada como solução de engenharia para quantificar qualidade de canais analógicos, suas aplicações são restritas. Assim, testes explícitos podem ser usados para verificar os resultados.

Os testes subjetivos, de uma forma geral, consomem muito tempo para serem aplicados e conseqüentemente são evitados, quando possível.

\subsubsection{O Olho Humano}

Considerando que, nas técnicas que se estuda, o objetivo é ajudar o observador a interpretar o conteúdo de uma imagem, é importante fazer uma breve descrição do sistema visual humano.

A luz de um objeto externo é focalizada pela córnea e cristalino para formar uma imagem do objeto sobre a retina no dorso do globo ocular. Uma fonte de degradação da imagem é o movimento do olho. Embora os movimentos involuntários do olho degradem a imagem, em geral, eles são importantes para manter a visibilidade contínua do campo visual uma vez que uma imagem que seja estacionária sobre a retina perde a cor e eventualmente desaparece.

A retina consiste de uma camada de foto-receptores e conexão entre células nervosas. Os foto-receptores, por sua vez, são de duas espécies: os cones e os bastonetes. Num olho normal existe cerca de 6 a 7 milhões de cones, estes estão concentrados na região central da retina, chamada fóvea e são altamente sensíveis a cores em níveis mais altos de iluminação (chamada visão diurna ou fotópica). 
Enquanto os bastonetes existem em cerca de 75 a 150 milhões distribuídos sobre a superfície da retina e servem para dar uma imagem global do campo de visão; além disso, não estão envolvidos em visão de cores e são sensíveis a níveis baixos de iluminação (chamada visão noturna ou escotópica).

Embora incompletas, as descrições acima procuram mostrar a complexidade do sistema visual.

\subsubsection{Limiar Visual}

Em codificação de imagens, o interesse maior está na visibilidade de distorção. A quantia de distorção que pode ser tolerada depende da qualidade global que se deseja. Para codificação com alta qualidade, qualquer diferença entre a imagem codificada e a original, que seja subjetivamente pequena, implica que distorções na codificação estão próximas do limiar visual.

Definição 1.1 (Limiar Visual) Limiar visual é o ponto em que um estímulo (uma perturbação ou distorção) torna-se visivel ou desaparece. É uma medida estatística e geralmente é definida como o ínfimo das amplitudes do estímulo tal que seja detectada sobre $50 \%$ das ocasiões.

No caso em que codificação de baixa qualidade é viável (por exemplo, baseada somente sobre considerações de custo), a magnitude subjetiva de distorção pode ser grande e estar consideravelmente acima (supra-limiar) do limiar de visibilidade. são:

Os fatores que afetam o limiar de visibilidade de um estímulo em particular

1. O fundo de luminância global contra qual a perturbação é apresentada. (efeito global)

2. O efeito masking de luminância supra-limiar. (efeito local)

3. Forma espacial e variação temporal de estímulos.

4. O campo visual é altamente não-homogêneo como uma função expansão pontual que muda rapidamente com a localização.

$\mathrm{Na}$ prática considera-se que os fatores acima agem independentemente, embora em imagens complexas da vida real o limiar de visibilidade de uma perturbação (ou estímulo) pode ser uma função complicada desses fatores. Quando a luminância 
vizinha $L_{V}$ é igual a luminância de fundo $L_{F}$, o limiar $\Delta L$ cresce linearmente com $L_{F}$, isto é, $\frac{\Delta L}{L_{F}}=$ cte. Isto é a chamada Lei de Weber.

Este efeito de limiar é considerado global pois o estímulo teste, o fundo e a vizinhança cobrem um grande número de pixels na exibição. Esses efeitos são usados geralmente para escolher o número de níveis de quantização.

Tem-se que o limiar de visibilidade $\Delta L$ apresenta forte dependência sobre a luminância de fundo próximas e uma fraca dependência sobre a luminância vizinha que é removida espacialmente do estímulo. Na prática a aplicação desses efeitos para codificação é mais complicada, considerando a iluminação do ambiente.

Geralmente, limiares de visibilidade altos ocorrem em regiões da imagem que são ou muito escuras ou muito claras e limiares baixos ocorrem em regiões de níveis escuros para médios.

Quando existe uma redução na visibilidade de um estímulo, isto é, quando ocorre um acréscimo no limiar de visibilidade pela não-uniformidade espacial ou temporal do fundo, este fenômeno é chamado masking do estímulo teste por um fundo não uniforme. Portanto, masking espacial é a visibilidade reduzida de um estímulo teste sobre ambos os lados de uma grande mudança na luminância de fundo.

\section{- 1.3 Redundâncias Estatísticas}

Assume-se que as propriedades estatísticas da imagem são conhecidas e podem ser medidas, mas na prática isto raramente acontece. Assume-se também que as estatísticas dos pixels são estacionárias, isto é, são as mesmas em toda parte da imagem.

\subsubsection{Redundâncias nos Dados Amostrados - Teoria de In- formação}

PCM (Pulse Code Modulation) é a forma mais simples de codificação de imagens. Neste sistema o sinal é geralmente amostrado numa taxa de Nyquist (a razão de amostragem é de pelo menos duas vezes a maior freqüência do sinal) e quantizado, ou seja, representado por uma quantia finita de bits, em um número de tons de cinza $(M)$ que, geralmente, é uma potência de $2\left(M=2^{K}\right)$, resultando numa codificação de $K$ bits. Este sistema não elimina qualquer redundância nos 
elementos da imagem.

É possível reduzir o número médio de bits por palavra de código, associando níveis de luminância que têm maiores probabilidades de ocorrência com palavras de código menores, enquanto que níveis com baixas probabilidades são associados às palavras de código maiores. Este método é chamado Codificação com Comprimento de Palavra Variável ou Codificação da Entropia.

É interessante determinar o número mínimo de bits exigidos para codificar o nível de luminância quantizado e gerar um código que obtenha este mínimo.

Definição 1.2 (Entropia) Suponha que o nível de luminância quantizado b tenha probabilidade de ocorrência $P(b)$ e que é associado a uma palavra de código de comprimento $L(b)$ bits. Então, a entropia da variável aleatória $B$ (aqui o valor do pixel é uma variável aleatória.), em bits/pixel, é definida por:

$$
H(B)=-\sum_{b=0}^{2^{K}-1} P(b) \log _{2} P(b)
$$

Tabela 1.2: Exemplo de algumas probabilidades e suas correspondentes entropias para $M=8$ variáveis aleatórias.

\begin{tabular}{|c|c|c|c|c|c|c|c|c|}
\hline \hline$P(0)$ & $P(1)$ & $P(2)$ & $P(3)$ & $P(4)$ & $P(5)$ & $P(6)$ & $P(7)$ & $\begin{array}{c}\text { entropia } \\
\text { (bits/pixel) }\end{array}$ \\
\hline \hline 1.000 & 0.000 & 0.000 & 0.000 & 0.000 & 0.000 & 0.000 & 0.000 & 0.00 \\
0.000 & 0.000 & 0.500 & 0.500 & 0.000 & 0.000 & 0.000 & 0.000 & 1.00 \\
0.000 & 0.000 & 0.250 & 0.250 & 0.250 & 0.250 & 0.000 & 0.000 & 2.00 \\
0.060 & 0.230 & 0.300 & 0.150 & 0.080 & 0.060 & 0.060 & 0.060 & 2.68 \\
0.125 & 0.125 & 0.125 & 0.125 & 0.125 & 0.125 & 0.125 & 0.125 & 3.00 \\
\hline \hline
\end{tabular}

A entropia $H(B)$ é uma medida da quantia de informação transportada por $B$. Por exemplo, se o valor de $B$ é altamente previsível, ou seja,

$$
P(b)= \begin{cases}1, & \text { se } b=b(0) \\ 0, & \text { caso contrário }\end{cases}
$$

então, $H(B)=0$. Por outro lado, se todos os valores de $B$ são iguais, isto é,

$$
P(b)=\frac{1}{2^{K}}=\frac{1}{M} \quad \forall b
$$


então, a entropia é maximizada e $H(B)=K$ bits/pixel. Em geral,

$$
0 \leq H(B) \leq \log _{2} 2^{K}
$$

A tabela (1.2) mostra algumas probabilidades e suas correspondentes entropias para $M=8$ variáveis aleatórias.

A entropia também fornece o limite inferior sobre o número médio de bits exigidos para codificar uma imagem. Assim, se o número médio de bits exigido por um codificador é:

$$
\bar{L}=\sum_{b=0}^{2^{K}-1} L(b) P(b) \quad \text { bits } / \text { pixel }
$$

então, se $\bar{L} \simeq H(B)$ o codificador é quase ótimo, mas se $\bar{L}$ é significativamente diferente de $H(B)$, então, este não o será.

Portanto, tem-se

$$
\bar{L} \geq H(B)
$$

\section{Código de Huffman}

-

O código de Huffman é um código de palavra de comprimento variável que minimiza $\bar{L}$ e suas palavras de comprimento médio $\bar{L}_{1}$ estão no seguinte intervalo; $[13$, 24]:

$$
H(B) \leq \overline{L_{1}} \leq H(B)+1 \quad \text { bits/pixel. }
$$

Como um exemplo, considera-se os elementos de uma imagem quantizados com 8 níveis, os quais estão associados suas probabilidades:

$\mathrm{Na}$ construção de um código de Huffman binário, figura (1.1), coloca-se os níveis ordenados pelas probabilidades correspondentes em ordem decrescente e caminha-se da direita para a esquerda. Em cada seção os dois ramos mais inferiores são combinados para formar um novo nó e segue uma reordenação de probabilidades em ordem decrescente. Essas probabilidades são usadas para iniciar a próxima seção.

A árvore pode ser modificada para eliminar cruzamentos, conforme figura

Depois da construção do código, a árvore é rearranjada e a codificação é executada da esquerda para a direita. Em cada nó, um passo acima produz um zero e um passo abaixo produz um 1 . 


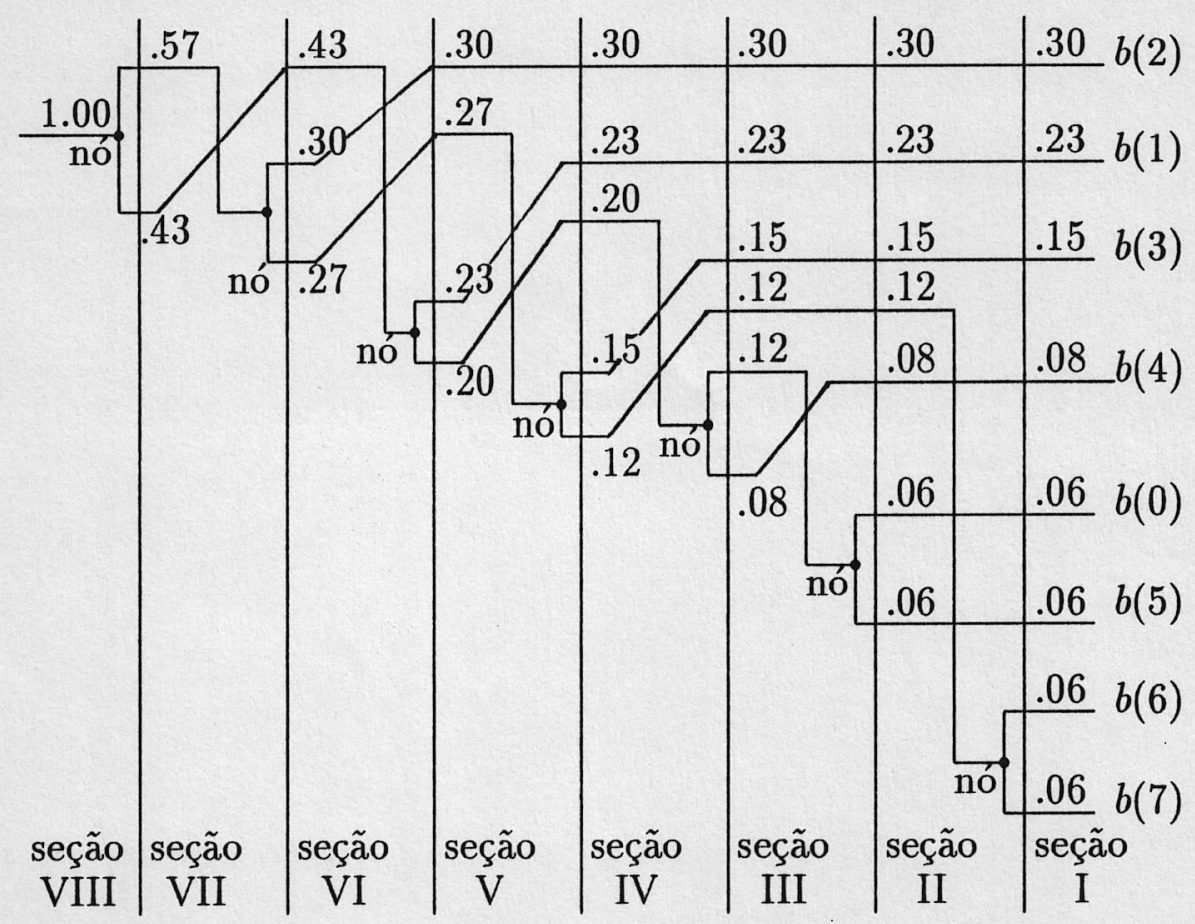

Figura 1.1: Construção de um código de Huffman binário - Procedimento da direita - para a esquerda.

Neste exemplo, tem-se que a entropia e o comprimento médio de palavra do código de Huffman são dados respectivamente por:

$$
H(B)=2.68 \quad \mathrm{bits} / \text { pixel } \quad \bar{L}=2.71 \quad \mathrm{bits} / \mathrm{pixel} .
$$

Vantagens e desvantagens do código de Huffman:

- O código de Huffman tem a propriedade de ser unicamente decodificável no sentido que uma seqüência de bits só pode ser decodificada de uma única maneira. Exemplo: o código,

$$
c_{1}=0 \quad c_{2}=1 \quad c_{3}=01 \quad c_{4}=10
$$

não é único, porque a seqüência de bits 0011 pode ser decodificada como $c_{1} c_{1} c_{2} c_{2}$ ou como $c_{1} c_{3} c_{2}$.

- O código de Huffman é ótimo (isto significa redundância mínima) no sentido que nenhum outro código unicamente decodificável pode ter menor taxa de bits para a mesma fonte de sinais. 


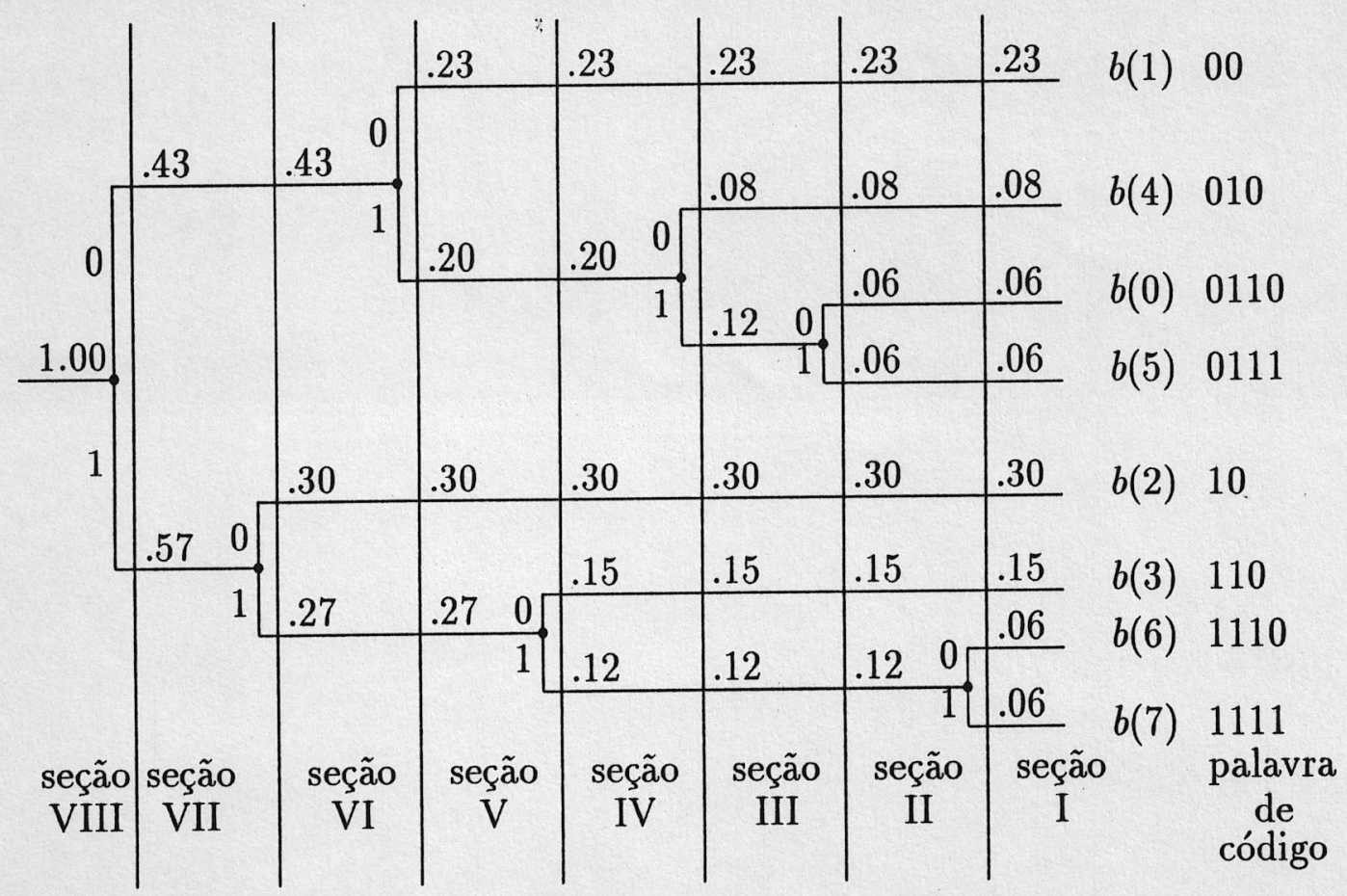

Figura 1.2: Construção de um código de Huffman binário - Procedimento de codi- ficação da esquerda para a direita.

- Na prática são usados códigos tendo um número pequeno de comprimento de palavra, pois geralmente são mais fáceis de implementar que código de Huffman.

- Geralmente palavras de códigos com comprimento variáveis perdem sincronização no caso de transmissão de bits de erros, isto é, alguns códigos podem ser decodificados incorretamente antes da decodificação correta ser reestabelecida e até mesmo pixels podem ser eliminados ou pixels extras adicionados.

\section{Codificação Preditiva}

A codificação preditiva é também conhecida como PCM preditiva ou DPCM (Differential Pulse Code Modulation). Um esquema deste tipo de codificação é mostrado na figura (1.3). 

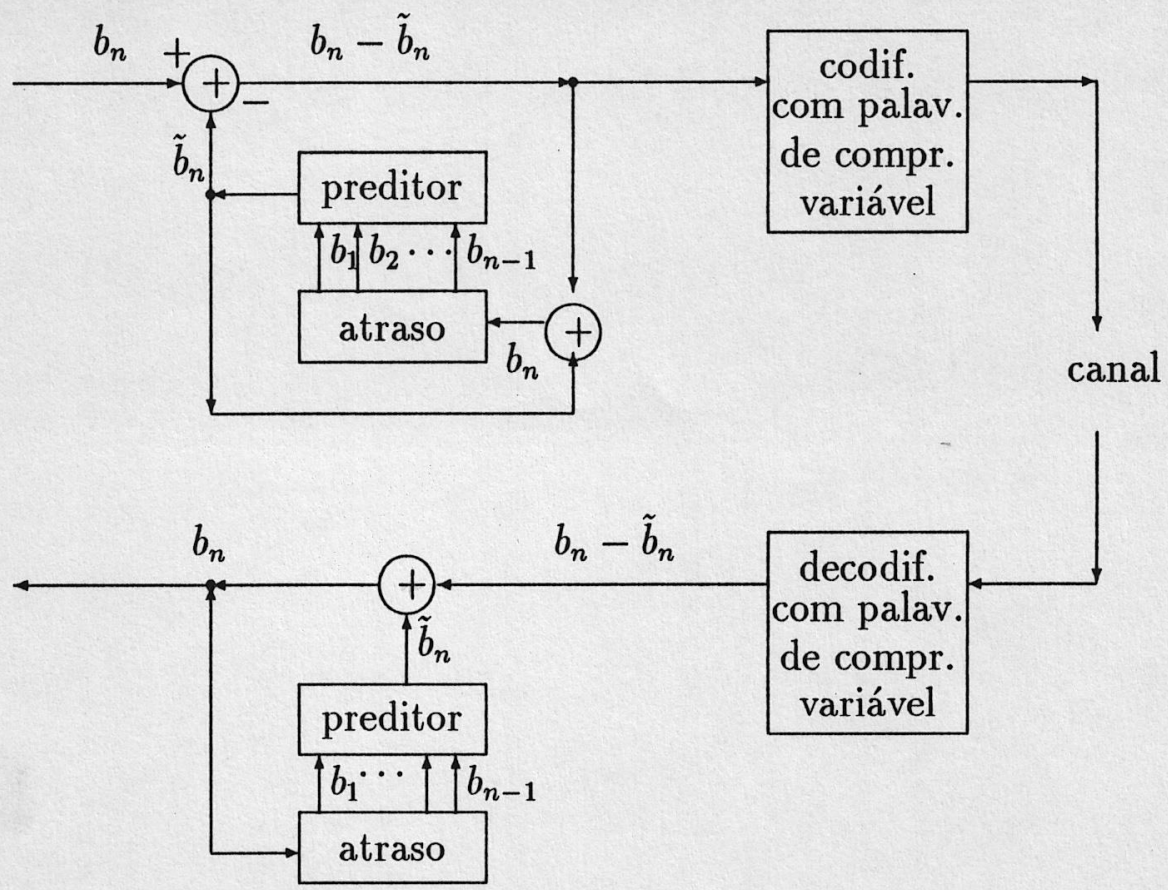

Figura 1.3: Codificação preditiva.

- Na codificação preditiva usa-se $(n-1)$ pixels anteriores para calcular uma predição $\tilde{b}_{n}$ do pixel $b_{n}$, ambos no codificador e decodificador. O sinal diferencial $\left(b_{n}-\tilde{b}_{n}\right)$ é, então, codificado geralmente com uma única palavra de código com comprimento variável.

Uma vantagem de uma codificação preditiva é que sinais diferenciais sucessivos têm muito menos dependência estatística, isto é, menos redundâncias que pixels sucessivos.

O objetivo principal da codificação preditiva é produzir um sinal diferencial $\left(b_{n}-\tilde{b}_{n}\right)$ que seja pequeno em relação a média e grande somente ocasionalmente, isto é, que tenha uma distribuição de probabilidade altamente "picotada" e uma pequena entropia. Então, para codificação tem-se o melhor preditor, a menor entropia e a razão de bits mais baixa.

\section{Codificação por Transformada Discreta}

Na codificação por transformada uma matriz de pixels é transformada em outra matriz de coeficientes. 
O objetivo principal da codificação por transformada é produzir coeficientes estatisticamente independentes, a fim de obter boa eficiência.

Um outro objetivo é a compactação de energia, que significa fazer tantos coeficientes bem pequenos quanto possível, tal que eles tornem-se insignificantes e não necessitem ser codificados para transmissão.

Um esquema geral para codificação por transformada é mostrado na figura
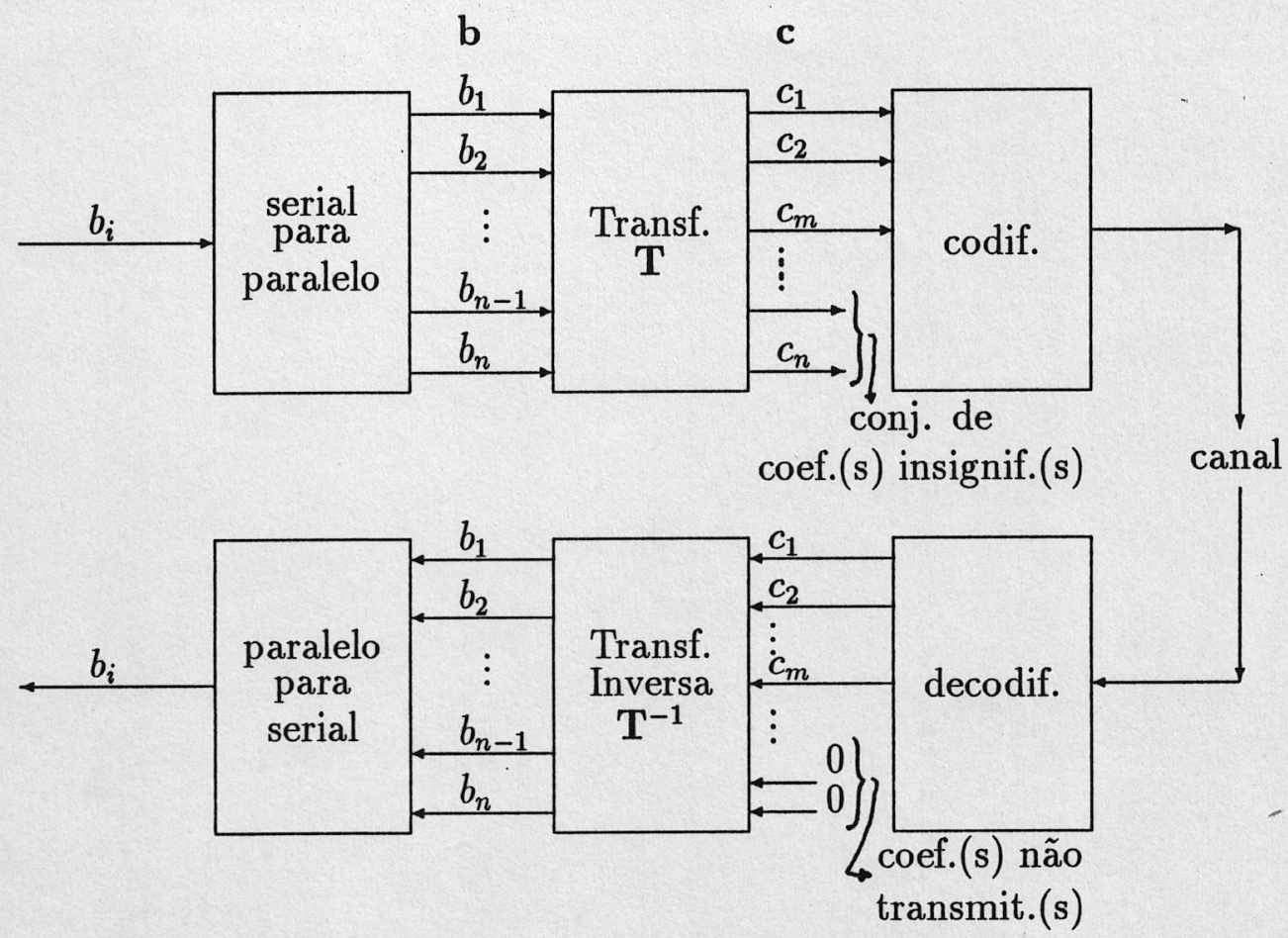

Figura 1.4: Codificação por transformada.

Cada bloco $\mathbf{b}$ de $\mathbf{n}$ pixels é transformado por uma matriz $\mathbf{T}$ para um bloco de coeficientes $\mathbf{c}$ e os coeficientes insignificantes são descartados. Os coeficientes restantes $m=p n(p \leq 1)$ são, então, codificados e transmitidos para o receptor, onde a operação inversa é realizada. 


\subsubsection{Codificação com Aproximação - Teoria Razão de Dis- torção}

Agora, além de redundâncias estatísticas, considera-se também redução de redundâncias subjetivas (ou seja, parte da informação visual que o observador é capaz de perceber).

Uma aproximação da Teoria de Informação para remoção de redundâncias subjetivas (codificação com um critério de fidelidade) foi desenvolvida por Shannon, [31], em 1948.

Considera-se o sistema clássico de comunicação da figura (1.5).

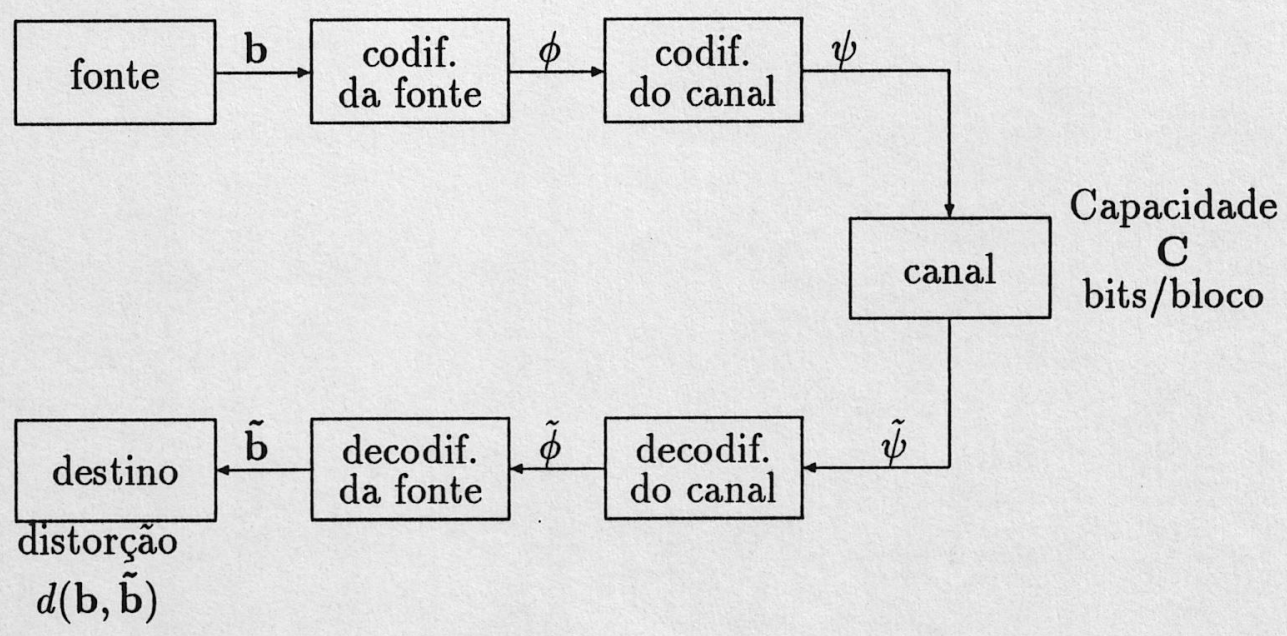

Figura 1.5: Representação de um sistema clássico de comunicação.

Neste sistema a fonte produz o bloco $\mathbf{b}$ de $\mathbf{n}$ pixels que são convertidos pelo codificador da fonte e do canal em palavras de código $\phi$ e $\psi$, respectivamente; e o canal possivelmente corrompido produz símbolos $\tilde{\phi}$ e $\tilde{\psi}$, que são decodificados para finalmente fornecer $\tilde{\mathbf{b}}$.

Supõe-se que a probabilidade condicional $P(\tilde{\psi} \mid \psi)$ do canal seja independente dos símbolos transmitidos anteriormente, ou seja, o canal seja sem memória.

Definição 1.3 (Informação Mútua) Dada $P(\psi)$, a informação mútua $I(\psi, \tilde{\psi})$ é uma medida da quantia de informação sobre $\psi$ que é transportada para $\tilde{\psi}$ pelo canal 
de transmissão e é dada por:

$$
I(\psi, \tilde{\psi})=\sum_{\psi, \tilde{\psi}} P(\psi) P(\tilde{\psi} \mid \psi) \log _{2} \frac{P(\tilde{\psi} \mid \psi)}{P(\tilde{\psi})} \quad \text { bits/símbolo. }
$$

Assim a capacidade $C$ do canal pode ser definida como:

$$
C=\frac{1}{n} \max _{P(\psi)}\{I(\psi, \tilde{\psi})\} \quad \text { bits } / \text { pixel }
$$

onde a maximização é feita sobre todas as distribuições de probabilidade possíveis sobre os símbolos $\psi$ do canal.

Exemplo 1.1 Supõe-se que o canal seja sem ruído, ou seja,

$$
P(\tilde{\psi} \mid \psi)= \begin{cases}1, & \tilde{\psi}=\psi \\ 0, & \text { caso contrário }\end{cases}
$$

então,

$$
I(\psi, \tilde{\psi})=H(\psi) \quad \text { bits } / \text { símbolo, }
$$

ou seja, o canal transporta todas as informações de $\psi$ para $\tilde{\psi}$. Neste caso, $I(\psi, \tilde{\psi})$ está maximizado se todas $\psi$ são provavelmente iguais. Agora, se o canal é ruidoso

- o cálculo da capacidade é mais complicado.

Para codificação da fonte sem distorção a razão de bits da saída do codificador fonte não pode ser menor que a entropia da fonte $H(b)$ em bits/bloco. Para uma transmissão segura, ela deve ser menor que a capacidade $C$ do canal. Então, para comunicação sem distorção, isto é, $\tilde{b}=\mathbf{b}$, deve-se ter:

$$
n C \geq H(\phi) \geq H(\mathbf{b}) \quad \text { bits/bloco. }
$$

Caso, $H(\phi)<H(\mathbf{b})$ a codificação da fonte torna-se irreversível, ocorrendo perda de informação e portanto $\tilde{b} \neq b$.

Então, define-se uma medida de distorção $d(\mathbf{b}, \tilde{b})$ e uma distorção média como:

$$
\bar{d}=E[d(\mathbf{b}, \tilde{\mathbf{b}})]
$$

que fornece o desempenho global do sistema, onde $E$ é a esperança estatística. ${ }^{1}$

${ }^{1}$ Para uma função $f$ de variável aleatória $b, E[f(b)] \triangleq \sum_{b=0}^{n} P(b) f(b)$ 
Exemplo 1.2 Uma medida de distorção muito usada é o erro médio quadráticoMSE (Mean Squared Error) que, para um vetor de $n$ pixels, torna-se:

$$
d(\mathbf{b}, \tilde{\mathbf{b}})=\frac{1}{n}|\mathbf{b}-\tilde{\mathbf{b}}|^{2}=\frac{1}{n} \sum_{i=1}^{n}\left(b_{i}-\tilde{b}_{i}\right)^{2} .
$$

A função razão de distorção $R(D)$ é definida como:

$$
R(D)=\frac{1}{n} \min _{P(\tilde{\mathbf{b}} \mid \mathbf{b})}\{I(\mathbf{b}, \tilde{\mathbf{b}})\}
$$

onde a minimização é feita sobre todas as $P(\tilde{\mathbf{b}} \mid \mathbf{b})$ tal que $\bar{d} \leq D$. Para se ter $\bar{d} \leq D$ é necessário ter $C \geq R(D)$.

A teoria de razão de distorção apenas fornece os limites dos métodos de codificação, não especificando como projetá-los.

Resumindo, o uso da teoria de razão de distorção para codificação de imagens apresenta os seguintes problemas:

- Dificuldade no cálculo da função razão de distorção $R(D)$.

- Deficiência na modelagem estatística da fonte, uma vez que estatísticas da fonte são não-gaussianas e variam consideravelmente de imagem para imagem e de região para região dentro de uma imagem, ou seja, elas são nãoestacionárias.

- Estabelecimento de um critério de distorção que leve em conta as características complexas do sistema visual humano e ao mesmo tempo seja tratável do ponto de vista matemático.

\subsubsection{Modelos Estatísticos}

Esta seç̧ão apresenta uma síntese de alguns modelos estatísticos, que podem ser vistos com maiores detalhes em [14].

Definição 1.4 (Função Auto-Correlação) É uma medida muito usada para avaliar a dependência estatistica entre pixels adjacentes e é definida por:

$$
R(x, y) \triangleq E\left[b b^{*}\right]
$$


onde: o pixel $b^{*}$ está $x$ unidades à direita e $y$ unidades abaixo do pixel $b$ na imagem.

$R(x, y)$ é muito mais fácil de ser calculada do que a entropia. Além disso, satisfaz as seguintes propriedades:

$$
\begin{aligned}
& R(0,0) \geq R(x, y) \\
& R(x, y)=R(-x,-y) .
\end{aligned}
$$

Definição 1.5 (Função Auto-Covariância Normalizada) É uma medida útil de dependência estatística entre pixels e é dada por:

$$
A C N(x, y)=\frac{R(x, y)-(E[b])^{2}}{E\left[b^{2}\right]-(E[b])^{2}}
$$

\section{Modelo Gaussiano}

Seja b um vetor coluna de n pixels. Assume-se que os pixels sejam tendenciosos, tal que $E[\mathbf{b}]=0$, com matriz correlação,

$$
\mathbf{R} \triangleq E\left[\mathbf{b b}^{*}\right]
$$

então, a função densidade de probabilidade-PDF (probability density function) Gaussiana do bloco b de pixels, com amplitude contínua é dada por:

$$
p(\mathbf{b})=\frac{1}{\sqrt{(\operatorname{det} \mathbf{R})(2 \pi)^{n}}} e^{\frac{-1}{2} \mathbf{b} \mathbf{R}^{-1} \mathbf{b}^{*}} \quad \mathbf{b} \in \Re .
$$

A função razão de distorção $D$, para vetores aleatórios gaussianos, é dada por:

$$
D=\frac{1}{n} \sum_{m=1}^{n} \min \left\{\phi, \lambda_{m}\right\}
$$

onde $\phi$ é um parâmetro não-negativo e $\lambda_{m}$ são os auto-valores correspondentes aos auto-vetores ortonormais de $\mathbf{R}$.

E o critério de distorção do MSE é sabido ser exatamente:

$$
n R(D)=\sum_{m=1}^{n} \max \left\{0, \frac{1}{2} \log _{2}\left[\frac{\lambda_{m}}{\phi}\right]\right\} \quad \text { bits/bloco. }
$$

Para valores de $D$ muito pequenos, ou seja, $\lambda_{m} \geq \phi \quad \forall m$, tem-se: $D=\phi \quad$ e

$$
\begin{aligned}
R(D) & =\frac{1}{2 n} \log _{2} \prod_{1}^{n} \frac{\lambda_{m}}{D} \\
& =\frac{1}{2} \log _{2} \frac{(\operatorname{det} \mathbf{R})^{\frac{1}{n}}}{D} \quad \text { bits/pixel. }
\end{aligned}
$$


A entropia para b é dada por:

$$
H(\mathbf{b})=\frac{n}{2} \log _{2}\left(2 \pi e(\operatorname{det} \mathbf{R})^{\frac{1}{n}}\right) .
$$

Uma das vantagens do modelo gaussiano é que, com a aplicação da transformada Karhunen-Loève-KLT, ver página (44), resulta em coeficientes que são estatisticamente independentes.

\section{Modelo Uniforme}

Uma PDF que algumas vezes é conveniente, é a distribuição uniforme:

$$
p(x)= \begin{cases}a^{-1}, & 0 \leq x \leq a \\ 0, & \text { caso contrário. }\end{cases}
$$

Se o domínio $(0, a)$ de uma variável aleatória (v.a.) uniforme é quantizado uniformemente usando $L$ níveis, então, o comprimento de um único intervalo de quantização é:

$$
\Delta=\frac{a}{L}
$$

Valores de uma v.a. dentro de um intervalo de quantização são todos representados pelo valor do ponto médio do intervalo. Então, o MSE devido a quantização, é o mesmo dentro de cada intervalo e, portanto, o MSE total é:

$$
\begin{aligned}
M S E & \triangleq L \int_{0}^{\Delta}\left(x-\frac{\Delta}{2}\right)^{2} p(x) d x \\
& =\frac{\Delta^{2}}{12}
\end{aligned}
$$

\section{Modelos de Correlação}

Muitas vezes assume-se que as estatísticas da imagem são isotrópicas, possuem média zero e as correlações:

$$
r(i, j) \triangleq E\left[b_{i} b_{j}\right]
$$

são modeladas conforme alguma função decrescente da distância geométrica $d(i, j)$ entre os pixels $b_{i}$ e $b_{j}$. Por exemplo,

$$
r(i, j)=\sigma^{2} \rho^{d(i, j)}
$$


onde $\rho<1$. Para imagens naturais, $\rho$ geralmente excede 0.90 .

Se vetores b são formados por blocos de pixels 1 por $N$, então, a equação (1.24) torna-se:

$$
r(i, j)=\sigma^{2} \rho^{|i-j|} .
$$

Exemplo 1.3 Usando este modelo pode-se estimar o MSE de codificação por transformada unitária quando somente uma fração $p<1$ dos coeficientes são transmitidos.

$$
\begin{aligned}
M S E & =\frac{1}{N} \sum_{m>p N}^{N} E\left[\left|c_{m}\right|^{2}\right] \\
& =\frac{1}{N} \sum_{m>p N}^{N} E\left[\mathbf{t}_{m}^{\prime} \mathbf{b} \mathbf{b}^{\prime} \mathbf{t}_{m}\right] \\
& =\frac{1}{N} \sum_{m>p N}^{N} \mathbf{t}_{m}^{\prime} \mathbf{R} \mathbf{t}_{m} \\
& =\frac{1}{N} \sum_{m>p N}^{N} \sum_{i=1}^{N} \sum_{j=1}^{N} r(i, j) t_{i m}^{\prime} t_{j m}
\end{aligned}
$$

\section{- Modelo Laplaciano}

A PDF Laplaciana é dada por:

$$
p(x)=\frac{\lambda}{2} e^{-\lambda|x|}, \quad x \in \Re
$$

e possui média zero e variância $\frac{2}{\lambda^{2}}$.

O modelo Laplaciano é útil, por exemplo, para projetar código de Huffman. Estabelecido um critério de distorção, o modelo pode ser usado para obter estratégias de quantização. Por exemplo, o quantizador MSE, que tem um número fixado de valores de saída, é obtido da seguinte forma: Para a entrada $x$, se $t_{K-1}<x<t_{K}$, então, a saída do quantizador é $l_{K}$.

O MSE global, devido a quantização é definido como:

$$
M S E=\sum_{K=1}^{L} \int_{t_{K-1}}^{t_{K}}\left(x-l_{K}\right)^{2} p(x) d x .
$$


Para $L$ fixo, as condições necessárias para minimização deste erro são:

$$
t_{K}= \begin{cases}-\infty, \infty, & K=0, L \quad \text { respectivamente } \\ \frac{1}{2}\left(l_{K}+l_{K+1}\right), & \text { caso contrário. }\end{cases}
$$

No caso de um quantizador Lloyd-Max (ver página 34) e assumindo $L$ grande e $p(x)$ simétrica em relação à origem, uma estimativa pode ser dada pela integral de Bennet,

$$
M S E \simeq \frac{1}{12 L^{2}}\left[\int_{t_{L-1}}^{t_{L}} p^{\frac{1}{3}}(x) d x\right]^{3} .
$$

E para variância unitária, obtém-se, [24]:

$$
D \simeq \frac{\Delta^{2}}{12}
$$

Portanto, tem-se que para razão de bit tão pequena quanto 1 bit por amostra, a quantização uniforme de variáveis aleatórias laplacianas produze aproximadamente o mesmo MSE que para variáveis aleatórias uniformes.

\section{Modelos Auto-Regressivos}

Um caminho para caracterizar uma imagem é considerá-la como uma coleção de sinais 1-D, ou seja, como uma seqüência de linhas (ou colunas), ignorando as dependências entre linhas (ou colunas).

Em tais casos é interessante considerar um modelo chamado processo autoregressivo (AR) causal de ordem $p$ ou processo de Markov de ordem $p$ :

$$
b_{i}=\sum_{K=1}^{p} a_{K} b_{i-K}+\epsilon_{i}
$$

onde: $\epsilon_{i}^{\prime} s$ são independentes e identicamente distribuídos com média zero.

Os modelos AR possuem as seguintes propriedades importantes:

1. O processo AR é estacionário e estável (no sentido BIBO-"bounded input bounded output") se, e somente se, as raízes do polinômio,

$$
A_{p}(x)=1-\sum_{K=1}^{p} a_{K} x^{-K}
$$


estão no interior do círculo unitário. Se isto ocorre, então, as correlações $r(i, j)=E\left[b_{i} b_{j}\right]$ podem ser obtidas mais facilmente. Caso se tenha um conjunto de correlações desejadas, uma fonte $A R$, que produza essas correlações, pode ser encontrada para qualquer grau de exatidão desejada.

2. O processo $A R$ causal de ordem 1 tem recebido maior atenção devido à sua tratabilidade analítica e computacional. Neste caso, $p=1, \quad 0<a_{1}<1$, tem-se:

$$
\begin{aligned}
& E\left[\epsilon_{i}^{2}\right]=\left(1-a_{1}^{2}\right) \sigma^{2} \\
& E\left[b_{i}^{2}\right]=\sigma^{2}
\end{aligned}
$$

e a matriz correlação é:

$$
r(i, j) \triangleq E\left[b_{i} b_{j}\right]=\sigma^{2} a^{|i-j|}
$$

3. Se o processo é Gauss-Markov de ordem 1, ou seja, se $\epsilon_{i}^{\prime} s$ são gaussianas, então, os $b_{i}^{\prime} s$ também serão; assim, a função razão de distorção é conhecida. Para $D$ pequeno e bloco grande, tem-se:

$$
R(D)=\frac{1}{2} \log _{2} \frac{\sigma^{2}\left(1-a_{1}^{2}\right)}{D} \quad \text { bits } / \text { pixel }
$$

onde:

$$
D<\frac{\sigma^{2}\left(1-a_{1}\right)}{1+a_{1}}
$$

4. Tem sido mostrado que, para este modelo a DCT apresenta um comportamento bastante próximo da KLT, para $0.5<a_{1}<1$, que ocorre algumas vezes na prática.

5. Este modelo tem sido usado para provar que codificação DPCM e KLT apresentam-se comparáveis para distorções baixas, ou seja, $D \leq 0.01 \sigma^{2}$, enquanto para distorções maiores a KLT é superior, [15]. 


\section{Capítulo 2}

\section{Técnicas de Compressão de Imagens}

\subsection{Introdução}

(

Considerando que para fazer uma representação digital de imagens exige-se um número muito grande de bits, o objetivo das técnicas de compressão é reduzir a transmissão e custo de armazenagem, preservando a qualidade da imagem.

As principais aplicações estão em transmissão de sinais de televisão, sensoriamento remoto, radar, teleconferência, comunicações de computadores, transmissão de fac-símile etc... Utiliza-se armazenamento de imagens em sistemas para acompanhamento de pacientes, em gráficos de engenharia, em arquivos de impressões digitais etc.

Devido a sua grande aplicação, técnicas de codificação e compressão têm sido muito importantes em Processamento de Imagens Digitais.

A eficiência de um algoritmo de compressão é medida por sua habilidade em comprimir os dados, a distorção resultante e também por sua complexidade computacional.

Este capítulo apresenta uma revisão das principais técnicas de codificação e compressão de imagens, indo de técnicas básicas, como PCM, a métodos híbridos.

Um processo de codificação envolve basicamente três operações, conforme pode ser visto no diagrama da figura (2.1): 
1. A amostragem, que mapeia um conjunto de dados de entrada para outro domínio onde o quantizador e codificador possam ser usados mais eficientemente, no sentido de que menos bits são exigidos para codificar os dados mapeados. Este mapeamento pode ser reversível ou não.

2. A quantização, que é um processo irreversível onde uma imagem com amplitudes contínuas é convertida numa com amplitudes discretas.

3. A codificação, onde cada amplitude discretizada do sinal é associada a uma palavra de código de comprimento finito. Esta operação é reversível.

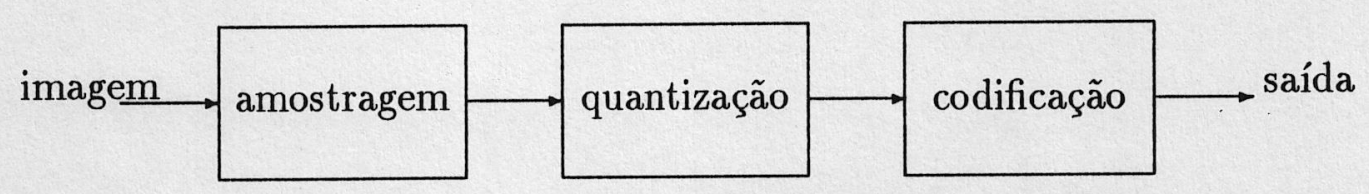

Figura 2.1: Processo de codificação.

\subsection{Técnicas Básicas de Compressão}

\subsubsection{PCM}

O processo PCM consiste em amostrar os elementos da imagem, geralmente numa razão de Nyquist, e quantizar cada amostra usando $2^{K}$ níveis. Cada nível é representado por uma palavra binária contendo $K$ bit, figura (2.2).

Embora PCM seja bastante simples, quando comparado com outras técnicas de codificação, apresenta-se ineficiente no sentido de que não elimina nenhuma redundância presente na imagem original.

Uma vez que a quantização é um processo irreversível, as distorções produzidas dependem do número de níveis de quantização e da relação sinal ruído do sinal de entrada. Assim, é sempre interessante minimizar o erro cometido para dada quantidade de níveis de quantização. O quantizador ótimo, conhecido como quantizador Lloyd-Max (ver página 34) minimiza o MSE para um dado número de níveis de quantização. 
A redução do número de níveis de intensidade em imagens monocromáticas pela diminuição do número de níveis de quantização conduz ao fenômeno de falsos contornos. Isso se caracteriza pelo aparecimento de transições visíveis de tons de cinza em regiões com variação relativamente suave de tonalidade. Para assegurar que falsos contornos não apareçam numa imagem monocromática são necessários pelo menos 64 níveis de cinza, [21].

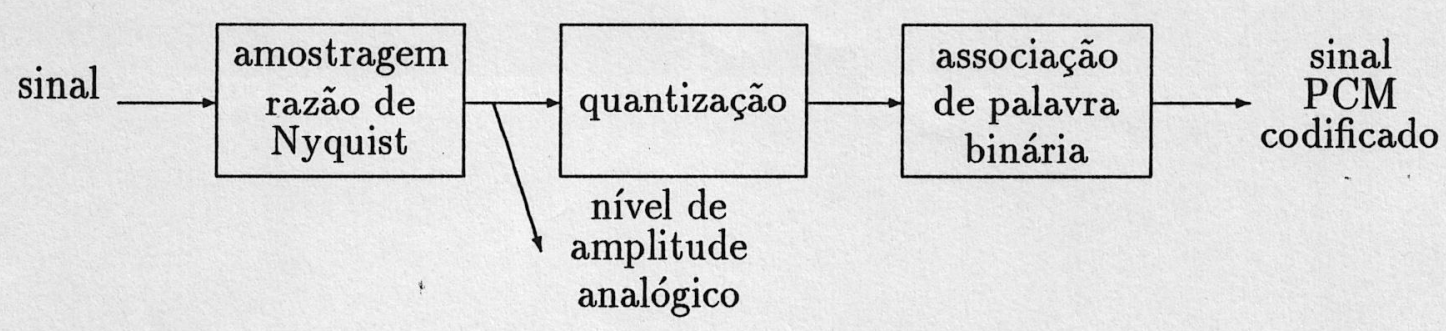

(a)

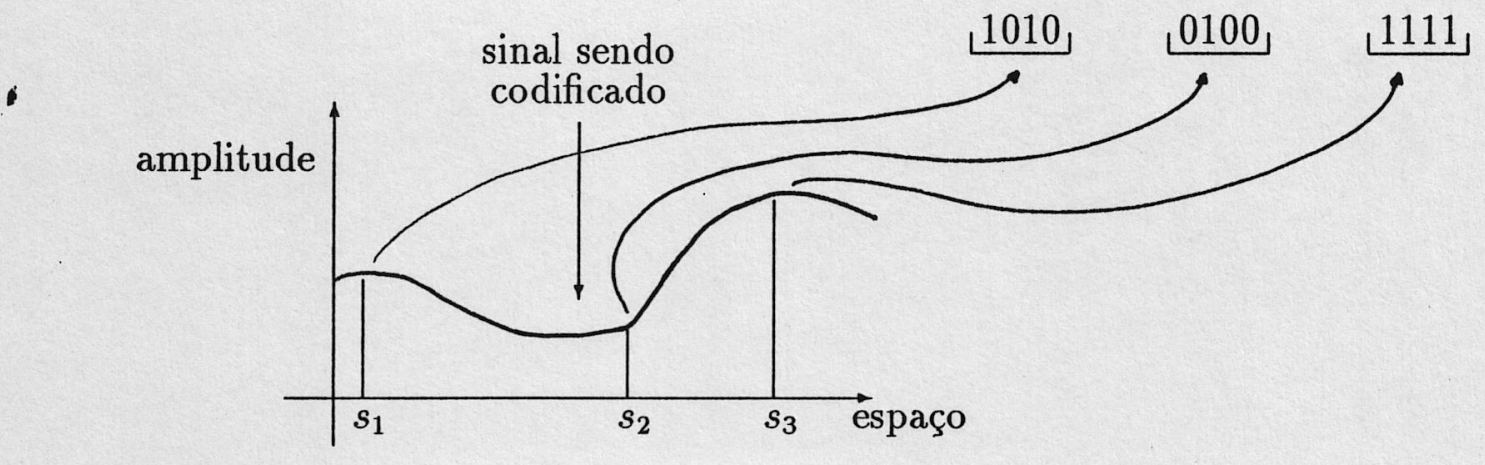

(b)

Figura 2.2: Codificação PCM. (a) Componentes de um codificador PCM. (b) Representação binária de 4 bits de níveis de amplitude entre 0 e 15 . 


\subsubsection{Quantização por Contraste}

É possível realizar um esquema de quantização do tipo compressão-quantização uniforme-expansão, levando-se em conta propriedades da percepção visual humana. Se $L$ e $\Delta L$ são dois valores de luminância tal que $L$ seja o menor valor incremental perceptível, então, pela Lei de Weber (ver página 7 ) $\frac{\Delta L}{L} \simeq$ cte. Isto significa que a sensibilidade visual é aproximadamente uniforme às variações da constante $C=\log L$ definida por $\Delta C=\frac{\Delta L}{L}$. Assim sendo, tem sido proposto na literatura funções do tipo logaritmo para o primeiro bloco do sistema (figura (2.3)).

$$
C=\left\{\begin{array}{l}
\alpha \log (1+\beta L), \quad L \in[0,1] \\
\alpha L^{\beta},
\end{array}\right.
$$

onde $\alpha$ e $\beta$ são constantes.

Resultados experimentais, [16], indicam que com a quantização por contraste, 4 bits são suficientes para eliminar os falsos contornos.

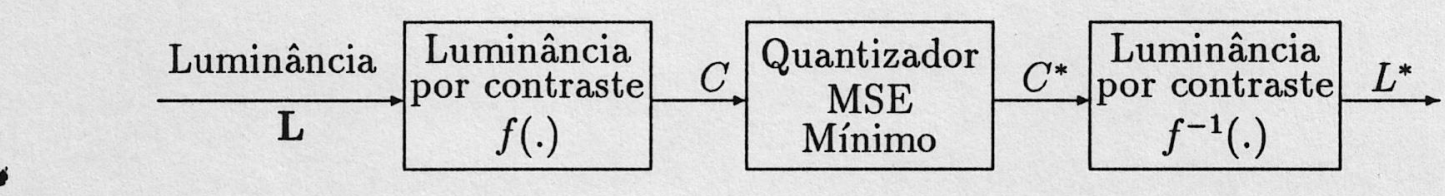

Figura 2.3: Quantizador por contraste visual.

\subsubsection{Quantização por Ruído Pseudo-Aleatório}

Outro método para minimizar efeitos de falsos contornos foi desenvolvido por Roberts [29]. Primeiro, adiciona-se uma pequena quantia de ruído pseudoaleatório, chamado dither, nas amostras de luminância antes da quantização. Para a exibição da imagem, a mesma ou outra seqüência pseudo-aleatória é subtraída na saída do quantizador (figura (2.4)).

Adicionando-se o ruído com média zero, algumas amostras a serem quantizadas superam os níveis de decisão originais, enquanto outras passam a ser inferiores a esses níveis. Geralmente, o nível de ruído deve ser escolhido de modo a afetar o bit menos significativo do quantizador. 
$0 \leq x \leq 1$

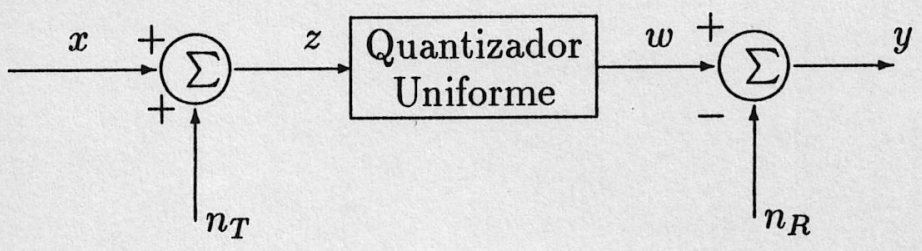

1

Figura 2.4: Quantizador por ruído pseudo-aleatório.

$\mathrm{Na}$ exibição da imagem, o ruído tende a preencher as regiões de contornos, de modo que a média da imagem não se altere. Todavia, há um aumento no MSE e uma degradação do tipo "neve" é introduzida na imagem.

\subsubsection{Codificação Run-Length}

\section{Codificação Run-Length 1-D}

$\mathrm{Na}$ codificação run-length uma seqüência de pixels $b_{1}, b_{2}, \ldots, b_{N}$, ao longo de uma linha é mapeada para uma seqüência de pares de inteiros $\left(g_{1}, l_{1}\right),\left(g_{2}, l_{2}\right), \ldots$, $\left(g_{K}, l_{K}\right)$, onde $g_{K}$ denota o nível de cinza e $l_{K}$ denota o comprimento de corrida, ou seja, o número de pixels justapostos, tendo o mesmo nível de cinza. A figura (2.5) ilustra um exemplo do esquema de codificação run-length, [8].

Uma maneira de efetuar a implementação da codificação run-length pode ser: $O$ bloco de imagem original em (a) é constituído de 8 bit/pixel, logo exige $8 \times 4 \times 8=256$ bit para codificação PCM. Se a cadeia codificada em (b) assume 8 bit para níveis de cinza e 3 bit para a corrida, então, exige $14 \times 11=154$ bit. Neste caso, a razão de compressão obtida é de 1.66:1 ou 4.81 bits/pixel.

A codificação run-length 1-D leva em consideração apenas a correlação horizontal entre pixels ao longo de uma linha, mas não a correlação entre pixels na direção vertical, [12]. 


$\begin{array}{llllllll}255 & 250 & 250 & 250 & 250 & 236 & 236 & 236 \\ 230 & 240 & 240 & 240 & 240 & 240 & 240 & 236 \\ 224 & 224 & 240 & 240 & 240 & 240 & 224 & 210 \\ 224 & 224 & 224 & 240 & 240 & 240 & 210 & 190\end{array}$

(a)

\begin{tabular}{l|l|l|l|l|l|l|l|l|l|l|l}
\hline 255 & 1 & 250 & 4 & 236 & 3 & 230 & 1 & 240 & 6 & \\
\hline & 236 & 1 & 224 & 2 & 240 & 4 & 224 & 1 & 210 & 1 & \\
\hline & 224 & 3 & 240 & 3 & 210 & 1 & 190 & 1 \\
\hline & 224 & & & & \\
\hline
\end{tabular}

(b)

Figura 2.5: Exemplo de codificação run-length 1-D.

\section{Codificação Run-Length 2-D}

$\mathrm{Na}$ codificação run-length 2-D também chamada de quantizador diferencial preditivo (PDQ), um vetor de pixels é mapeado para uma seqüência de pares de inteiros $\left(\Delta^{\prime}, \Delta^{\prime \prime}\right)$, onde $\Delta^{\prime}$ é a diferença entre pontos iniciais de corridas sobre linhas sucessivas e $\Delta^{\prime \prime}$ é a diferença entre comprimentos de corridas sobre linhas sucessivas, junto com os indicadores "novo início" (new start) e "união" (merge), usados para denotar o início e o fim de cada área escura (ver figura (2.6)); [10].

Portanto, nesta técnica em vez de comprimento de corridas, transmite-se as diferenças entre comprimentos de corridas correspondentes de linhas sucessivas, ou seja, para cada linha compara-se com a próxima linha e transmite-se basicamente as transições de branco a preto $\left(\Delta^{\prime}\right)$ e as mudanças nos comprimentos de corridas $\operatorname{pretos}\left(\Delta^{\prime \prime}\right)$.

Num esquema alternativo, chamado DDC - double delta coding, transmitese as mudanças de localizações de transição de preto para branco $\left(\Delta^{\prime \prime \prime}\right)$, em vez de $\left(\Delta^{\prime \prime}\right)$.

Conclui-se que quando existe imagens com grandes áreas de mesmo nível, a codificação run-length 2-D é mais eficiente. Para muitas pequenas áreas de mesmo nivel, a codificação run-length 1-D é mais eficiente. 


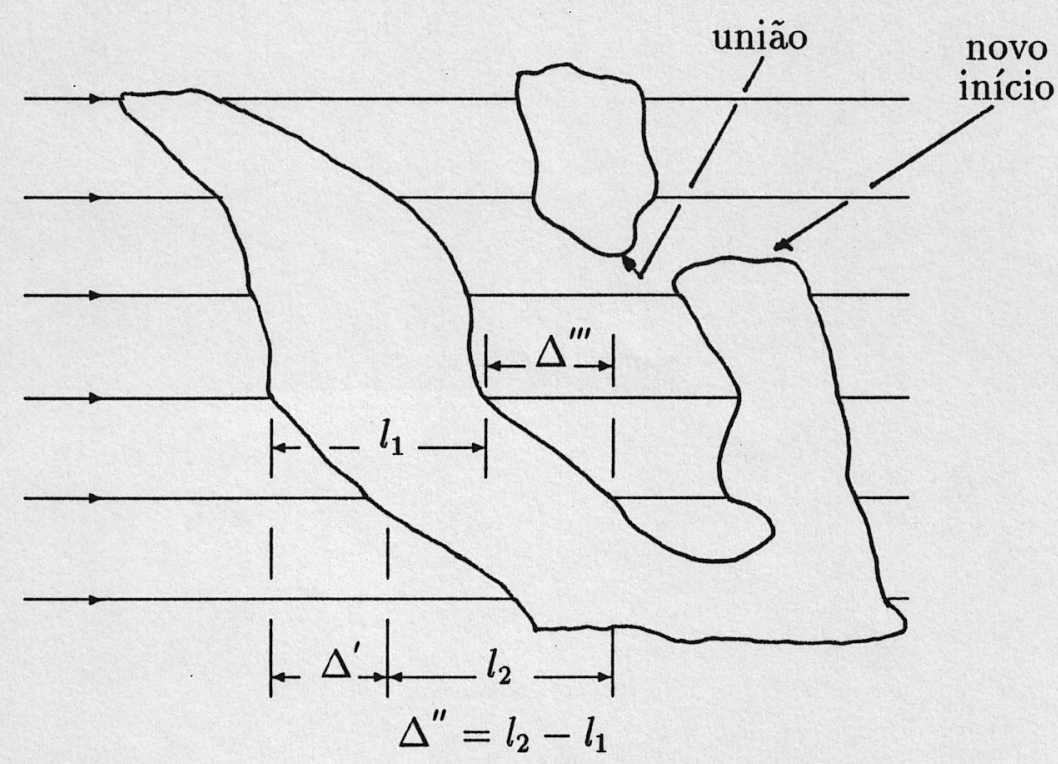

Figura 2.6: Técnica de codificação run-lenght 2-D.

\subsection{Codificação Preditiva}

No sistema PCM, entradas sucessivas para o quantizador eram tratadas independentemente tal que nenhuma avaliação das redundâncias estatísticas da imagem eram feitas. A codificação preditiva explora essas redundâncias entre pixels adjacentes, [24].

Considera-se $b_{1}, \ldots, b_{n}$ um bloco de pixels e supõe-se que os pixels $b_{1}, \ldots, b_{n-1}$ já tenham sido transmitidos. Na codificação preditiva a informação atual a ser codificada e transmitida é:

$$
\varepsilon_{n}=b_{n}-\tilde{b}_{n}
$$

chamada sinal diferencial ou erro de predição, onde $\tilde{b}_{n}$ é a predição de $b_{n}$, função dos pixels transmitidos anteriormente $b_{1} b_{2} \ldots b_{n-1}$. (Ver figura (2.7)).

O sinal diferencial $\left(b_{n}-\tilde{b}_{n}\right)$ é quantizado para um conjunto de $L$ níveis de amplitude discreta, dos quais são representados como palavras binárias de comprimento fixo ou variável e, então, são enviados para o canal de transmissão. Assim, o codificador preditivo possui três componentes básicos: 


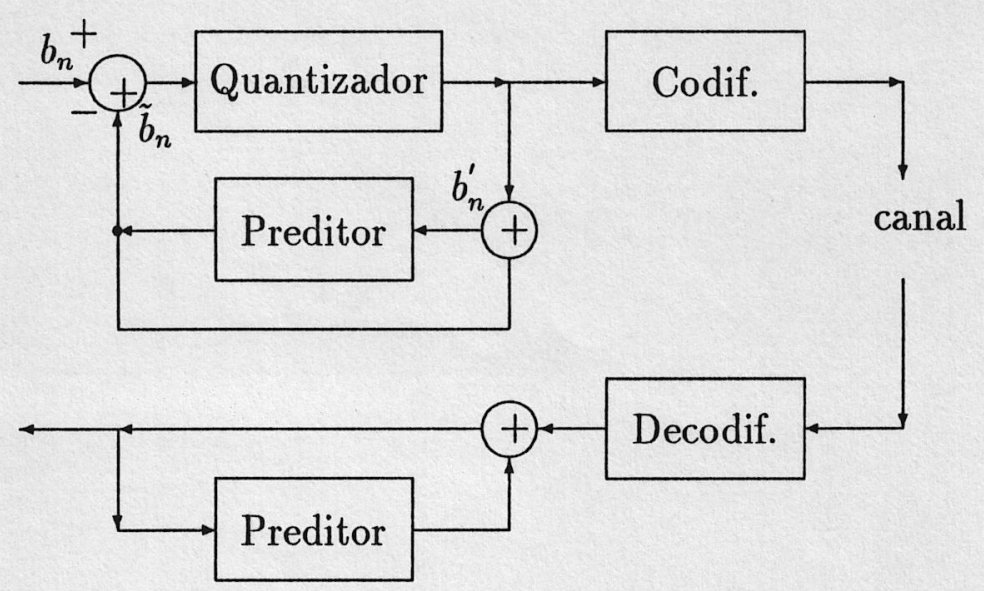

Figura 2.7: Diagrama de blocos de um codificador e decodificador preditivo.

1. Preditor.

2. Quantizador.

3. Associador de códigos.

Um método de transmissão de dados comum, utilizando quantização preditiva é chamado de Modulação Diferencial por Pulsos-DPCM (Differential Pulse Code Modulation). Dependendo do número de níveis de quantização, uma distinção é feita entre Modulą̧ão Delta-DM (Delta Modulation), que tem $L=2$ e DPCM, que tem $L>2$.

\subsubsection{Modulação Delta (DM)}

DM é a forma mais simples de codificação preditiva, em que o preditor é simplesmente uma função atraso de 1 passo e um quantizador de 1 bit ou 2 níveis é usado para obter uma representação de 1 bit do sinal. Então,

$$
\varepsilon(n)=b(n)-\tilde{b}(n-1)
$$

Um diagrama de blocos do codificador DM é mostrado na figura (2.8), onde um sinal analógico serve como entrada para um dispositivo que determina a 
polaridade de um gerador de pulsos, cuja saída é integrada. Se a diferença $\varepsilon(n)$ entre o sinal de entrada $b(n)$ e a saída do integrador $\tilde{b}(n-1)$ for positiva, então, o pulso gerado é positivo, caso contrário ele é negativo. No receptor os pulsos são coletados e integrados para reconstruir o sinal, convenientemente suavizado por um filtro passa-baixa.

As principais limitações que ocorrem com o sistema DM são:

- Sobrecarga: ocorre quando o intervalo de quantização é muito pequeno e assim o sistema não é capaz de acompanhar bordas onde a variação do sinal é rápida.

- Ruído Granular: se o intervalo de quantização é aumentado para compensar o efeito anterior surge este problema, que resulta de uma oscilação visível entre os dois níveis de quantização em regiões uniformes da imagem.

Essas limitações também ocorrem na codificação DPCM e podem ser observadas na figura (2.9). Assim, a escolha adequada da razão de amostragem resulta de um compromisso entre esses dois problemas conflitantes.

Variações de modulação delta, tais como DM adaptativa, podem melhorar sua execução. Contudo, podem tornar-se tão complexas quanto o sistema de codificação DPCM, a ser examinado na próxima subsecção.

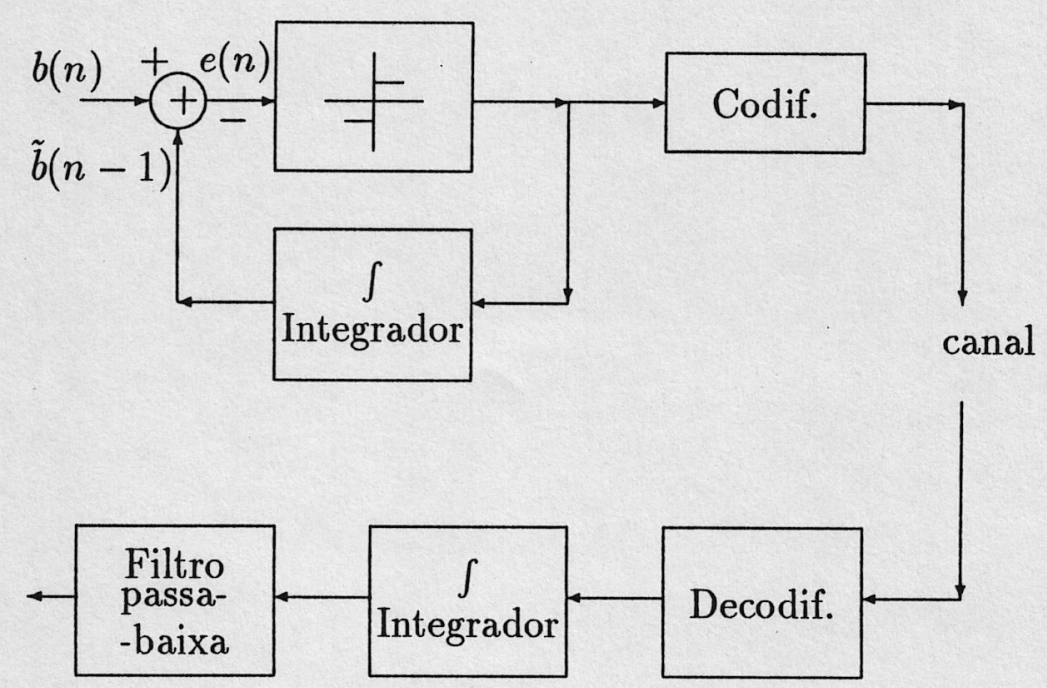

Figura 2.8: Diagrama de blocos do sistema de modulação delta. 


\subsubsection{Codificação DPCM}

No sistema de codificação de imagem DPCM o sinal analógico é primeiro amostrado numa razão superior a de Nyquist e a diferença entre o valor atual e sua predição é quantizada e codificada para transmissão.

Em sua forma mais simples, DPCM usa o valor codificado do pixel anterior horizontalmente como uma predição. Contudo, preditores mais sofisticados usam linhas anteriores (preditores 2-D), bem como quadros anteriores de informação (preditor inter-quadros).

Existem três componentes no processo DPCM: preditor, quantizador e associador de códigos, que podem ser combinados para codificação de diferentes tipos de imagens.

\section{Preditores}

Preditores para codificação DPCM podem ser classificados como:

- linear ou não-linear: se a predição é uma função linear ou não-linear dos valores dos pixels transmitidos anteriormente;

- 1-D ou 2-D: se o preditor usa pixel anterior na mesma linha do pixel sendo predito ou se usa pixel(s) na(s) linha(s) anterior(es), também;

- inter-quadros: usa pixel de quadros transmitidos anteriormente;

- fixos ou adaptativos: preditores adaptativos mudam suas características como uma função dos dados, enquanto fixos mantêm as mesmas características independentes dos dados.

A principal dificuldade no uso da teoria de predição linear para codificação é a falta de um modelo estatístico que descreva exatamente o sinal e, além disso, minimize o erro médio quadrático de predição.

Preditores 2-D oferecem, em geral, uma pequena redução do MSE em comparação com os preditores 1-D. Contudo, com o uso de preditores 2-D as bordas verticais tendem a ser melhor representadas bem como os efeitos visuais de erros de transmissão são diminuídos. A predição 2-D reduz o erro sobre bordas verticais mas aumenta o erro sobre as horizontais, quando comparada com predição 1-D. 
No caso de preditor inter-quadros a sobrecarga sobre bordas verticais é reduzida, contudo a melhora em relação ao MSE não é muito significativa.

Outra variação em predição adaptativa é usar uma soma ponderada de vários preditores, onde os pesos são transferidos de pixel a pixel e são escolhidos observando-se certas características de pixels vizinhos que já foram transmitidos.

Um dos problemas que surgem com a utilização de predição é o efeito de erros de transmissão, por exemplo, no codificador DPCM a predição de cada pixel é feita usando certos pixels transmitidos anteriormente. Então, um erro de transmissão em qualquer pixel pode afetar um ou mais pixels futuros que, por sua vez, pode afetar todos os pixels subseqüentes.

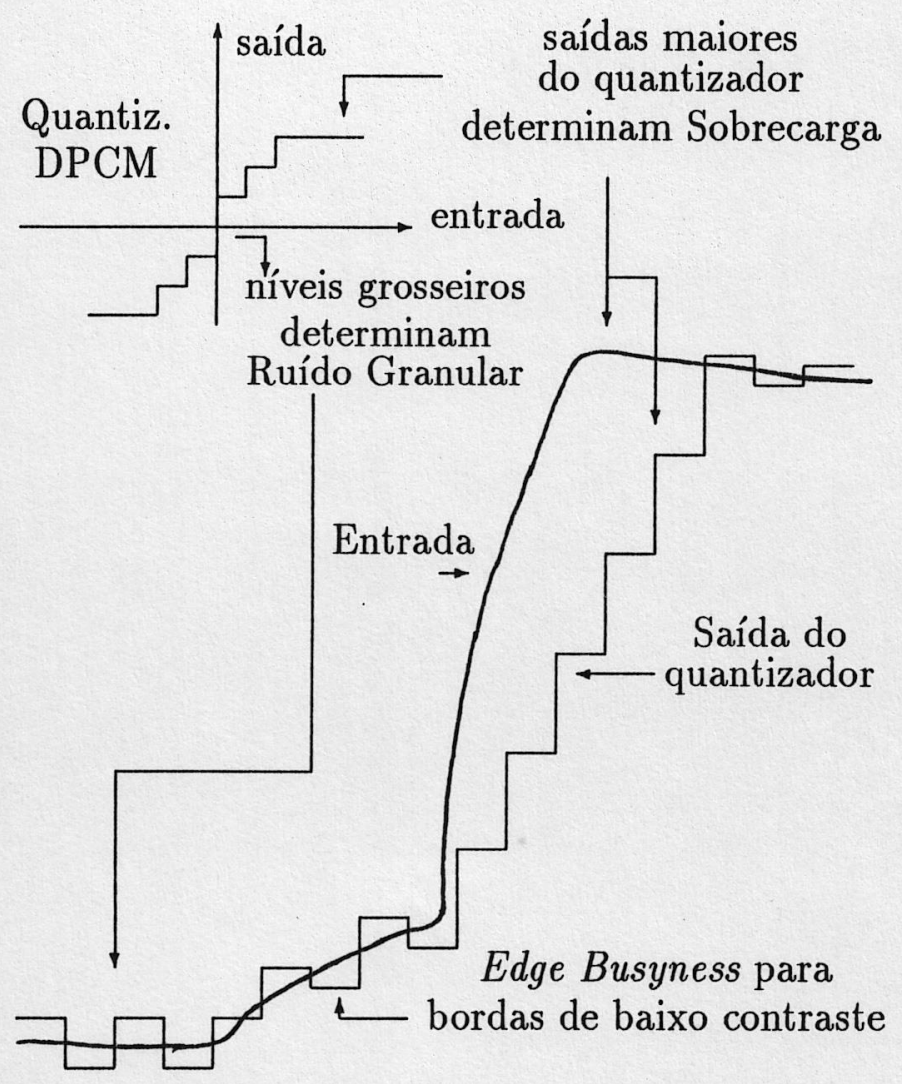

Figura 2.9: Uma classificação intuitiva de distorção na quantização devido a codificação DPCM. Três classes de ruídos são identificadas: ruído granular, sobrecarga e edge busyness. 


\section{Quantização}

O quantizador de um codificador DPCM pode ser projetado para limitar os três tipos de degradações associadas: ruído granular, sobrecarga e edge busyness.

Conforme pode ser observado na figura (2.9), se os níveis internos (correspondentes às magnitudes pequenas do sinal diferencial) do quantizador são grosseiros, então, ruído granular torna-se visível nas áreas de pequenos detalhes da imagem. Por outro lado, se o domínio dinâmico (ou seja, maior nível representativo) do quantizador é também pequeno, então, para toda borda de alto contraste resulta em sobrecarga.

Finalmente, edge busyness é causada por bordas, cujas mudanças de contraste acontecem gradualmente. Quantizadores podem ser projetados sobre bases estatísticas ou usando certas medidas psico-visuais. Eles podem ser adaptativos ou fixos.

\section{Quantização Não-Adaptativa}

Quantizadores ótimos projetados com base estatística têm sido obtidos - usando o critério do MSE mínimo.

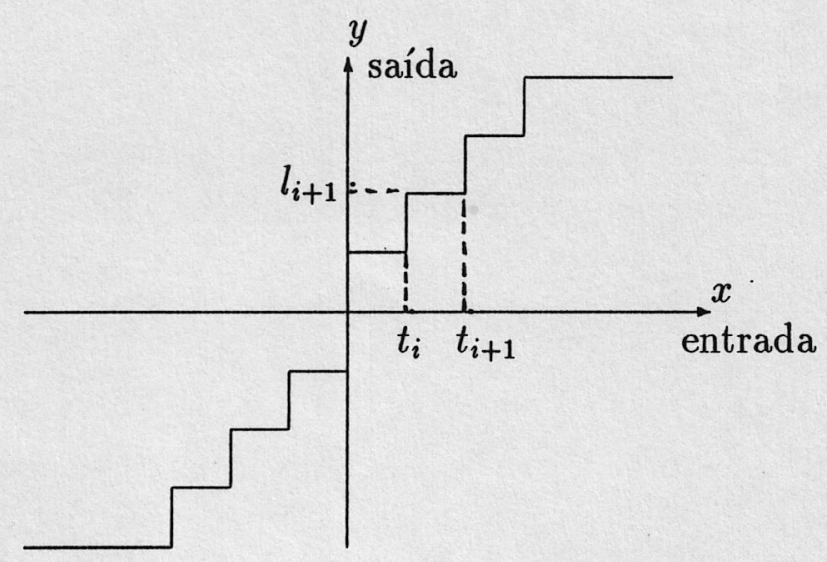

Figura 2.10: Características de um quantizador. $x$ é a entrada e $y$ é a saída. $t_{i}$ e $l_{i}$ são níveis de decisão e reconstrução, respectivamente. Entradas entre $t_{i}$ e $t_{i+1}$ são representadas por $l_{i+1}$. 
Considerando a figura (2.10), seja $x$ uma entrada para o quantizador DPCM com densidade de probabilidade $p(x)$, então, pode-se obter os parâmetros do quantizador, minimizando o MSE:

$$
\begin{aligned}
M S E & =E\left[(x-y)^{2}\right]=\int_{x_{1}}^{x_{L+1}}(t-y)^{2} p(t) d t \\
& =\sum_{K=1}^{L} \int_{t_{K-1}}^{t_{K}} f\left(x-l_{K}\right) p(x) d x
\end{aligned}
$$

onde:

$$
\begin{gathered}
t_{0}<t_{1}<\ldots<t_{L}, \text { são os níveis de decisão; } \\
l_{1}<l_{2}<\ldots<l_{L}, \text { são os níveis de reconstrução; } \\
\text { e } f(.) \text { é uma função erro não-negativa. }
\end{gathered}
$$

Assume-se também conforme figura (2.10) que para toda entrada $x$, se $t_{K-1}<x \leq t_{K}$, então, a saída do quantizador é $l_{K}$.

Para um número de níveis $L$ fixo as condições necessárias para otimalidade com respeito a $t_{K}$ e $l_{K}$ são dadas por:

$$
\begin{gathered}
\frac{\partial M S E}{\partial t_{K}}=0 \quad \text { e } \quad \frac{\partial M S E}{\partial l_{K}}=0 \\
f\left(t_{K-1}-l_{K-1}\right)=f\left(t_{K-1}-l_{K}\right), \quad K=2, \ldots, L \\
\int_{t_{K-1}}^{t_{K}} \frac{\partial f\left(x-l_{K}\right)}{\partial l_{K}} p(x) d x=0, \quad K=1, \ldots, L
\end{gathered}
$$

e assumindo que $f($.$) é diferenciável.$

Para o critério do MSE, $f(z)=z^{2}$ e assim, as equações anteriores reduz-se ao quantizador Lloyd-Max:

$$
\begin{aligned}
& t_{K}=\frac{l_{K}+l_{K+1}}{2} \\
& l_{K}=\frac{\int_{t_{K-1}}^{t_{K}} x p(x) d x}{\int_{t_{K-1}}^{t_{K}} p(x) d x} .
\end{aligned}
$$

Para uma melhor qualidade da imagem, quantizadores podem ser projetados sobre a base de um critério psico-visual. Contudo, devido à complexidade do sistema visual humano, duas aproximações são consideradas: 
- No primeiro método, um quantizador é projetado tal que o erro de quantização esteja em um limiar de visibilidade, enquanto minimiza o número de níveis de quantização ou a entropia da saída do quantizador.

- No segundo método, o projeto do quantizador objetiva minimizar um erro médio quadrático de quantização ponderado, onde os pesos são obtidos por testes subjetivos. Tal otimização pode ser semelhante a quantização do MSE, onde a densidade de probabilidade é substituída por uma função peso. Embora a escolha ótima de uma função peso seja desconhecida, quantizadores ótimos projetados sobre a base de funções peso têm sido bem sucedidos. Os quantizadores usados na prática são baseados em tentativa e erro.

\section{Quantização Adaptativa}

É vantajosa a adaptação do quantizador DPCM devido à variação de estatísticas da imagem e da fidelidade de reprodução exigida em diferentes regiões da imagem.

Geralmente deseja-se segmentar uma imagem em várias sub-imagens tal que a percepção do ruído de quantização, bem como as propriedades estatísticas do sinal diferencial dentro da sub-imagem sejam uniformes e estacionárias.

Contudo, isto é uma tarefa extremamente difícil, uma vez que a percep̧̧ão do ruído e as estatísticas podem não estar suficientemente relacionadas umas com as outras.

Algumas aproximações para esta situação idealizada têm sido feitas, algumas puramente estatísticas e outras baseadas sobre certos critérios psico-visuais.

Por exemplo, pode-se trabalhar no domínio da freqüência e dividir o sinal em duas bandas de frequêencias, a fim de explorar a sensibilidade do olho a variações em detalhes da imagem. Neste caso, o sinal na banda de baixa freqüência é amostrado em uma razão baixa, mas é quantizado finamente por causa da alta sensibilidade do olho a ruídos nas regiões de baixa frequêencia. A componente de alta freqüência do sinal é amostrada em uma razão alta, mas é quantizada grosseiramente, devido à redução da sensibilidade do olho a ruídos em regiões cheias de detalhes.

Aproximações no domínio do pixel, para quantização adaptativa, iniciamse com uma medida de detalhes espaciais (chamada Função Masking ou Função Atividade) e, então, obtém-se experimentalmente a relação entre a visibilidade do ruído e a medida de detalhes espaciais, [25]. 
Concluindo, embora as regras ótimas para adaptação ainda não sejam conhecidas, regras baseadas em tentativa e erro têm mostrado redução significativa na razão de bit, comparadas com sistemas não-adaptativos.

\section{Associador de Códigos}

Como a ocorrência dos níveis de saída do quantizador não é uniforme, fazse a representação usando uma palavra de código de comprimento variável (por exemplo, Huffman). A razão de bit média para tal código é bastante próxima da entropia do sinal de saída do quantizador.

Um código de comprimento variável para um codificador DPCM do pixel anterior com 16 níveis, [26], é mostrado na tabela (2.1).

Tabela 2.1: Um código de comprimento variável para um sinal do codificador DPCM com 16 níveis de quantização.

\begin{tabular}{|c|c|r|}
\hline \hline no. nível & $\begin{array}{c}\text { compr. da palav. } \\
\text { de código }\end{array}$ & \multicolumn{1}{|c|}{ código } \\
\hline \hline 1 & 12 & 100101010101 \\
2 & 10 & 1001010100 \\
3 & 8 & 10010100 \\
4 & 6 & 100100 \\
5 & 4 & 1000 \\
6 & 4 & 1111 \\
7 & 3 & 110 \\
8 & 2 & 01 \\
9 & 2 & 00 \\
10 & 3 & 101 \\
11 & 4 & 1110 \\
12 & 5 & 10011 \\
13 & 7 & 1001011 \\
14 & 9 & 100101011 \\
15 & 11 & 10010101011 \\
16 & 12 & 100101010100 \\
\hline \hline
\end{tabular}

Níveis internos ocorrem muito mais vezes e, portanto, são representados por uma palavra de comprimento menor. 
Um dos problemas com o uso de códigos de comprimento variáveis é que a razão de bit da saída do codificador fonte muda com o conteúdo da imagem local.

\subsection{Codificação Híbrida}

Na codificação por transformada, o próximo capítulo irá tratar em detalhes deste tipo de transformada, primeiro divide-se uma dada imagem $N \times N$ em um número de subimagens. Para codificação $1-\mathrm{D}$, as subimagens são de tamanho $1 \times n$, com $n<N$ e cada subimagem pode ser interpretada como um vetor n-dimensional. Para codificação 2-D, as subimagens são geralmente matrizes quadradas $n \times n$ de pixels, com $n<N$. Após dividir a imagem em subimagens, codifica-se cada subimagem como sendo única, independente das outras.

Tem-se visto que a codificação por transformada envolve alta complexidade tanto no aspecto de armazenagem quanto no computacional. Para fontes de estatísticas estacionárias, codificação por transformada com blocos grandes remove todas as redundâncias estatísticas presentes no sinal fonte.

Contudo, para imagens do mundo real, que não apresentam estatísticas estacionárias, o tamanho dos blocos pode ser diminuído de forma que técnicas adaptativas possam se acomodar às mudanças estatísticas em áreas locais. Blocos pequenos podem ser usados se a codificação adaptativa levar em consideração as propriedades psico-visuais do observador humano. Porém, com blocos pequenos redundâncias de bloco para bloco podem existir após codificação por transformada. Este problema pode ser resolvido parcialmente por Codificação Híbrida.

Basicamente a codificação híbrida combina codificação por transformada e codificação preditiva, conforme mostra a figura (2.11).

Na codificação híbrida considera-se pequenos blocos, avalia-se os coeficientes e executa-se DPCM nos coeficientes usando como preditores os coeficientes de blocos transmitidos anteriormente. Existem três esquemas básicos:

1. Transformada 1-D ao longo das linhas da imagem, seguida por DPCM na direção vertical.

2. Transformada 2-D de pequena dimensão (por exemplo, $4 \times 4$ ) e DPCM, usando coeficientes transformados do bloco anterior na direção horizontal para efetuar a predição.

3. Codificação por transformada 2-D e DPCM temporal entre quadros. 


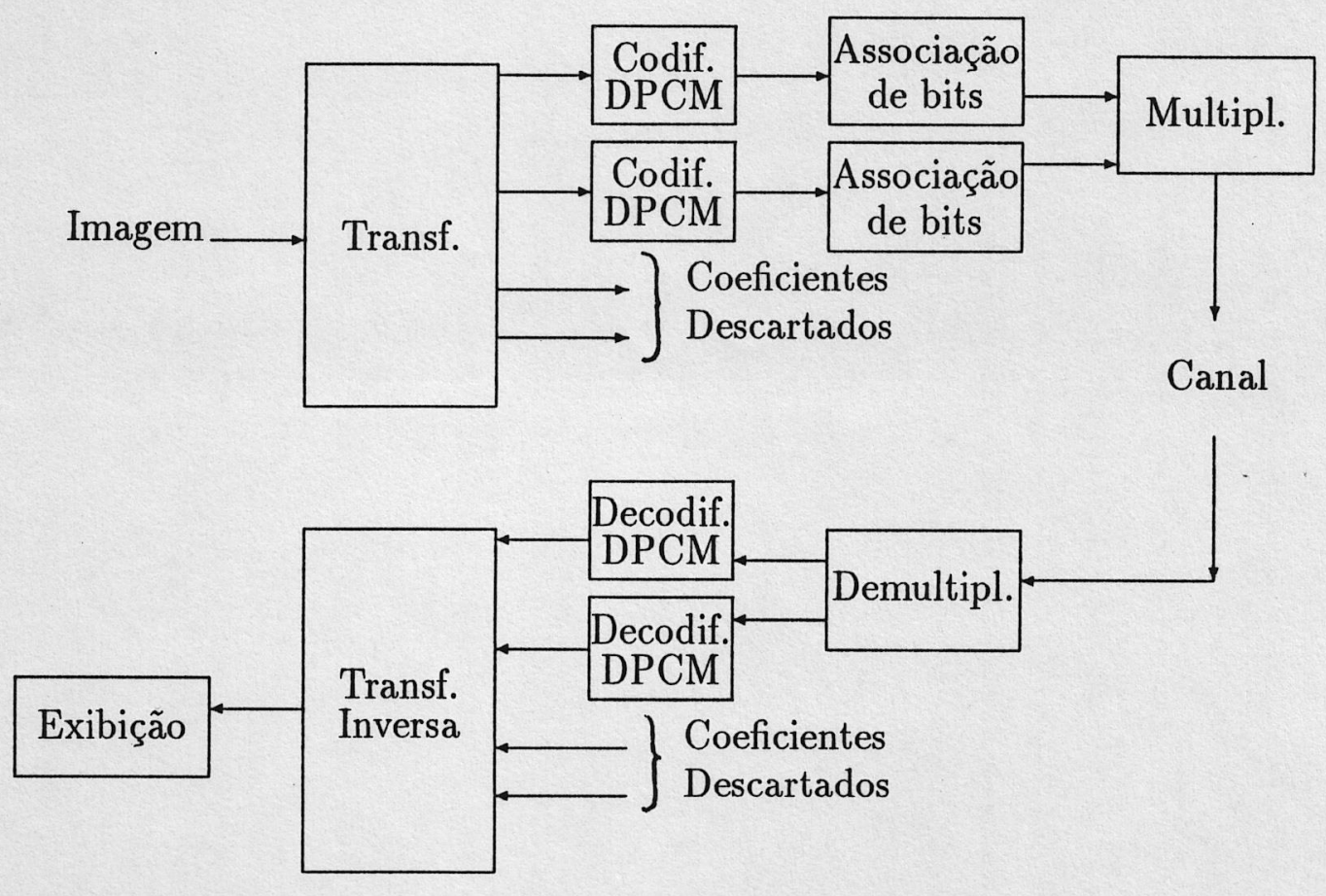

Figura 2.11: Sistema de codificação híbrida.

\subsection{Codificação por Blocos de Imagens}

Pode-se codificar e transmitir blocos de $n$ pixels, a fim de reduzir a razão de bits. Seja $\mathbf{b}=\left(b_{1} b_{2} \ldots b_{n}\right)$ um vetor de pixels de tamanho $n$, onde as componentes são valores de $K$ bit quantizados. Assim, existe $2^{\text {nK }}$ possíveis valores para b. Neste contexto, fala-se do vetor aleatório $\mathbf{B}$, cujos possíveis valores são $\{\mathbf{b}\}$ com distribuição de probabilidade $\{P(\mathbf{b})\}$.

Logo, pode-se definir a entropia de n-ésima ordem ou entropia de bloco como:

$$
H(\mathbf{B})=-\sum_{\mathbf{b}=\mathbf{0}}^{2^{n k}-1} P(\mathbf{b}) \log _{2} P(\mathbf{b}) \quad \text { bits } / \text { n-uplas. }
$$

Se os pixels do bloco são completamente independentes uns dos outros, então, pode-se esperar que $\mathbf{B}$ forneça $\mathrm{n}$ vezes $\operatorname{tantas}$ informações quanto $B$, ou 
seja,

$$
H(\mathbf{B})=n H(B) \quad \text { bits } / \text { pixel, }
$$

onde:

$$
P(\mathbf{b})=P\left(b_{1}\right) P\left(b_{2}\right) \ldots P\left(b_{n}\right) \quad \forall \mathbf{b} .
$$

Porém, se os pixels são altamente dependentes, ou seja, se seus valores são bastante semelhantes em relação a média, então, conhecendo-se uns poucos pixels observa-se muito sobre o restante, e espera-se que a informação divulgada por B seja muito menor, ou seja,

$$
\frac{1}{n} H(\mathbf{B}) \leq H(B) \quad \text { bits/pixel. }
$$

A expressão acima com igualdade implica nos dois sentidos que os pixels são estatisticamente independentes. Pode-se construir um código de Huffman para as n-dimensão $\{\mathbf{b}\}$ de acordo com a distribuição de probabilidade $\{P(\mathbf{b})\}$ resultando em $2^{\text {nK }}$ palavras de código, como pode ser visto pela figura (2.12).

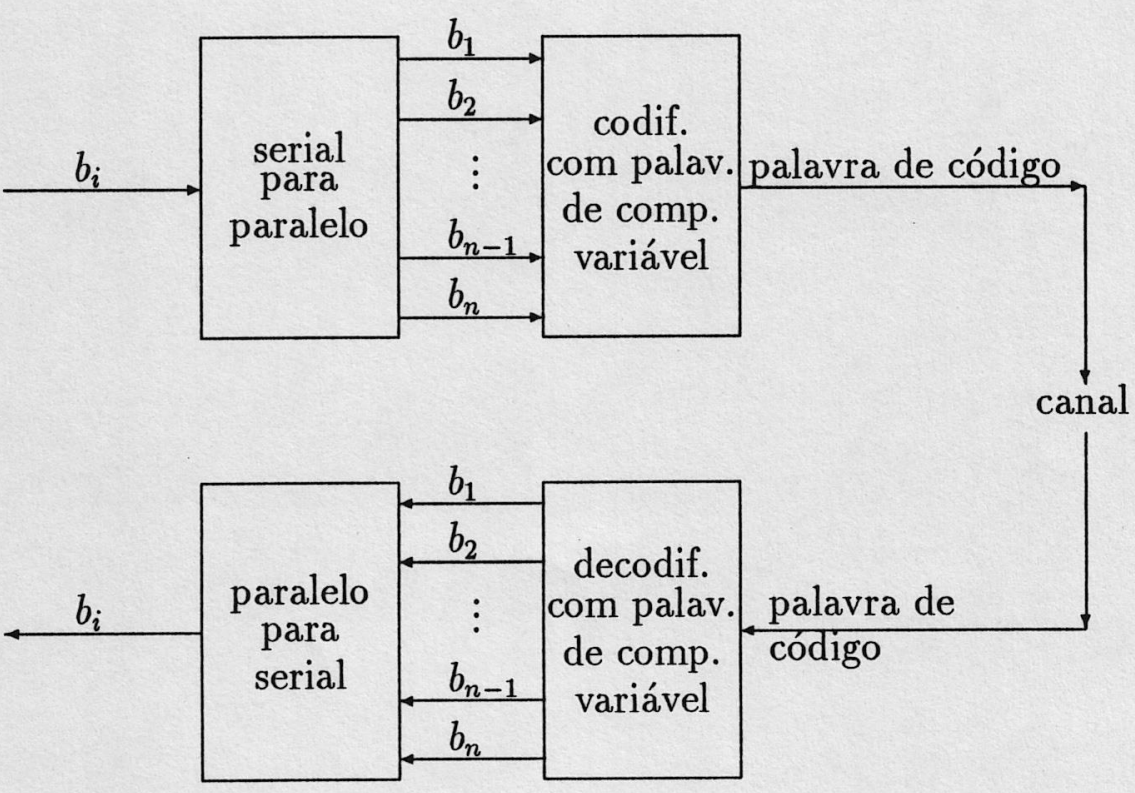

Figura 2.12: Codificação com palavra de comp. variável de $\mathrm{n}$ pixels. Para quantização de $K$ bits, $2^{n K}$ palavras de códigos são exigidas. 


\subsubsection{Codificação por Truncamento de Blocos (BTC)}

O objetivo da Codificação por Truncamento de Blocos consiste em quantizar os pixels de um bloco $L \times L$ de tal forma que preserve a média e a variância. Usa um quantizador com 2 níveis para descrever a forma de um bloco [11,17].

O primeiro passo é medir a média e a variância do bloco:

$$
\begin{aligned}
\bar{b} & =\frac{1}{L^{2}} \sum_{i=1}^{L} \sum_{j=1}^{L} b_{i j} \\
\sigma^{2} & =\frac{1}{L^{2}} \sum_{i=1}^{L} \sum_{j=1}^{L}\left(b_{i j}-\bar{b}\right)^{2}
\end{aligned}
$$

Estas medidas são, então, quantizadas e transmitidas. No próximo passo os pixels do bloco são quantizados em dois níveis, usando $\bar{b}$ como um limiar, ou seja, um 1 ou 0 é enviado, dependendo se $b_{i j}$ é maior ou menor que $\bar{b}$, respectivamente.

No receptor calcula-se $q$, o número de 1 's recebidos para o bloco, o número de zeros é, então, $p=L^{2}-q$. Logo depois faz-se a avaliação dos dois níveis do quantizador, que preservam média e variância, os quais são dados por:

$$
\begin{aligned}
& L_{0}=\bar{b}-\sigma \sqrt{\frac{q}{p}} \\
& L_{1}=\bar{b}+\sigma \sqrt{\frac{p}{q}}
\end{aligned}
$$

Finalmente cada pixel é decodificado para $L_{0}$ ou $L_{1}$, dependendo se um zero ou um 1 foi recebido, respectivamente. Usando blocos de tamanho $4 \times 4$ pixels e 8 bits para cada média e variância, a razão de bit do codificador é de 2 bits/pixel.

O exemplo seguinte, figura (2.13), [8], mostra o resultado de um bloco de valores de pixels sendo codificado e reconstruído.

Com codificação BTC pode-se obter boa qualidade em razões no domínio de 1 - 2 bits/pixel. Contudo, isto somente é verdade para blocos pequenos, do tipo $4 \times 4$ pixels. 


$$
\begin{aligned}
& \text { bloco de entrada : } \quad B=\left(\begin{array}{rrrr}
121 & 114 & 56 & 47 \\
37 & 200 & 247 & 255 \\
16 & 0 & 12 & 169 \\
43 & 5 & 7 & 251
\end{array}\right)
\end{aligned}
$$

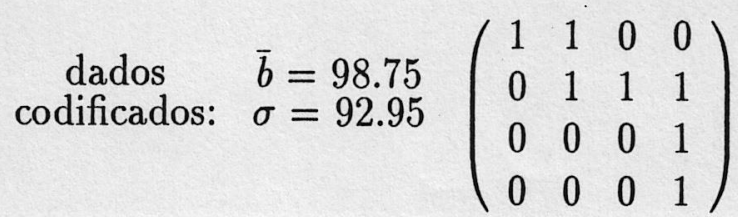

$$
\begin{aligned}
& \text { bloco reconstruído: } \quad\left(\begin{array}{rrrr}
204 & 204 & 17 & 17 \\
17 & 204 & 204 & 204 \\
17 & 17 & 17 & 204 \\
17 & 17 & 17 & 204
\end{array}\right)
\end{aligned}
$$

Figura 2.13: Exemplo de codificação BTC.

\subsubsection{Quantização Vetorial (VQ)}

- Esta subsecção está baseada nas referências $[19,23]$. Um dos processos mais importantes na codificação de imagens é a quantização. Conforme foi visto, a quantização escalar envolve basicamente duas operações:

1. particiona-se o domínio de possíveis valores de entrada em uma coleção de sub-domínios ou subconjuntos, e

2. para cada subconjunto escolhe-se um valor constante representativo para ser a saída.

De acordo com a Teoria Razão de Distorção de Shannon, um melhor desempenho é sempre obtido codificando vetores em vez de escalares.

\section{Definição 2.1 (Quantizador Vetorial ou Quantizador Multidimensional:)} Um quantizador vetorial (VQ) pode ser definido como um mapeamento $Q$ do espaço Euclidiano K-dimensional $R^{K}$ em um subconjunto finito $Y$ de $R^{K}$. Então,

$$
\begin{aligned}
Q: R^{K} & \longrightarrow Y \\
\mathbf{b} & \leadsto Q(\mathbf{b})=\tilde{\mathbf{b}}
\end{aligned}
$$

onde $Y=\left\{\tilde{b}_{i}, i=1 \ldots, n\right\}$ é o conjunto de vetores reprodução e n é o número de vetores em $Y$. 
A operação de quantização vetorial simples aplicada a imagens pode ser descrita como segue:

- a matriz da imagem é particionada em vetores de tamanho conveniente;

- cada vetor é, então, comparado a um conjunto padrão de vetores previamente armazenados;

- uma palavra de código identificando a melhor correspondência é, então, transmitida.

A figura (2.14) mostra um sistema simples de codificação por VQ. O melhor mapeamento $Q$ é aquele que minimiza o MSE.

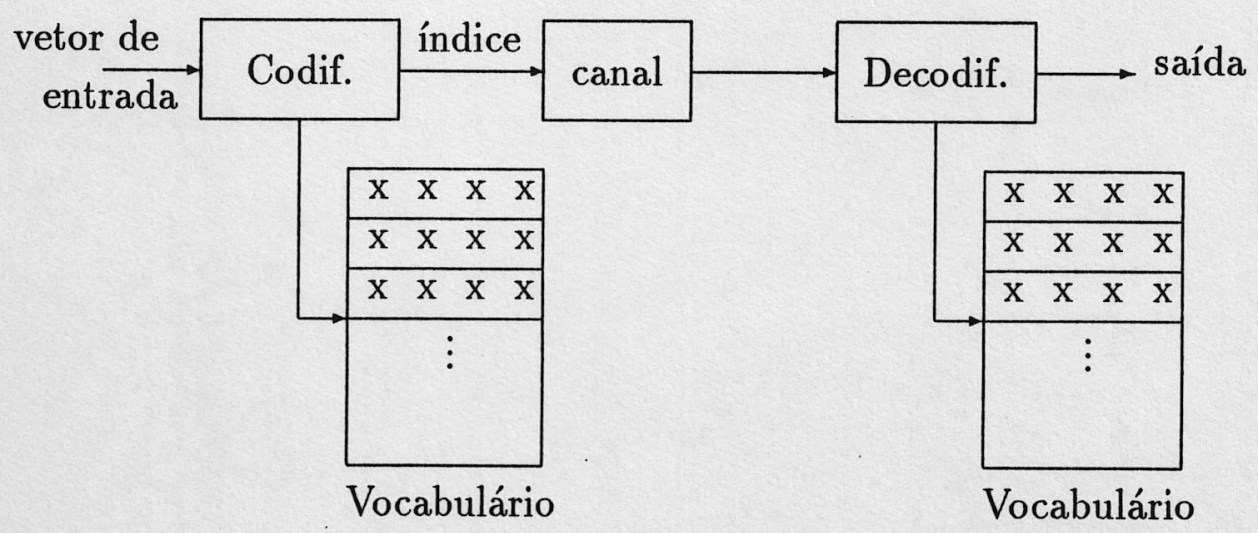

Figura 2.14: Quantização Vetorial Simples. 


\section{Capítulo 3}

\section{Codificação de Imagens por Transformada}

\subsection{Introdução}

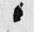

Em virtude do interesse especial nesta técnica de compressão, deixou-se de apresenta-lá no capítulo anterior para uma melhor explanação neste.

A codificação por transformada, conforme diagrama de blocos da figura (3.1), baseia-se na idéia de aplicar uma transformação linear sobre uma imagem ou sobre uma subimagem. Para isto, primeiro arranja-se a imagem, subimagem ou, em geral, um bloco de pixels em um vetor coluna b de comprimento $N$. Supondo $T$ uma transformação unitária, obtém-se:

$$
\begin{aligned}
& \mathbf{c}=\mathbf{T} \mathbf{b} \\
& \mathbf{b}=\mathbf{T}^{*} \mathbf{c}
\end{aligned}
$$

Uma vez que a informação sobre b é ou perda ou ganho por uma transformação reversível, entropias não são mudadas, isto é, $H(\mathbf{b})=H(\mathbf{c})$ bits/bloco.

Além disso, caso encontre-se uma transformada que remova a dependência estatística, isto é, produza coeficientes $\left\{c_{1}, c_{2}, \ldots, c_{n}\right\}$ que são estatisticamente independentes, então,

$$
H(\mathbf{c})=\sum_{m=1}^{n} H\left(c_{m}\right) \quad \text { bits } / \text { bloco }
$$




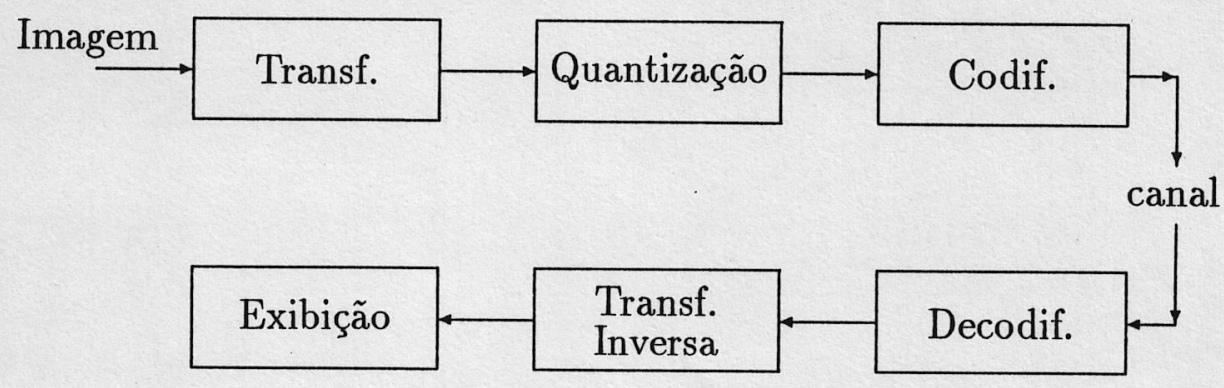

Figura 3.1: Sistema de Codificação por Transformada.

O vetor $\mathbf{b}$ pode ser construído explorando a correlação horizontal 1-D de pixels. Pode, ainda, ser construído de uma matriz $L \times L$ de pixels, simplesmente colocando no final da coluna (ou linha) de $L$ pixels o início da próxima, para formar um único vetor coluna de comprimento $n=L^{2}$ e, neste caso, a codificação por transformada explora a correlação na direção horizontal e vertical na imagem.

Uma terceira possibilidade para construir o vetor $\mathbf{b}$ é denotar a matriz $L \times L$ de pixels da imagem por uma matriz quadrada $\mathbf{B}=\left(b_{i j}\right)$ e considerar uma transformada separável.

A transformação separável exige $2 L^{3}$ operações, enquanto a transformação , coluna da equação (3.2) exige $N^{2}=L^{4}$ operações. Então, a transformada separável pode ser preferível para $L>2$.

Pode-se, então, dividir este capítulo iniciando com a Transformada Ótima de Karhunen-Loève - KLT, em seguida, descrevendo com detalhes a Transformada Discreta do Co-Seno - DCT (Discrete Cosine Transform). A fim de justificar a opção pela DCT faz-se uma comparação entre algumas transformadas, além de uma breve descrição do padrão JPEG (Joint Photographic Experts Group). Após ter selecionado a transformada descreve-se a atribuição de bit ótima para os coeficientes.

\subsection{Transformada Ótima de Karhunen-Loève (KLT)}

Não encontrou-se ainda uma transformação capaz de remover completamente dependência estatística entre os coeficientes. Contudo, a correlação estatística pode ser removida usando a KLT, uma vez que os coeficientes transformados da KLT satisfazem, para $m \neq n$,

$$
E\left[c_{m} c_{n}\right]=E\left[c_{m}\right] E\left[c_{n}\right]
$$


ou

$$
E\left[\left(c_{m}-E\left[c_{m}\right]\right)\left(c_{n}-E\left[c_{n}\right]\right)\right]=\lambda_{m} \delta_{m n} \quad \forall m, n
$$

onde: $\lambda_{m}$ é a variância de $c_{m}$.

A KLT pode ser obtida assumindo que os vetores de pixel apresentam uma tendência a possuir média zero, isto é,

$$
E[\mathbf{b}]=0 \quad \text { e, portanto, } \quad E[\mathbf{c}]=0
$$

Assim, de (1.14):

$$
\begin{aligned}
\mathbf{R} & =E\left[\mathbf{b b}^{*}\right] \\
& =E\left[\mathbf{T}^{*} \mathbf{c c} \mathbf{c}^{*} \mathbf{T}\right]=\mathbf{T}^{*} E\left[\mathbf{c c}^{*}\right] \mathbf{T}
\end{aligned}
$$

Como $\mathbf{T}^{-1}=\mathbf{T}^{*}$, tem-se:

$$
\mathbf{R T}^{*}=\mathbf{T}^{*} E\left[\mathbf{c c}^{*}\right]
$$

De (3.4) e do fato da média ser zero, tem-se que $E\left[\mathbf{c c}^{*}\right]$ é uma matriz diagonal $N \times N$ com as variâncias de $c_{m}$, ao longo da diagonal principal. Logo,

$$
\mathbf{R} \mathbf{t}_{\mathbf{m}}=\lambda_{m} \mathbf{t}_{\mathbf{m}} \quad m=1 \ldots N,
$$

ou seja, os vetores básicos da KLT são auto-vetores da matriz correlação $\mathbf{R}$, ortonormalizados para satisfazer:

$$
t_{m}^{*} t_{n}=\delta_{m n}
$$

As variâncias $\left\{\lambda_{m}\right\}$ dos coeficientes da KLT são auto-valores de $\mathbf{R}$ e, uma vez que $\mathbf{R}$ é simétrica e definida positiva, eles são reais e positivos.

Além de decorrelacionar os coeficientes, a KLT tem outra propriedade útil: ela maximiza o número de coeficientes que são bem pequenos, tal que eles tornemse insignificantes. Considere, por exemplo, que os coeficientes da KLT, $\left(c_{1} \ldots c_{N}\right)$, sejam ordenados de acordo com a variância não-crescente, isto é, $\lambda_{1}$, o maior e $\lambda_{N}$, o menor. Considere também que foram transmitidos somente os primeiros $p N$ coeficientes, onde $0<p<1$. 0 receptor usa o vetor coluna truncado:

$$
\tilde{\mathbf{c}}=\left(c_{1}, \ldots, c_{p N}, 0, \ldots, 0\right)^{t}
$$

para formar os valores dos pixels reconstruídos:

$$
\tilde{\mathbf{b}}=\mathbf{T}^{*} \tilde{\mathbf{c}}
$$


O MSE entre os pixels originais b e os pixels reconstruídos $\tilde{b}$ é, então:

$$
\begin{aligned}
M S E & =E\left[\frac{1}{N} \sum_{i=1}^{N}\left(b_{i}-\tilde{b}_{i}\right)^{2}\right]=\frac{1}{N} E\left\{|\mathbf{b}-\tilde{\mathbf{b}}|^{2}\right\} \\
& =\frac{1}{N} E\left\{|\mathbf{c}-\tilde{\mathbf{c}}|^{2}\right\} \\
& =\frac{1}{N} \sum_{p N+1}^{N} \lambda_{m} .
\end{aligned}
$$

\subsection{Algoritmo Rápido para a Transformada Dis- creta do Co-Seno}

A transformada discreta do co-seno (DCT) tem se tornado uma transformada de grande interesse nos últimos anos, principalmente devido ao grande sucesso em aplicações de processamento de sinais digitais, especialmente em compressão de imagens.

Em 1974 Ahamed et al., [1], mostraram que a DCT de um sinal de $N$ pontos poderia ser calculada usando uma DFT (Discrete Fourier Transform) de $2 N$ pontos.

- Chen et al., [3], usou decomposição de matrizes para obter um algoritmo especial com uma melhora considerável quando comparado com a aproximação convencional usando uma FFT (Fast Fourier Transform) com o dobro do tamanho do sinal de entrada. Narasimha e Peterson, [22], desenvolveram um algoritmo no qual uma DFT de $N$ pontos ( $N$ par) poderia ser usada para avaliar uma DCT utilizando-se o sinal de entrada reordenado.

Considerando a possibilidade de usar um software para calcular a FFT, em vez de um algoritmo especial para a DCT, decidiu-se utilizar um algoritmo desenvolvido por Makhoul, [20], para $N$ par ou ímpar, considerado uma extensão do algoritmo de Narasimha e Peterson.

Neste início de anos 90, Sun et al., [32], e Cho e Lee, [4], implementaram a DCT em hardware, reduzindo o custo e tamanho de muitos sistemas de compressão de imagens.

\subsubsection{Transformada Discreta do Co-Seno 2-D}

Dada uma seqüência real bidimensional de dados $\left\{x\left(n_{1}, n_{2}\right), 0 \leq n_{1} \leq N_{1}-\right.$ 
$\left.1,0 \leq n_{2} \leq N_{2}-1\right\}$, a seqüência DCT bidimensional $\left\{C\left(k_{1}, k_{2}\right), 0 \leq k_{1} \leq N_{1}-1\right.$, $\left.0 \leq k_{2} \leq N_{2}-1\right\}$ pode ser obtida usando uma DFT real de $\left(N_{1} \times N_{2}\right)$ pontos.

Seja $y\left(n_{1}, n_{2}\right)$ uma extensão par de $\left(2 N_{1} \times 2 N_{2}\right)$ pontos de $x\left(n_{1}, n_{2}\right)$ definida por:

$$
y\left(n_{1}, n_{2}\right)= \begin{cases}x\left(n_{1}, n_{2}\right) ; & 0 \leq n_{1} \leq N_{1}-1 \\ y\left(2 N_{1}-n_{1}-1, n_{2}\right) ; & 0 \leq n_{2} \leq N_{2}-1 \\ & N_{1} \leq n_{1} \leq 2 N_{1}-1 \\ y\left(n_{1}, 2 N_{2}-n_{2}-1\right) ; & 0 \leq n_{2} \leq N_{2}-1 \\ y\left(2 N_{1}-n_{1}-1,2 N_{2}-n_{2}-1\right) ; & 0 \leq n_{1} \leq N_{1}-1 \\ & N_{2}+1 \leq n_{2} \leq 2 N_{2}-1 \\ & N_{1} \leq n_{1} \leq N_{1}-1 \\ & N_{2} \leq n_{2} \leq 2 N_{2}-1\end{cases}
$$

A figura (3.2) mostra um exemplo onde $N_{1}=3$ e $N_{2}=4$ e os números na figura são os valores dos pixels. Ver também equação (3.17).

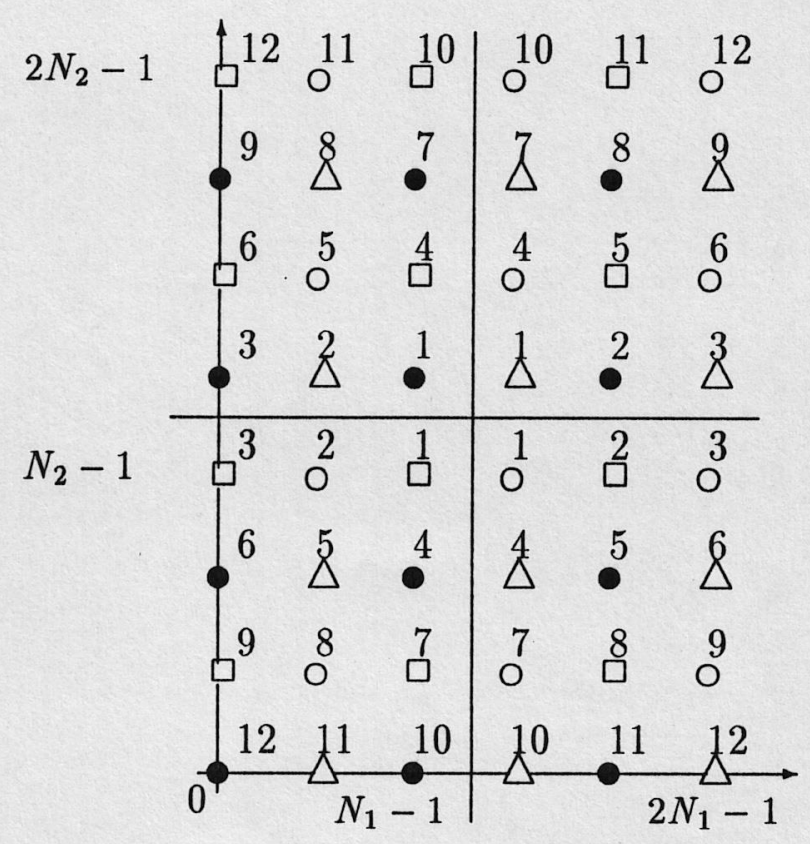

Figura 3.2: Exemplo de uma seqüência 2-D com $\left(N_{1} \times N_{2}\right)$ pontos e suas extensões pares com $\left(2 N_{1} \times 2 N_{2}\right)$ pontos. 
Observa-se que o número de amostras em $y\left(n_{1}, n_{2}\right)$ é $4 N_{1} N_{2}$, ou seja, 4 vezes o número em $x\left(n_{1}, n_{2}\right)$. Generalizando para uma seqüência $m$ - $\mathrm{D}$, o número de amostras na seqüência extendida $y\left(n_{1}, n_{2}, \ldots, n_{m}\right)$ é $2^{m}$ vezes o número de amostras em $x\left(n_{1}, n_{2}, \ldots, n_{m}\right)$.

A DFT 2-D de $y\left(n_{1}, n_{2}\right)$ é dada por:

$$
Y\left(k_{1}, k_{2}\right)=\sum_{n_{1}=0}^{2 N_{1}-1} \sum_{n_{2}=0}^{2 N_{2}-1} y\left(n_{1}, n_{2}\right) W_{N_{1}}^{n_{1} k_{1}} W_{N_{2}}^{n_{2} k_{2}}
$$

onde: $W_{M}=e^{-i \frac{2 \pi}{M}}$.

Substituindo (3.10) em (3.11), pode-se mostrar que:

$$
Y\left(k_{1}, k_{2}\right)=W_{2 N_{1}}^{-k_{1} / 2} W_{2 N_{2}}^{-k_{2} / 2} C\left(k_{1}, k_{2}\right)
$$

onde:

$$
C\left(k_{1}, k_{2}\right)=4 \sum_{n_{1}=0}^{N_{1}-1} \sum_{n_{2}=0}^{N_{2}-1} x\left(n_{1}, n_{2}\right) \cos \frac{\left(2 n_{1}+1\right) k_{1}}{2 N_{1}} \cos \frac{\left(2 n_{2}+1\right) k_{2}}{2 N_{2}},
$$

$0 \leq k_{1} \leq N_{1}-1, \quad 0 \leq k_{2} \leq N_{2}-1$ é a DCT 2-D da seqüência $x\left(n_{1}, n_{2}\right)$.

Assim para calcular a DCT $C\left(k_{1}, k_{2}\right)$ de (3.11) e (3.12) ou de (3.13) exige-se o cálculo da DFT de uma seqüência real de $\left(2 N_{1} \times 2 N_{2}\right)$ pontos.

Pode-se mostrar ainda que $Y\left(k_{1}, k_{2}\right)$ possui as seguintes propriedades:

$$
\begin{aligned}
Y\left(2 N_{1}-k_{1}, 2 N_{2}-k_{2}\right) & =Y^{*}\left(k_{1}, k_{2}\right) \\
Y\left(2 N_{1}-k_{1}, 0\right) & =Y^{*}\left(k_{1}, 0\right) \\
Y\left(0,2 N_{2}-k_{2}\right) & =Y^{*}\left(0, k_{2}\right) \\
Y\left(N_{1}, k_{2}\right)=Y\left(k_{1}, N_{2}\right) & =0 .
\end{aligned}
$$

As três primeiras equações constituem as propriedades de hermitiana simétrica em duas dimensões, uma vez que $y\left(n_{1}, n_{2}\right)$ é real. A quarta propriedade é conseqüência do tipo de simetria par de $y\left(n_{1}, n_{2}\right)$.

Substituindo essas propriedades na DFT inversa 2-D:

$$
y\left(n_{1}, n_{2}\right)=\frac{1}{4 N_{1} N_{2}} \sum_{k_{1}=0}^{2 N_{1}-1} \sum_{k_{2}=0}^{2 N_{2}-1} Y\left(k_{1}, k_{2}\right) W_{2 N_{1}}^{-n_{1} k_{1}} W_{2 N_{2}}^{-n_{2} k_{2}}
$$

tem-se que a DCT 2-D inversa de $C\left(k_{1}, k_{2}\right)$ é dada por:

$$
x\left(n_{1}, n_{2}\right)=\frac{1}{N_{1} N_{2}} \sum_{k_{1}=0}^{N_{1}-1} \sum_{k_{2}=0}^{N_{2}-1} C^{*}\left(k_{1}, k_{2}\right) \cos \frac{\pi\left(2 n_{1}+1\right) k_{1}}{2 N_{1}} \cos \frac{\pi\left(2 n_{2}+1\right) k_{2}}{2 N_{2}}
$$


onde:

$$
C^{*}\left(k_{1}, k_{2}\right)=\left\{\begin{array}{lll}
C(0,0) / 4, & k_{1}=0, & k_{2}=0 \\
C\left(k_{1}, 0\right) / 2, & k_{1} \neq 0, & k_{2}=0 \\
C\left(0, k_{2}\right) / 2, & k_{1}=0, & k_{2} \neq 0 \\
C\left(k_{1}, k_{2}\right), & k_{1} \neq 0, & k_{2} \neq 0
\end{array}\right.
$$
$2 \mathrm{~N}_{2}$ ) pontos.

Assim $x\left(n_{1}, n_{2}\right)$ pode ser calculada usando uma DFT inversa 2-D de $\left(2 N_{1} \times\right.$

\subsubsection{Transformada Rápida Discreta do Co-Seno 2-D (FDCT)}

Agora mostrar-se-á que a DCT pode ser obtida de uma DFT de $\left(N_{1} \times N_{2}\right)$ pontos de uma seqüência real, em vez de uma DFT de $\left(2 N_{1} \times 2 N_{2}\right)$ pontos, resultando numa economia de $25 \%$.

Divide-se $y\left(n_{1}, n_{2}\right)$ em quatro seqüências de $\left(N_{1} \times N_{2}\right)$ pontos, iniciando com os quatro pontos em $(0,0),(1,0),(0,1)$ e $(1,1)$, respectivamente, e tomando todo segundo ponto após aquele.

No caso $m$-D,$y\left(n_{1}, n_{2}, \ldots, n_{m}\right)$ é dividida em $2^{m}$ "cantos" do cubo unitário $m$-D, de $(0,0, \ldots, 0)$ a $(1,1, \ldots, 1)$ e tomando todo segundo pontos após aquele. A seqüência que inicia em $\left(i_{1}, i_{2}, \ldots, i_{m}\right)$, onde cada $i_{k}=0$ ou 1 , é definida por - $y\left(2 n_{1}+i_{1}, 2 n_{2}+i_{2}, \ldots, 2 n_{m}+i_{m}\right)$.

As quatro seqüências são dadas por:

$$
\begin{aligned}
v\left(n_{1}, n_{2}\right) & =y\left(2 n_{1}, 2 n_{2}\right) \\
w_{1}\left(n_{1}, n_{2}\right) & =y\left(2 n_{1}+1,2 n_{2}\right) \\
w_{2}\left(n_{1}, n_{2}\right) & =y\left(2 n_{1}, 2 n_{2}+1\right) \\
w_{3}\left(n_{1}, n_{2}\right) & =y\left(2 n_{1}+1,2 n_{2}+1\right)
\end{aligned}
$$

onde: $\quad 0 \leq n_{1} \leq N_{1}-1, \quad 0 \leq n_{2} \leq N_{2}-1$.

No exemplo da figura (3.2) as quatro seqüências são representadas por: discos cheios $\left(v\left(n_{1}, n_{2}\right)\right)$, triângulos $\left(w_{1}\left(n_{1}, n_{2}\right)\right)$, quadrados $\left(w_{2}\left(n_{1}, n_{2}\right)\right)$ e discos abertos $\left(w_{3}\left(n_{1}, n_{2}\right)\right)$. Observa-se que cada seqüência contém todas as amostras em $x\left(n_{1}, n_{2}\right)$, mas em uma versão reordenada.

De (3.17) e (3.10), pode-se mostrar que:

$$
\begin{aligned}
& w_{1}\left(n_{1}, n_{2}\right)=v\left(N_{1}-n_{1}-1, n_{2}\right) \\
& w_{2}\left(n_{1}, n_{2}\right)=v\left(n_{1}, N_{2}-n_{2}-1\right) \\
& w_{3}\left(n_{1}, n_{2}\right)=v\left(N_{1}-n_{1}-1, N_{2}-n_{2}-1\right)
\end{aligned}
$$


Seja $V\left(k_{1}, k_{2}\right)$ a DFT 2-D de $\left(N_{1} \times N_{2}\right)$ pontos de $v\left(n_{1}, n_{2}\right)$ :

$$
V\left(k_{1}, k_{2}\right)=\sum_{n_{1}=0}^{N_{1}-1} \sum_{n_{2}=0}^{N_{2}-1} v\left(n_{1}, n_{2}\right) W_{N_{1}}^{n_{1} k_{1}} W_{N_{2}}^{n_{2} k_{2}}
$$

Substituindo (3.18) e (3.17) em (3.11) e usando (3.12), tem-se:

$$
C\left(k_{1}, k_{2}\right)=2 \operatorname{Re}\left\{W_{4 N_{1}}^{k_{1}}\left[W_{4 N_{2}}^{k_{2}} V\left(k_{1}, k_{2}\right)+W_{4 N_{2}}^{-k_{2}} V\left(k_{1}, N_{2}-k_{2}\right)\right]\right\}
$$

ou:

$$
C\left(k_{1}, k_{2}\right)=2 \operatorname{Re}\left\{W_{4 N_{2}}^{k_{2}}\left[W_{4 N_{1}}^{k_{1}} V\left(k_{1}, k_{2}\right)+W_{4 N_{1}}^{-k_{1}} V\left(N_{1}-k_{1}, k_{2}\right)\right]\right\} .
$$

De (3.20) ou de (3.21) tem-se que:

$$
C\left(k_{1}, k_{2}\right)=4 \sum_{n_{1}=0}^{N_{1}-1} \sum_{n_{2}=0}^{N_{2}-1} v\left(n_{1}, n_{2}\right) \cos \frac{\pi\left(4 n_{1}+1\right) k_{1}}{2 N_{1}} \cos \frac{\pi\left(4 n_{2}+1\right) k_{2}}{2 N_{2}} .
$$

Portanto, de (3.20) ou (3.21) e (3.19), tem-se que a DCT pode ser calculada usando uma DFT de $\left(N_{1} \times N_{2}\right)$ pontos, em vez de uma DFT de $\left(2 N_{1} \times 2 N_{2}\right)$ pontos, resultando numa economia de $25 \%$.

Em vez de usar (3.17) pode-se obter $v\left(n_{1}, n_{2}\right)$ diretamente de $x\left(n_{1}, n_{2}\right)$ por:

$$
v\left(n_{1}, n_{2}\right)= \begin{cases}x\left(2 n_{1}, 2 n_{2}\right) ; & 0 \leq n_{1} \leq\left[\frac{N_{1}-1}{2}\right], \\ x\left(2 N_{1}-2 n_{1}-1,2 n_{2}\right) ; & 0 \leq n_{2} \leq\left[\frac{N_{2}-1}{2}\right] ; \\ & {\left[\frac{N_{1}+1}{2}\right] \leq n_{1} \leq N_{1}-1,} \\ x\left(2 n_{1}, 2 N_{2}-2 n_{2}-1\right) ; & 0 \leq n_{2} \leq\left[\frac{N_{2}-1}{2}\right] ; \\ & 0 \leq n_{1} \leq\left[\frac{N_{1}-1}{2}\right], \\ x\left(2 N_{1}-2 n_{1}-1,2 N_{2}-2 n_{2}-1\right) ; & {\left[\frac{N_{2}+1}{2}\right] \leq n_{2} \leq N_{2}-1 ;} \\ & {\left[\frac{N_{1}^{2}+1}{N_{2}}\right] \leq n_{1} \leq N_{1}-1,} \\ & {\left[\frac{N_{2}+1}{2}\right] \leq n_{2} \leq N_{2}-1 ;}\end{cases}
$$

onde: $[a]$ denota "a parte inteira de a".

\subsubsection{Transformada Rápida Inversa do Co-Seno - FDCT Inversa}

A FDCT inversa 2-D de $C\left(k_{1}, k_{2}\right)$ é obtida primeiro calculando $V\left(k_{1}, k_{2}\right)$ a partir de $C\left(k_{1}, k_{2}\right)$. 
Define-se uma quantidade complexa $C_{c}\left(k_{1}, k_{2}\right)$ não tomando a parte real em (3.20) e, então, mostra-se que:

$$
C_{c}\left(k_{1}, k_{2}\right)=C\left(k_{1}, k_{2}\right)-i C\left(N_{1}-k_{1}, k_{2}\right)
$$

Encontra-se $C_{c}^{*}\left(N_{1}-k_{1}, N_{2}-k_{2}\right)$, adiciona e subtrai o resultado de $C_{c}\left(k_{1}, k_{2}\right)$, reduzindo-se a:

$$
\begin{aligned}
V\left(k_{1}, k_{2}\right)= & \frac{1}{4} W_{4 N_{1}}^{-k_{1}} W_{4 N_{2}}^{-k_{2}}\left\{\left[C\left(k_{1}, k_{2}\right)-C\left(N_{1}-k_{1}, N_{2}-k_{2}\right)\right]\right. \\
& \left.-i\left[C\left(N_{1}-k_{1}, k_{2}\right)+C\left(k_{1}, N_{2}-k_{2}\right)\right]\right\}
\end{aligned}
$$

onde: $0 \leq k_{1} \leq N_{1}-1 \quad$ e $\quad 0 \leq k_{2} \leq N_{2}-1$.

Como $V\left(k_{1}, k_{2}\right)$ é simétrica hermitiana, calcula-se apenas metade dos valores em (3.25) e, ainda, necessita-se do fato que:

$$
C\left(N_{1}, k_{2}\right)=C\left(k_{1}, N_{2}\right)=0 \quad \forall k_{1}, k_{2}
$$

Depois de calcular $V\left(k_{1}, k_{2}\right), v\left(n_{1}, n_{2}\right)$ é calculada da DFT inversa:

$$
v\left(n_{1}, n_{2}\right)=\frac{1}{N_{1} N_{2}} \sum_{k_{1}=0}^{N_{1}-1} \sum_{k_{2}=0}^{N_{2}-1} V\left(k_{1}, k_{2}\right) W_{N_{1}}^{-n_{1} k_{1}} W_{N_{2}}^{-n_{2} k_{2}}
$$

E $x\left(n_{1}, n_{2}\right)$ é obtida de $v\left(n_{1}, n_{2}\right)$ usando a equação (3.23).

Agora pode-se especificar o algoritmo completo para o cálculo da FDCT e a FDCT inversa.

\section{Algoritmo FDCT}

Dada a seqüência real $x\left(n_{1}, n_{2}\right), 0 \leq n_{1} \leq N_{1}-1,0 \leq n_{2} \leq N_{2}-1$.

1. Forma-se a seqüência $v\left(n_{1}, n_{2}\right)$ usando a equação $(3.23)$;

2. Calcula-se a DFT $V\left(k_{1}, k_{2}\right)$ a partir de $v\left(n_{1}, n_{2}\right)$, para. $0 \leq k_{1} \leq N_{1}-1$, $0 \leq k_{2} \leq N_{2}-1$;

3. Obtém-se $C\left(k_{1}, k_{2}\right)$ a partir de $V\left(k_{1}, k_{2}\right)$, conforme (3.20) ou (3.21). 


\section{Algoritmo FDCT Inversa}

que:

Dada a DCT $C\left(k_{1}, k_{2}\right), 0 \leq k_{1} \leq N_{1}-1,0 \leq k_{2} \leq N_{2}-1$ e considerando

$$
C\left(N_{1}, k_{2}\right)=C\left(k_{1}, N_{2}\right)=0 \quad \forall k_{1}, k_{2}
$$

1. Calcula-se $V\left(k_{1}, k_{2}\right)$ a partir de $C\left(k_{1}, k_{2}\right)$ usando a equação (3.25);

2. Calcula-se $v\left(n_{1}, n_{2}\right)$, a DFT inversa de $V\left(k_{1}, k_{2}\right)$, utilizando-se de um algoritmo rápido para a DFT inversa;

3. Finalmente, $x\left(n_{1}, n_{2}\right)$ é obtida de $v\left(n_{1}, n_{2}\right)$ também usando (3.23).

\subsection{Comparação entre Transformadas}

Esta secção baseia-se na referência [5] onde faz-se uma comparação geral entre as transformadas mais usadas, considerando sua eficiência em compactar energia e decorrelacionar os dados.

A maioria da energia dos dados concentra-se em poucos coeficientes (no canto superior esquerdo da matriz) e os restantes podem ser reservados para uma aplicação de codificação com exatidão reduzida ou omitidos completamente quando a fonte de dados é reconstruída sobre transformação inversa.

Este é o princípio básico do processo de codificação por transformada e a propriedade de compactar energia de várias transformadas é um aspecto que pode ser comparado quantitativamente.

Determina-se a quantia relativa de energia nos primeiros $M$ coeficientes da diagonal na matriz de covariância, no total de $N$ :

$$
\eta_{E}=\frac{\sum_{j=1}^{M} Y_{j j}}{\sum_{j=1}^{N} Y_{j j}}
$$

onde para uma transformada ortonormal o denominador é igual a $N$.

A eficiência na decorrelação é:

$$
\eta_{c}=1-\left\{\frac{\sum Y}{\sum X}\right\}
$$


onde:

$$
\begin{aligned}
& \sum X=\sum_{j=1}^{N} \sum_{k=1}^{N}\left|X_{j k}\right| \\
& \sum Y=\sum_{j=1}^{N} \sum_{k=1}^{N}\left|Y_{j k}\right|
\end{aligned}
$$

Portanto, quando a matriz de covariância no domínio da transformada tiver uma forma diagonal isto corresponderá a uma eficiência de $100 \%$.

Considera-se como exemplo a DCT com um bloco de $N=8$ e um coeficiente de correlação entre pixels de 0.91 .

A matriz de covariância no domínio espacial é mostrado na equação (3.30), onde todos os valores ao longo das linhas setadas são idênticos e tem-se assumido uma variância unitária e os dados de entrada com média zero. A matriz de covariância correspondente no domínio da transformada é mostrada na equação (3.31).

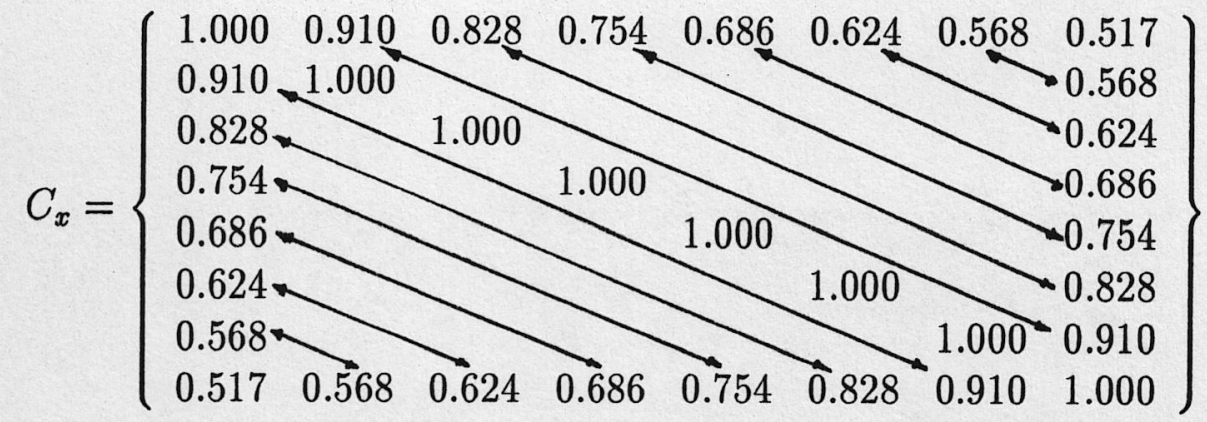

$$
\begin{aligned}
& C_{y}=\left\{\begin{array}{rrrrrrrr}
6.344 & 0.000 & -0.291 & 0.000 & -0.066 & 0.000 & -0.021 & 0.000 \\
0.000 & 0.930 & 0.000 & -0.027 & 0.000 & -0.008 & 0.000 & -0.002 \\
-0.291 & 0.000 & 0.312 & 0.000 & -0.001 & 0.000 & 0.000 & 0.000 \\
0.000 & -0.027 & 0.000 & 0.149 & 0.000 & -0.001 & 0.000 & 0.000 \\
-0.066 & 0.000 & -0.001 & 0.000 & 0.094 & 0.000 & 0.000 & 0.000 \\
0.000 & -0.008 & 0.000 & -0.001 & 0.000 & 0.068 & 0.000 & 0.000 \\
-0.021 & 0.000 & 0.000 & 0.000 & 0.000 & 0.000 & 0.055 & 0.000 \\
0.000 & -0.002 & 0.000 & 0.000 & 0.000 & 0.000 & 0.000 & 0.049
\end{array}\right\}
\end{aligned}
$$

Das equações (3.30) e (3.31), as seguintes quantidades podem ser calculadas, onde $X_{j k}$ e $Y_{j k}$ representam os termos individuais nas duas funções:

$$
\begin{aligned}
& \sum X=42.748 \quad \text { soma total das covariâncias dos dados } \\
& \sum Y=0.835 \text { soma total das covariâncias transformadas }
\end{aligned}
$$


onde $N=8$; neste caso, os somatórios excluem os termos da diagonal (variâncias) para os quais $j=k$.

A eficiência de decorrelação, para este exemplo, é $98.05 \%$. E a eficiência em compactar energia é, então:

$$
\begin{array}{ccccccccc}
M & 1 & 2 & 3 & 4 & 5 & 6 & 7 & 8 \\
\eta_{E}(\%) & 79.3 & 90.9 & 94.8 & 96.7 & 97.9 & 98.7 & 99.4 & 10,0
\end{array}
$$

\subsubsection{Eficiência em Compactar Energia $\eta_{E}$}

A figura (3.3) mostra a eficiência em compactar energia para várias transformadas para o caso de $N=8$.

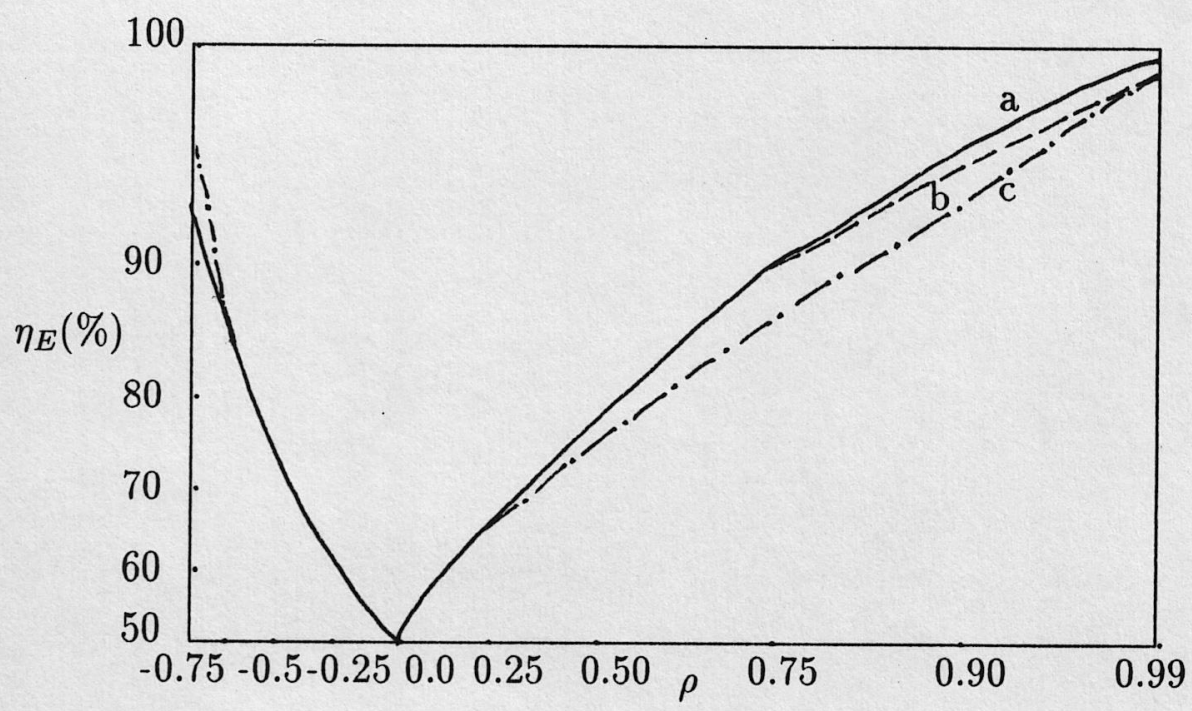

Figura 3.3: Eficiência em compactar energia $\eta_{E}(N=8$, com 4 coeficientes conservados) em função do coeficiente de correlação. (a) DCT, (b) KLT (0.36) e (c) DFT.

O melhor desempenho é fornecido pela DCT e é idêntico ao da KLT (0.91) ${ }^{1}$ e a transformada com o desempenho mais pobre é a DFT; as curvas para todas

\footnotetext{
1 a notação implica que os vetores básicos foram calculados por um processo de Markov de ordem 1 e coeficiente de correlação 0.91
} 
as outras transformadas: WHT (Wash- Hadamard Transform), DST (Discrete Sine Transform), Haar, Slant estão entre a DFT e a DCT.

A figura (3.4) mostra os valores das variâncias dos coeficientes para $N=16$ e $\rho=0.91$ para a DCT, DFT e DST, respectivamente.

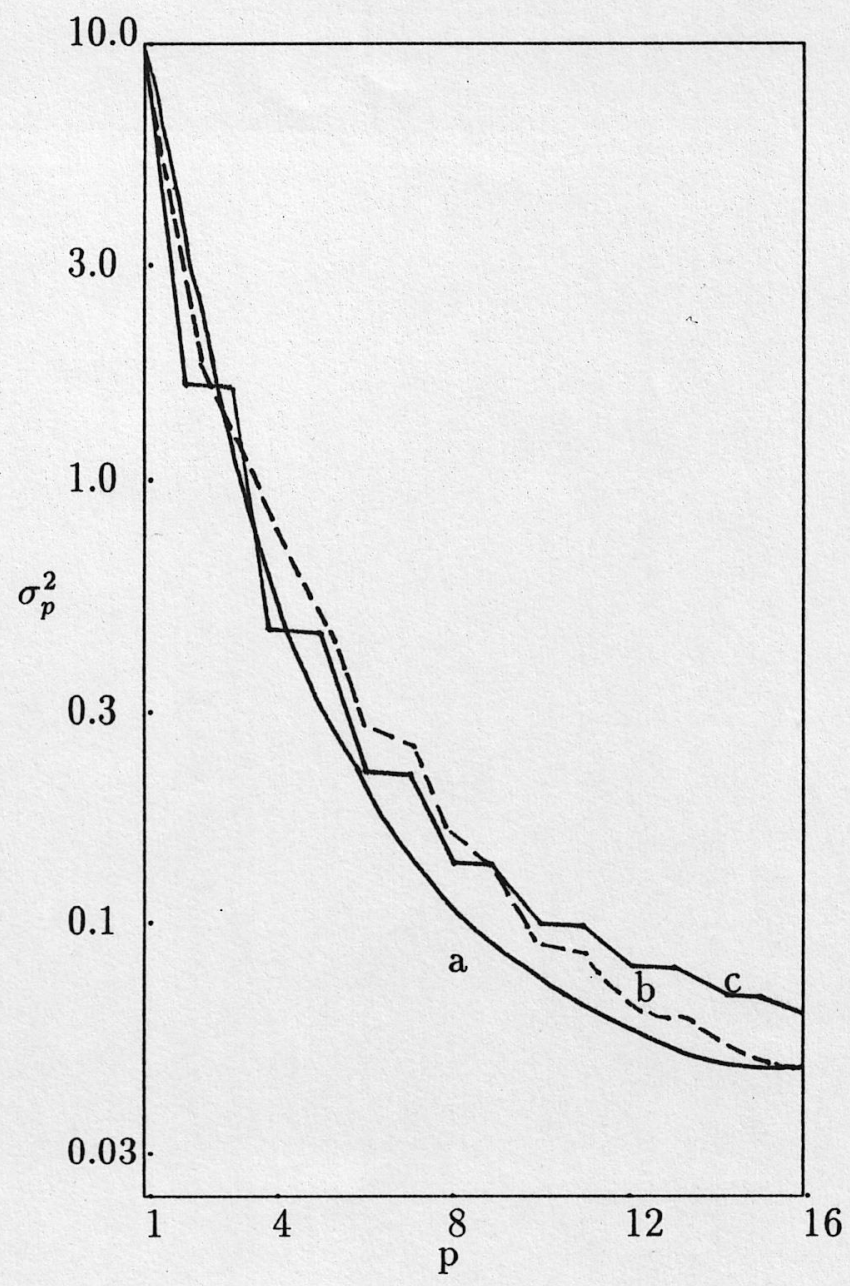

Figura 3.4: Variância do coeficiente transformado $\sigma_{p}^{2}$ em função da ordem $p$ do coeficiente; $\rho=0.91 ; N=16$. (a) DCT, (b) DFT e (c) DST.

Boa compactação exige que as magnitudes das variâncias tenham um decaimento rápido com o aumento na ordem dos coeficientes e a DCT é novamente melhor neste sentido e também, em contraste com outras transformadas, seu decaimento apresenta aspecto não serrilhado. 


\subsubsection{Eficiência na Decorrelação $\eta_{c}$}

A decorrelação é outra propriedade importante na operação das transformadas ortogonais.

A decorrelação é indicada pela matriz de covariância (ou correlação) no domínio da transformada que, no caso de decorrelação perfeita, apresenta uma forma diagonal.

As magnitudes dos termos de covariância fora da diagonal em qualquer matriz de covariância indicam a correlação entre as várias seqüências envolvidas e, como a equação (3.29), a razão dos somatórios de tais termos nos domínios dos dados e da transformada demonstra o grau de sucesso que a transformada tem em eliminar a correlação entre os dados.

Nas figuras seguintes, decorrelação perfeita é representada por $100 \%$ e nenhuma redução na correlação por $0 \%$.

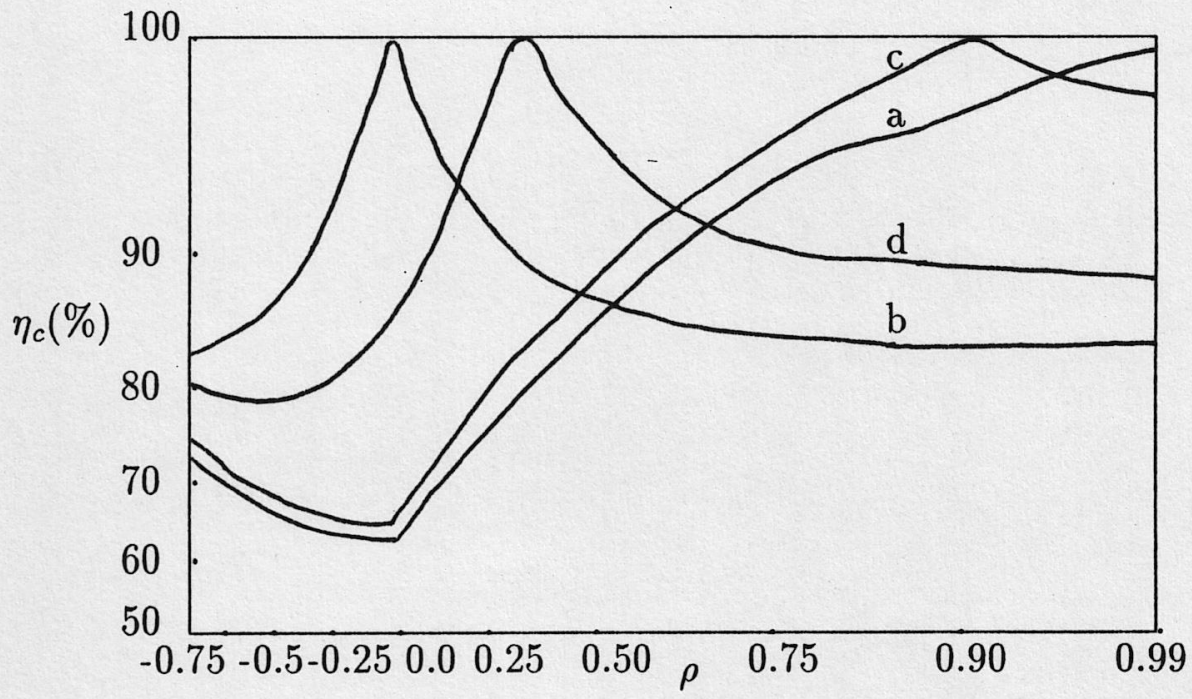

Figura 3.5: Eficiência na decorrelação $\eta_{c}(N=8)$ em função do coeficiente de correlação (a) DCT, (b) DST, (c) KLT e (d) KLT (0.36).

A figura (3.5) mostra o comportamento de algumas transformadas com relação ao coeficiente de correlação dos dados de entrada para $N=8$. 
Observa-se que todas transformadas são razoavelmente eficientes quando o valor de $\rho$ é maior que cerca de 0.9 , com a exceção da transformada do seno (DST) que apresenta um desempenho melhor na região de correlação pequena.

Observa-se, entretanto que, resultados podem estar sujeitos a erros, uma vez que, quando $\rho$ tende a zero ambos somatórios na equação (3.29) também tendem a zero, levando a um resultado indeterminado.

A melhor transformada é a DCT que, contudo, agora tem um desempenho medido diferente da KLT. Para comparação, a curva para a KLT (0.36) está incluída também e esses resultados demonstram que, geralmente, existe uma grande variação no desempenho de decorrelação quando o tipo de transformada e os parâmetros da operação são variados, como é o caso para o comportamento de compactação de energia.

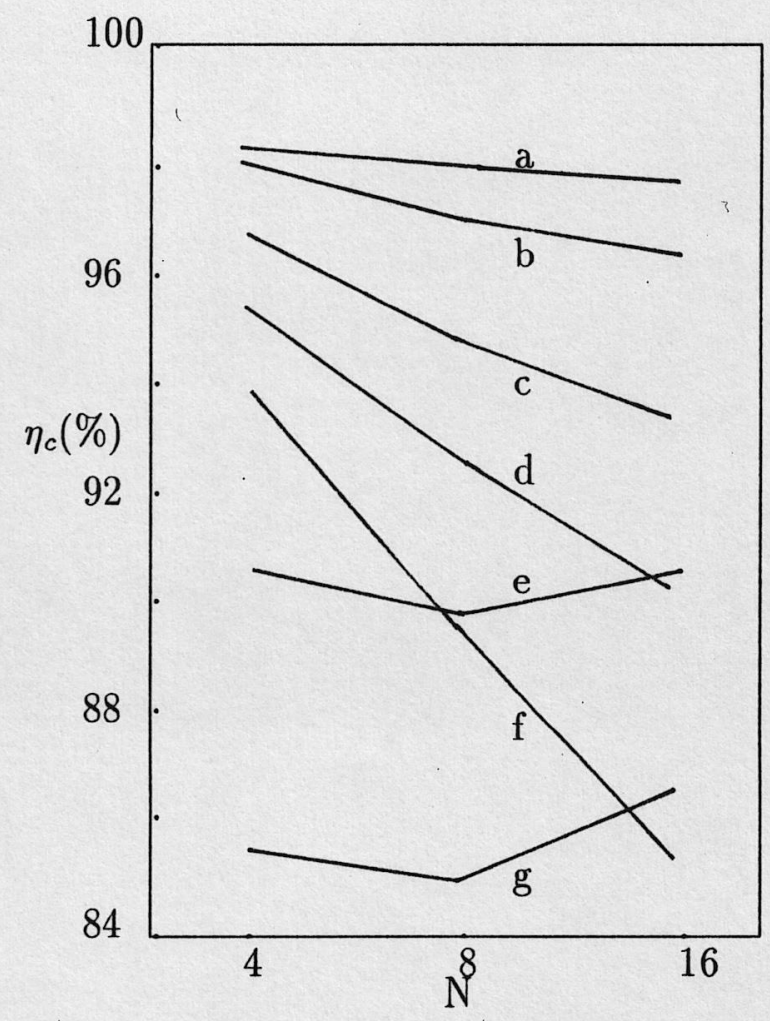

Figura 3.6: Eficiência na decorrelação $\eta_{c}$ em função do tamanho do bloco da transformada, $\rho=0.91$. (a) DCT, (b) Slant, (c) WHT, (d) Haar, (e) KLT, (f) DFT e (g) DST. 
O efeito da variação do tamanho do bloco sobre $\eta_{c}$ é mostrado na figura (3.6). Em geral, blocos de tamanhos maiores reduzem o desempenho da transformada nesta questão, embora isto não seja sempre verdade para a DST e KLT (o resultado para a KLT $(0.91)$ é $100 \%$ para todo $N$ ). Para as melhores transformadas, contudo, o efeito é pequeno.

\subsection{JPEG}

O JPEG (Joint Photographic Experts Group) é um grupo formado com a colaboração entre CCITT (Consultive Committee International of Telegraph e Telephones) e ISO (International Standard Organization). Esse grupo tem trabalhado nos últimos anos para estabelecer o primeiro padrão internacional de compressão de imagens "paradas", em escala de cinza e colorida, [33].

A técnica de compressão por transformada desenvolvida pelo JPEG e como muitas outras, esta baseada na DCT. Observa-se que neste padrão utiliza-se basicamente multiplicações de matrizes para implementação da DCT usando também blocos de tamanho $8 \times 8$. Assim, nenhuma técnica mais eficiente foi utilizada para aumentar a velocidade da DCT.

A quantização é o próximo passo no processo de compressão JPEG fundamentalmente caracterizado por perda de informação, uma vez que se deseja reduzir o número de bits necessários para armazenar um valor inteiro. Para isto o JPEG utiliza uma matriz de quantização.

Todo elemento na matriz de coeficientes possui um correspondente na matriz de quantização dado pelo valor de quantização $Q$, que indica o tamanho do passo do quantizador, dado por:

$$
Q\left(k_{1}, k_{2}\right)=1+\left(\left(1+k_{1}+k_{2}\right) * \text { fator de qualidade }\right),
$$

onde o fator de qualidade é fixado pelo usuário, estando entre 1 e 25. Quanto maior este valor maior a perda de informação.

Assim, a quantização é definida por:

$$
F^{Q}\left(k_{1}, k_{2}\right)=\text { Arredondar } \mathrm{p} / \text { inteiro mais próximo }\left\{\frac{D C T\left(k_{1}, k_{2}\right)}{Q\left(k_{1}, k_{2}\right)}\right\}
$$

onde $F^{Q}\left(k_{1}, k_{2}\right)$ indica os valores quantizados dos coeficientes $\operatorname{DCT}\left(k_{1}, k_{2}\right)$. 
$\mathrm{Na}$ decodificação, a dequantização é a função inversa:

$$
D C T^{\prime}\left(k_{1}, k_{2}\right)=F^{Q}\left(k_{1}, k_{2}\right) * Q\left(k_{1}, k_{2}\right) .
$$

Após quantização, o coeficiente que ocupa a posição $(0,0)$ é codificado como a diferença dos termos DC de blocos anteriores na ordem de codificação. Em seguida todos os coeficientes quantizados são ordenados pela seqüência zig-zag, ver página 68, para serem codificados ou usando o Código de Huffman [13] ou Codificação Aritmética [34,18].

\subsection{Seleção e Quantização de Coeficientes}

Depois de ter selecionado uma transformada que represente um compromisso entre decorrelação eficiente e habilidade em compactar energia, o próximo passo no processo de codificação por transformada é a seleção e quantização eficiente desses coeficientes que serão conservados para transmissão ou armazenagem, constituindo-se em uma etapa tão importante quanto a escolha, por exemplo, do tipo de transformada ou tamanho do bloco.

\subsubsection{Seleção de Coeficientes}

Conforme foi visto nas secções anteriores, codificação por transformada explora a propriedade de compactação de energia. Somente uma pequena quantia dos coeficientes é quantizada e codificada. Existe basicamente dois tipos de estratégias usadas para determinar quais coeficientes serão codificados: amostragem por zona $\mathrm{e}$ amostragem por limiar, $[5,21,24,27]$.

\section{Amostragem por zona}

$\mathrm{Na}$ amostragem por zona somente os coeficientes dentro de uma região especificada são codificados para transmissão. Muitos fatores, tais como a transformada usada e o número de bits disponíveis afetam a forma geométrica da zona e o tamanho. 
Duas formas típicas de zona usadas na DCT são mostradas na figura (3.7). Os coeficientes nas regiões sombreadas são codificados, enquanto aqueles nas regiões não sombreadas são descartados e definidos como zero.

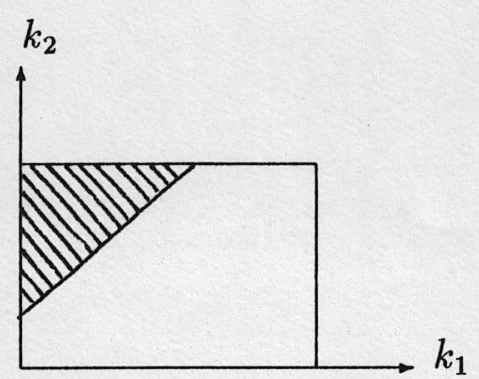

(a)

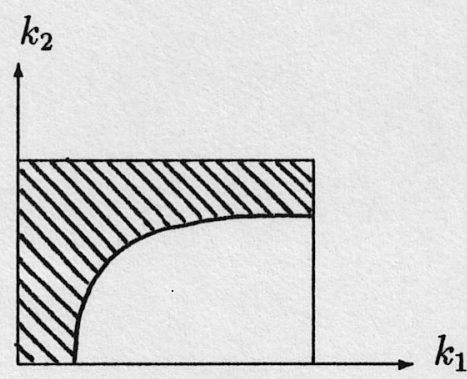

(b)

Figura 3.7: Exemplos de regiões usadas para amostragem por zona para a DCT.

\section{Amostragem por limiar}

$\mathrm{Na}$ amostragem por limiar cada coeficiente cuja magnitude ultrapasse um dado limiar é codificado.

Do ponto de vista de compactação de energia, amostragem por limiar é preferível à amostragem por zona, uma vez que na amostragem por zona alguns coeficientes com magnitudes pequenas podem ser codificados, enquanto aqueles com magnitudes maiores são descartados, pois as zonas são pré-especificadas.

$\mathrm{Na}$ amostragem por limiar somente os coeficientes com grandes magnitudes são selecionados. Contudo, além dos coeficientes é necessário transmitir a informação de suas posições. Se por um lado este método pode melhorar o desempenho da codificação, por outro a complexidade pode aumentar devido ao fato de que o número de coeficientes a serem transmitidos varia com o bloco.

$\mathrm{O}$ método de amostragem por limiar pode ser considerado um método adaptativo de codificação, uma vez que os coeficientes a serem transmitidos variam de bloco para bloco. Um outro tipo de adaptação consiste em obter uma medida de atividade espacial do bloco ("indice de atividade") que pode ser medido segundo uma soma ponderada dos valores absolutos dos coeficientes (Gimlett, [9], citado por Mascarenhas, [21]) e atribuir mais bits para codificar aqueles blocos com índice de atividade maior. 


\subsubsection{Atribuição de Bits}

Dado um número de bits fixado para codificar um bloco, tem-se que dividir esses bits entre os coeficientes dentro do bloco. É sempre útil atribuir mais bits para um coeficiente com uma variância maior. Para a DCT, a variância é muito maior para coeficientes de baixa freqüência do que para coeficientes de alta freqüência.

A seguir desenvolver-se-á um algoritmo para obter a atribuição de bit ótima para os coeficientes, baseado em [6].

A distorção do MSE definido na equação (1.12), pode ser reescrita como:

$$
D=\frac{1}{N} \sum_{k=1}^{N} \sigma_{k}^{2} f\left(n_{k}\right)
$$

onde $\sigma_{k}^{2}$ é a variância do coeficiente $b_{i}, f(n)$ é a função distorção do quantizador para variáveis aleatórias de entrada de variância unitária; e $n_{k}$ é o número de bit atribuído para quantizar o $k$-ésimo coeficiente. $f(n)$ depende do quantizador e da PDF que modela a fonte a ser quantizada, mas infelizmente não existe uma expressão exata para $f($.$) .$

Se a razão média desejada é de $p$ bits/pixel a alocação de bit é:

$$
n_{k}= \begin{cases}h\left(\theta f^{\prime}(0)\right) /\left(\sigma_{k}^{2}\right) & \text { se } 0 \leq \theta \leq \sigma_{k}^{2} \\ 0 & \text { se } \theta \geq \sigma_{k}^{2}\end{cases}
$$

onde $h($.$) é uma função inversa de f^{\prime}($.$) e \theta$ é a raiz da equação restrição:

$$
\sum_{k: \sigma_{k}^{2} \geq 0} n_{k}=\sum_{k: \sigma_{k}^{2} \geq 0} h\left(\frac{\theta f^{\prime}(0)}{\sigma_{k}^{2}}\right)=N p
$$

Assim, para uma razão média de $p$ bit/pixel, então:

$$
\frac{1}{N} \sum_{k=1}^{N} n_{k}=p
$$

Para um valor fixo de $p$, deseja-se encontrar a atribuição de bit $n_{k} \geq 0$ para $b_{k}$, tal que a distorção $D$ seja minimizada.

Para o quantizador de Shannon, a função razão de distorção tem uma expressão exata, dada por:

$$
f(n)=2^{-2 n}
$$


e a atribuição de bit ótima é dada por:

$$
n_{k}=n_{k}(\theta)=\max \left(0, \frac{1}{2} \log _{2} \frac{\sigma_{k}^{2}}{\theta}\right)
$$

onde $\theta$ é determinado tal que:

$$
\frac{1}{N} \sum_{k=1}^{N} n_{k}(\theta)=p
$$

A distorção minimizada na razão $p$ é dada por:

$$
D_{\min }=\frac{1}{N} \sum_{k=1}^{N} \min \left(\theta, \sigma_{k}^{2}\right)
$$

Na prática a atribuição de bit exige minimizar (3.35) sujeito a (3.38), com a restrição de que $n_{k}$ sejam inteiros não negativos.

A solução deste problema deve-se a Fox, [7], conforme citação feita por Farrelle [6] e Jain [15].

A fim de descrever o algoritmo, tem-se $N p$ bit para atribuir aos $N$ coeficientes, a fim de obter uma razão média de $p$ bit por pixel e considerando que já tem-se atribuídos $n$ dos bits. Agora deseja-se atribuir o próximo bit de tal maneira que se tenha distorção mínima.

Assumindo o quantizador de Shannon, então, a distorção associada com o coeficiente $k$ é:

$$
d_{k}=\sigma_{k}^{2} f\left(n_{k}\right)=\frac{\sigma_{k}^{2}}{2^{2 n k}}
$$

e se aumentar $n_{k}$ para $\left(n_{k}+1\right)$, então:

$$
d_{k} \longleftarrow \sigma_{k}^{2} f\left(n_{k}+1\right)=\frac{\sigma_{k}^{2}}{2^{2\left(n_{k}+1\right)}}=\frac{d_{k}}{4}
$$

Os retornos máximos são obtidos quando o próximo bit é atribuído para o coeficiente com distorção máxima e a redução global na distorção média é, então: $\left(\frac{3 \max \left(d_{k}\right)}{4 N}\right)$; algoritmo (1).

Generalizando para uma função razão de distorção qualquer, o próximo bit pode ser atribuído ao coeficiente que forneça o máximo:

$$
\Delta_{k} \triangleq \sigma_{k}^{2}\left[f\left(n_{k}\right)-f\left(n_{k}+1\right)\right]
$$

e com redução global na distorção média de:

$$
\frac{1}{N} \max \left(\Delta_{k}\right)
$$


(1) Algoritmo de Atribuição Inteira de Bit de Shannon

1. Inicializa:

$$
\begin{aligned}
n_{k}=0 ; \quad d_{k} & =\sigma_{k}^{2} ; \quad k=1, \ldots, N \\
\text { totalbit } & =0, \quad R=0.0 \\
D & =\frac{1}{N} \sum_{k=1}^{N} d_{k}
\end{aligned}
$$

2. Enquanto existirem bits para serem atribuídos $($ totalbit $<N p)$ Início

- Encontra o índice, $k^{*}$, para a distorção máxima:

$$
d_{k^{*}}=\max _{k}\left(d_{k}\right)
$$

- Atribui o próximo bit para o $k^{*}$-ésimo coeficiente:

$-n_{k^{*}} \longleftarrow\left(n_{k^{*}}+1\right)$

$-d_{k^{*}} \longleftarrow d_{k^{*}} / 4$

- totalbit $\longleftarrow($ totalbit +1$)$

$-R \longleftarrow R+1 / N$

$-D \longleftarrow D-\frac{3 d_{k^{*}}}{4 N}$

Fim

(2) Algoritmo de Atribuição Inteira de Bit Geral

1. Inicializa:

$$
\begin{aligned}
n_{k}=0 ; \quad d_{k} & =\sigma_{k}^{2} ; \quad k=1, \ldots, N \\
\text { totalbit } & =0, \quad R=0.0 \\
D & =\frac{1}{N} \sum_{k=1}^{N} d_{k}
\end{aligned}
$$

2. Enquanto existirem bits para serem atribuídos $($ totalbit $<N p)$ 
Início

- Encontra o índice, $k^{*}$, para o retorno máximo:

$$
\Delta_{k^{*}}=\max _{k}\left(\Delta_{k}\right)
$$

- Atribui o próximo bit para o $k^{*}$-ésimo coeficiente:

$-n_{k^{*}} \longleftarrow\left(n_{k^{*}}+1\right)$

$-d_{k^{*}} \longleftarrow d_{k^{*}}-\Delta_{k^{*}}$

- totalbit $\longleftarrow($ totalbit +1$)$

$-R \longleftarrow R+1 / N$

$-D \longleftarrow D-\frac{\Delta_{k^{*}}}{N}$

Fim

Uma característica importante destes dois algoritmos é que eles produzem a atribuição correta em números inteiros 


\section{Capítulo 4}

\section{Resultados Experimentais}

\subsection{Introdução}

Os resultados deste trabalho são apresentados neste capítulo, bem como aspectos de implementação do processo "adaptativo" de compressão, exemplo e trabalhos futuros.

O sistema foi desenvolvido em plataforma Sun SPARC station 2 sob ambiente SunOS 4.1 ("UNIX like") em linguagem C, [30], todos produtos da Sun MicroSystems. A visualização das imagens foi realizada com o utilitário XV 3.00 (de John Bradley), sobre ambiente gráfico OpenWindows 2.0 também da Sun MicroSystems.

Para avaliar a qualidade objetiva das imagens usou-se o MSE, página (16), bem como a razão sinal ruído - SNR, definida como:

$$
S N R \triangleq 10 \log _{10} \frac{255^{2}}{M S E} \quad d B
$$

onde assumiu-se uma imagem de 8 bits (substitui-se 255 por 127 para uma imagem de 7 bits, por exemplo). 


\subsection{O Processo de Compressão e Descompressão}

O diagrama de blocos da figura (4.1) contém o processo de codificação e decodificação por transformada, que é o mesmo da figura (2.1) apenas com maiores informações a respeito do processo de implementação.

No processo de codificação a imagem digital é dividida em blocos de $8 \times 8$ pixels e uma FDCT 2-D é aplicada sobre cada bloco conforme descrição feita na página 51. Para tanto utilizou-se a rotina da referência [28] para implementação da FFT.

A fim de se determinar a matriz alocação de bit para posterior quantização definiu-se um Limiar L igual a média da imagem de forma que, pelo valor da média de um bloco, este passa a ser classificado em dois grupos, acima e abaixo da média da imagem. Daqui gera-se matrizes médial e variâncial para os coeficientes usando os blocos transformados do grupo1 e média2 e variância2 para o segundo grupo.

Para isto fez-se necessário gerar um vetor mapa de classificação, onde uma posição será zero se o bloco for do grupo1 e será 1 se for do grupo2.

A fim de obter as matrizes atribuições de bits considerou-se como aproximações iniciais matrizes de bits estritamente suficientes para armazenamento das matrizes média1 e média2, em vez de iniciar com zero conforme algoritmo, ver página 63.

Como gerou-se duas matrizes alocações de bits a razão média de bits por pixel também pode ser diferente, uma razão $p_{1}$ associada à matriz alocação $1 \mathrm{e}$ uma razão $p_{2}$ para a outra matriz alocação de bit.

Neste trabalho deixou-se de avaliar a função densidade de probabilidade que melhor modela os coeficientes transformados. Portanto, não foi preocupação encontrar uma função razão de distorção $f($.$) ideal que represente as características$ do quantizador e da PDF. Para algumas aproximações ver [6].

Em razão do exposto acima optou-se pela função razão de distorção de Shannon dada pela expressão da equação (3.39), que é a curva de desempenho de um codificador ótimo de bloco para uma fonte gaussiana sem memória [6]. Portanto, implementou-se o algoritmo de atribuição Inteira de Bit de Shannon da página 63.

Logo após geradas as matrizes alocações de bits partiu-se para o próximo passo que foi quantizar os coeficientes a partir dessas matrizes.

A codificação de Huffman constitui-se no passo final no processo de transmissão e para tanto os coeficientes quantizados são preparados para serem representados com palavras de código de comprimentos variáveis. 

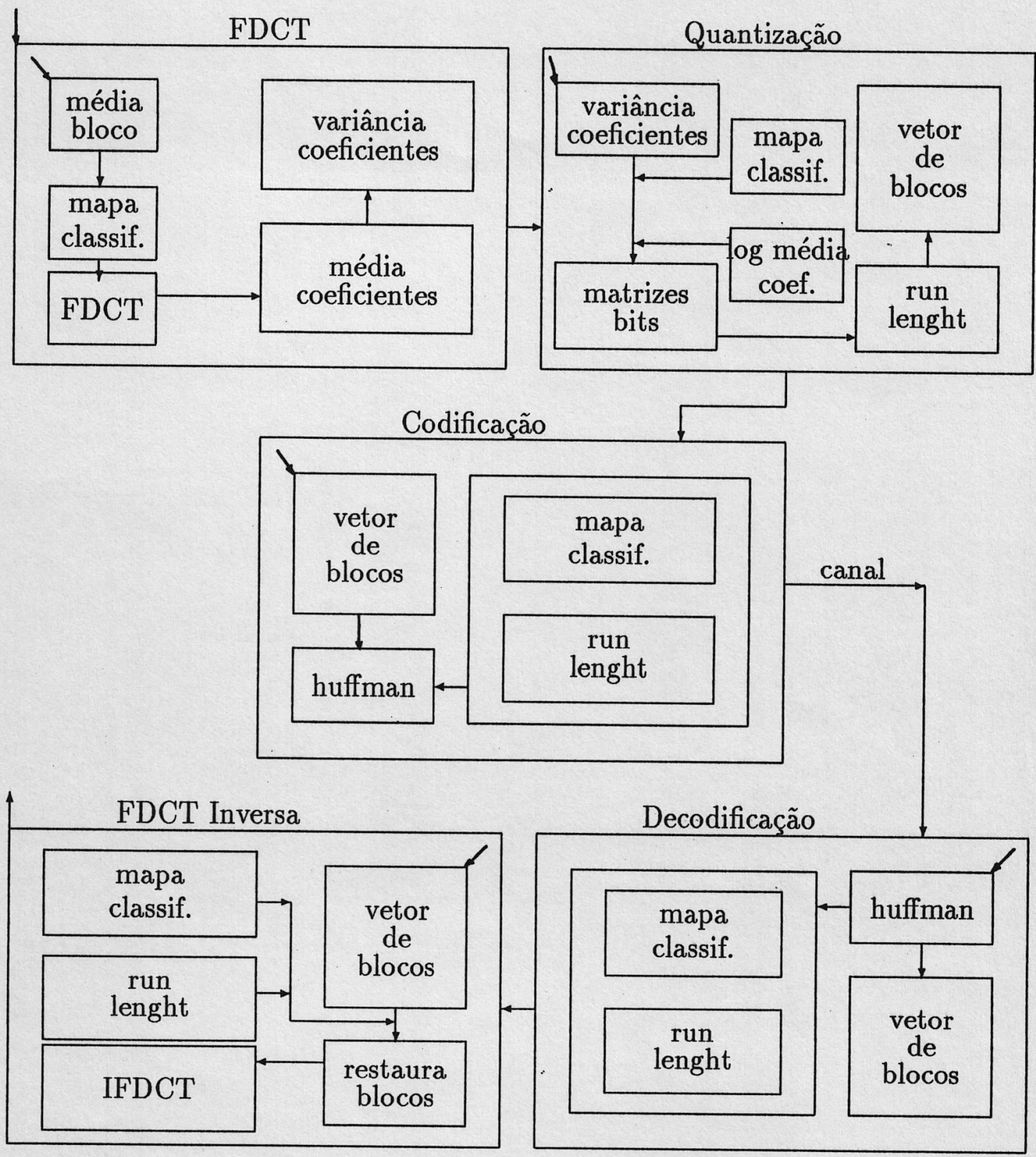

Figura 4.1: Processo "Adaptativo" de Codificação e Decodificação por Transformada Utilizado. 
Baseada nas matrizes de atribuição de bits cria-se os vetores "run-lenght1" e "run-lenght2" ordenados pela seqüência "zig-zag" como mostra a figura (4.2).

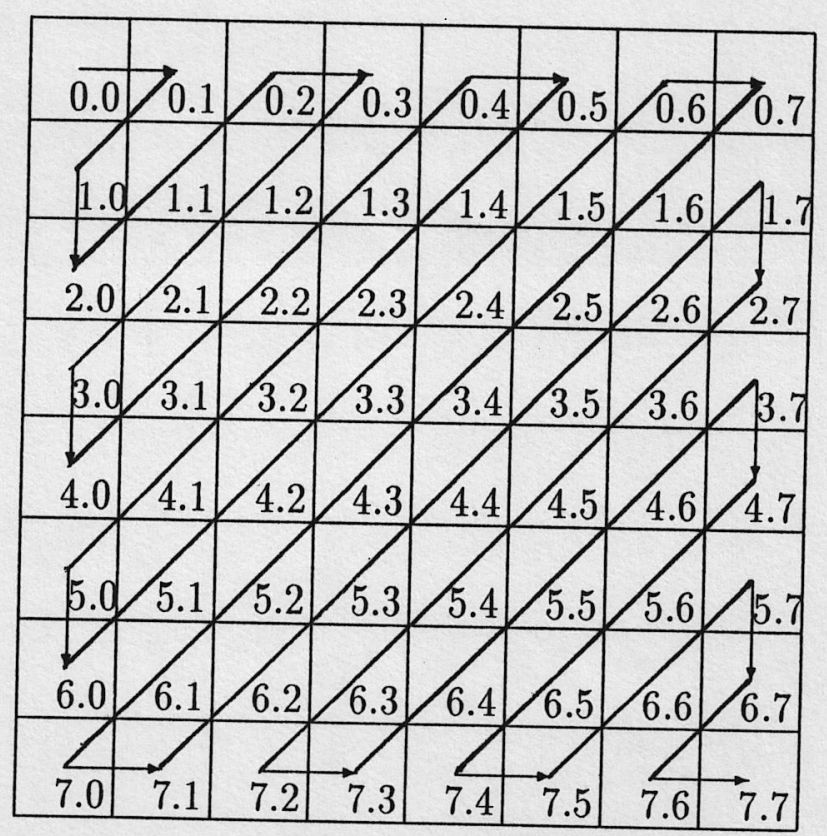

- Figura 4.2: Caminho da seqüência "zig-zag", colocando coeficientes com freqüências mais baixas antes dos coeficientes com freqüências mais altas. Para blocos de tamanho $8 \times 8$ esta seqüência foi implementada em linguagem
C pela seguinte estrutura:

struct zigzag \{

int linha;

int coluna;

\} ZigZag[ $\left[\mathrm{N}^{*} \mathrm{~N}\right]=$ 
$\{0,0\}$,

$\{0,1\},\{1,0\}$,

$\{2,0\}, \quad\{1,1\}, \quad\{0,2\}$,

$\{0,3\},\{1,2\},\{2,1\},\{3,0\}$,

$\{4,0\},\{3,1\},\{2,2\},\{1,3\},\{0,4\}$,

$\{0,5\},\{1,4\},\{2,3\},\{3,2\},\{4,1\},\{5,0\}$,

$\{6,0\},\{5,1\},\{4,2\},\{3,3\},\{2,4\},\{1,5\},\{0,6\}$,

$\{0,7\},\{1,6\},\{2,5\},\{3,4\},\{4,3\},\{5,2\},\{6,1\},\{7,0\}$,

$\{7,1\},\{6,2\},\{5,3\},\{4,4\},\{3,5\},\{2,6\},\{1,7\}$,

$\{2,7\},\{3,6\},\{4,5\},\{5,4\},\{6,3\},\{7,2\}$,

$\{7,3\},\{6,4\},\{5,5\},\{4,6\},\{3,7\}$,

$\{4,7\},\{5,6\},\{6,5\},\{7,4\}$,

$\{7,5\},\{6,6\},\{5,7\}$,

$\{6,7\},\{7,6\}$,

$\{7,7\}$

\}

Os vetores "run-lenght" são determinados de tal maneira que as posições ímpares nos vetores guardam o número de elementos não nulos nas matrizes atribuição de bits e as posições pares guardam o número de elementos nulos.

Após a criação dos vetores "run-lenght" parte-se para a geração de um vetor de blocos quantizados com somente as posições ímpares dos vetores "run-lenght" com auxílio do vetor mapa de classificação.

Assim, os coeficientes quantizados, que serão codificados, são acessados através da seqüência "zig-zag" para se determinar a posição linha e coluna do bloco. Portanto, são codificados o vetor de blocos bem como as informações paralelas: vetor mapa de classificação e vetores "run-lenght1" e "run-lenght2".

O algoritmo de codificação de Huffman, página 9, assume que o arquivo de dados consiste de valores de pixels onde alguns valores ocorrem mais freqüentemente do que outros. Constroí-se um vetor que identifica a freqüência de cada valor. Então, controí-se a estrutura de árvore de Huffman do vetor de freqüência. O propósito da árvore é associar cada valor com uma string de bit ou palavra de código. Aos valores mais freqüentes são associadas palavras menores e aos menos freqüentes são associadas string de bit maiores e, assim os dados no arquivo podem ser comprimidos, $[2]$.

$\mathrm{Na}$ recepção faz-se a decodificação de Huffman do vetor de blocos. Os blocos são restaurados a partir dos vetores "run-lenght1" , "run-lenght2" e mapa de classificação, em seguida, aplica-se a FDCT Inversa, dada pelo algoritmo da página 52 , ao bloco truncado a fim de se obter os blocos no domínio espacial e 
conseqüentemente a imagem reconstruída.

\subsection{Imagens Originais}

É muito importante verificar o desempenho de qualquer técnica de compressão, processando algumas imagens com características distintas. Além disso, do ponto de vista computacional, não se espera que um algoritmo seja tão sensível a ponto de, a cada tipo de imagem. necessitar de um estágio de codificação particular. Isto somente torna-se desejável quando se trabalha com um tipo específico de imagem.

Em princípio desejava-se estudar técnicas de compressão específicas para imagens médicas, mas como não foram analisadas características particulares deste tipo de imagem e nem mesmo estas foram introduzidas nos algoritmos, resolveu-se fazer alguns testes usando duas imagens médicas obtidas por ressonância magnética pelo tomógrafo do IFSC, e duas imagens de satélite obtidas pelo LANDSAT.

As imagens utilizadas na simulação computacional estão em formato PGM (Portable Graymap), onde as imagens médicas contêm $256 \times 256$ pixels com cada pixel representado por 256 níveis de cinza, com a imagem médica jor256s representada com 7 bit/pixel. Já as imagens de satélite contêm $512 \times 512$ pixels com cada pixel representado por 7 bits e 8 bits. As imagens originais são mostradas na figura (4.3) e suas estatísticas são dadas na tabela (4.1).

Tabela 4.1: Imagens Originais com suas Estatísticas.

\begin{tabular}{|l|c|c|c|c|c|c|c|}
\hline \hline imagem & tipo & tamanho & $\begin{array}{c}\text { média } \\
\mu\end{array}$ & $\begin{array}{c}\text { variância } \\
\sigma^{2}\end{array}$ & $\begin{array}{c}\text { pixel } \\
\text { min }\end{array}$ & $\begin{array}{c}\text { pixel } \\
\text { max }\end{array}$ & entropia \\
\hline \hline jor256s & médica & $256 \times 256$ & 40.871 & 54.483 & 0 & 127 & 6.596 \\
agmat3 & médica & $256 \times 256$ & 22.812 & 88.857 & 0 & 255 & 3.031 \\
cps5 & satélite & $512 \times 512$ & 78.756 & 38.507 & 0 & 255 & 6.397 \\
brasília & satélite & $512 \times 512$ & 60.028 & 43.821 & 0 & 127 & 5.216 \\
\hline \hline
\end{tabular}




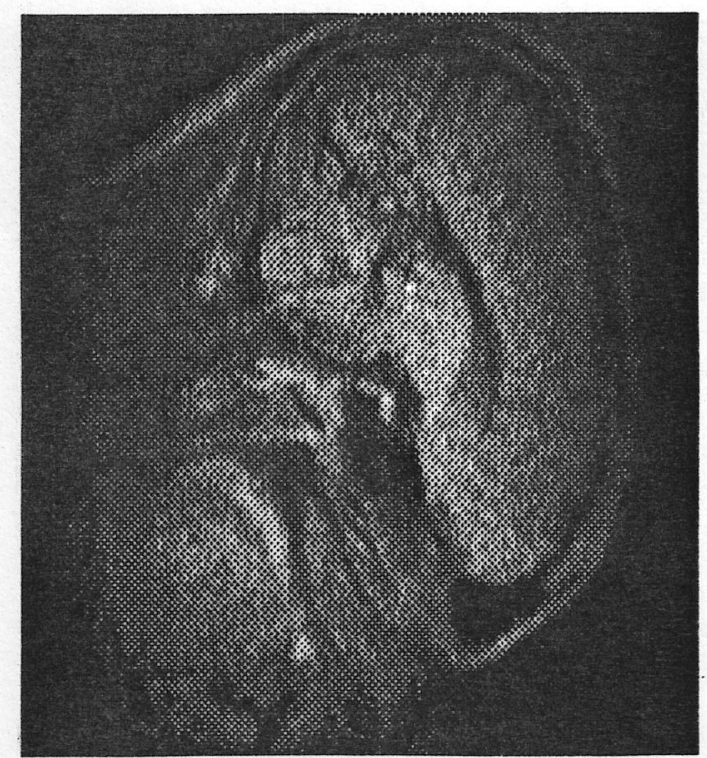

(a)

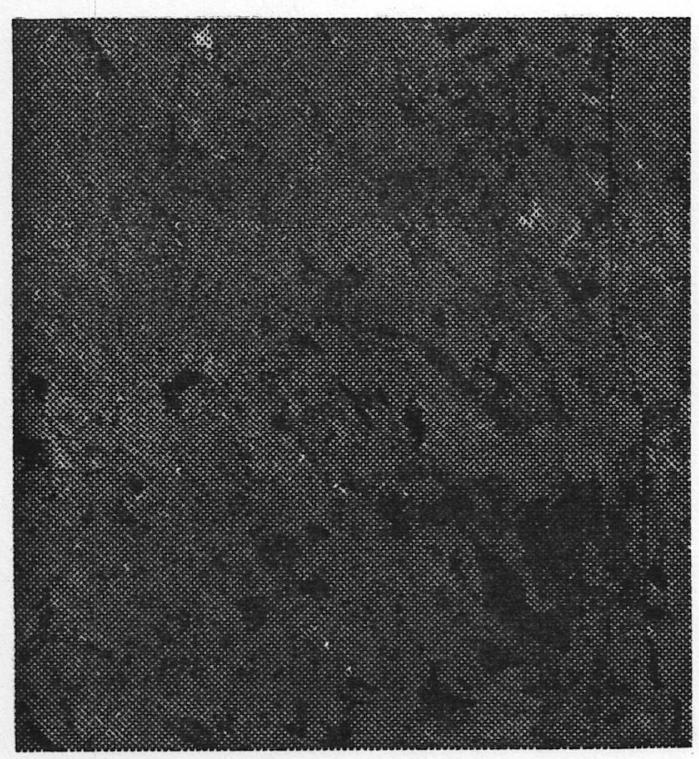

(c)

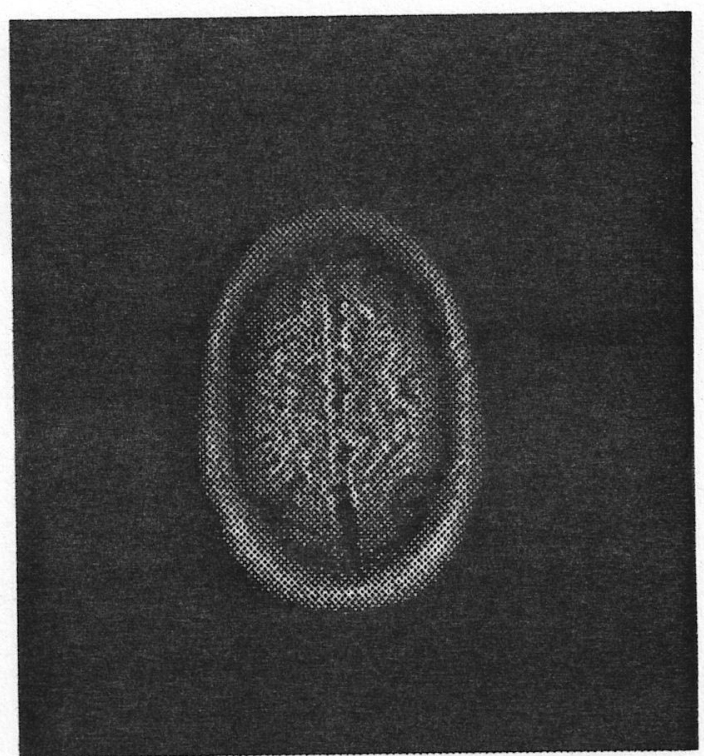

(b)

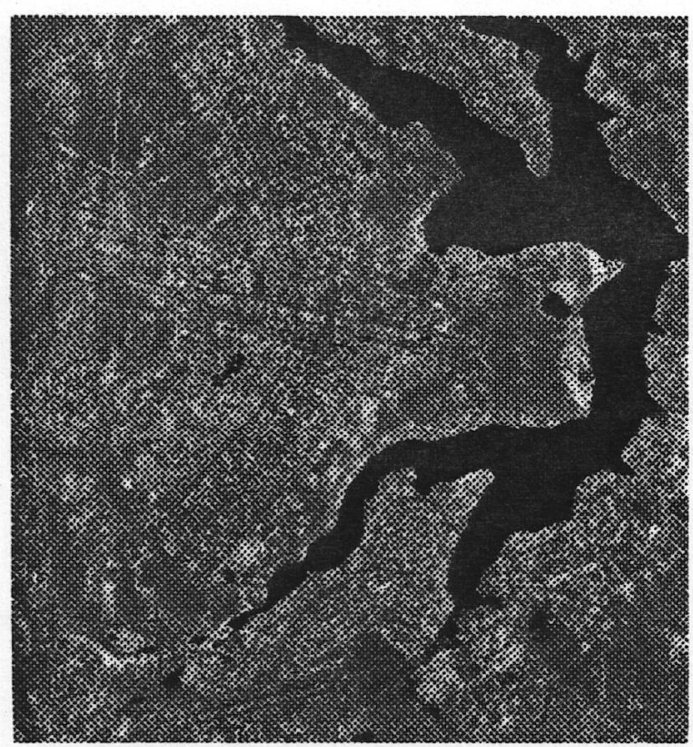

(d)

Figura 4.3: Imagens Originais Utilizadas. (a) Imagem jor256s; (b) Imagem agmat3; (c) Imagem cps5 e (d) Imagem brasilia 


\subsection{Exemplo}

Descreve-se aqui todo o processo usado através de um pequeno exemplo. Considere um bloco $8 \times 8$ da imagem cps 5 de 8 bits/pixel e este subdividido em blocos de $4 \times 4$.

$\begin{array}{llllllll}50 & 45 & 50 & 54 & 51 & 70 & 80 & 71 \\ 51 & 49 & 54 & 57 & 52 & 70 & 87 & 68 \\ 43 & 51 & 61 & 56 & 53 & 62 & 83 & 73 \\ 48 & 58 & 64 & 66 & 63 & 66 & 81 & 74 \\ 49 & 52 & 52 & 59 & 68 & 69 & 76 & 88 \\ 57 & 55 & 49 & 55 & 68 & 64 & 68 & 63 \\ 64 & 59 & 64 & 66 & 64 & 64 & 61 & 64 \\ 81 & 64 & 57 & 58 & 62 & 68 & 64 & 64\end{array}$

Bloco 1: $\quad$ média $=53.56$ variância $=11.31$

$\begin{array}{llll}50 & 45 & 50 & 54 \\ 51 & 49 & 54 & 57 \\ 43 & 51 & 61 & 56 \\ 48 & 58 & 64 & 66\end{array}$

Bloco 2: $\quad$ média $=69.00$ variância $=19.07$

$\begin{array}{llll}51 & 70 & 80 & 71 \\ 52 & 70 & 87 & 68 \\ 53 & 62 & 83 & 73 \\ 63 & 66 & 81 & 74\end{array}$

Bloco 3: $\quad$ média $=58.81$ variância $=13.84$

$\begin{array}{llll}49 & 52 & 52 & 59 \\ 57 & 55 & 49 & 55 \\ 64 & 59 & 64 & 66 \\ 81 & 64 & 57 & 58\end{array}$

Bloco 4: $\quad$ média $=67.18$ variância $=11.56$

$\begin{array}{llll}68 & 69 & 76 & 88 \\ 68 & 64 & 68 & 63 \\ 64 & 64 & 61 & 64 \\ 62 & 68 & 64 & 64\end{array}$


Assim para um limiar $L=65$, tem-se o seguinte vetor mapa de classificação:

$$
\text { mapa }=\left[\begin{array}{llll}
0 & 1 & 0 & 1
\end{array}\right]
$$

Aplicando a FDCT sobre os blocos de coeficientes obtém-se:

$$
\begin{array}{rrrrrrrr}
107.1 & -11.9 & -1.2 & 2.0 & 138.0 & -21.5 & -16.6 & 8.1 \\
-4.2 & 3.8 & 3.9 & 0.8 & -1.1 & -0.9 & -4.1 & -2.0 \\
1.1 & -0.2 & 1.1 & -0.8 & 0.7 & 1.6 & 2.2 & -1.7 \\
-1.7 & -0.6 & -1.7 & 0.8 & -1.2 & -1.8 & 1.7 & -0.2
\end{array}
$$

$$
\begin{array}{rrrrrrrr}
117.6 & 3.7 & 6.5 & -0.6 & 134.3 & -4.3 & 1.2 & -0.7 \\
-7.3 & -6.9 & -2.2 & -2.2 & 5.4 & -4.6 & 2.5 & 1.5 \\
0.2 & 2.5 & 0.8 & -0.1 & 3.8 & -4.5 & 0.3 & -1.5 \\
1.9 & -4.9 & -1.1 & 1.4 & 0.9 & -2.4 & 1.8 & -1.6
\end{array}
$$

As matrizes $\log _{2}(\mid$ média1 $\mid+1)$ e $\log _{2}(\mid$ média2 $\mid+1)$, que serão aproximações iniciais que fornecem as respectivas matrizes atribuições de bits:

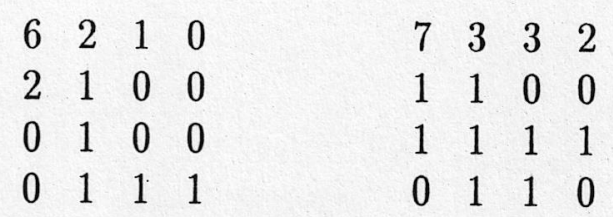

Aplicando o algoritmo de atribuição de bits para uma razão $p_{1}=p_{2}=2$ obtém-se, respectivamente:

$\begin{array}{llllllll}8 & 4 & 3 & 1 & 7 & 5 & 5 & 3 \\ 3 & 3 & 2 & 1 & 2 & 2 & 1 & 0 \\ 0 & 2 & 0 & 0 & 1 & 2 & 1 & 1 \\ 1 & 2 & 1 & 1 & 0 & 1 & 1 & 0\end{array}$

Assim, os coeficientes transformados são quantizados a partir destas matrizes atribuições de bits, fornecendo os seguintes valores: 


$$
\begin{array}{rrrlrrrr}
107 & -12 & -1 & 2 & 128 & -22 & -17 & 8 \\
-4 & 4 & 4 & 1 & -1 & -1 & -2 & 0 \\
0 & 0 & 0 & 0 & 1 & 2 & 2 & -2 \\
-2 & -1 & -2 & 1 & 0 & -2 & 2 & 0 \\
& & & & & & & \\
118 & 4 & 7 & -1 & 128 & -4 & 1 & -1 \\
-7 & -7 & -2 & -2 & 4 & -4 & 2 & 0 \\
0 & 3 & 0 & 0 & 2 & -4 & 0 & -1 \\
2 & -4 & -1 & 1 & 0 & -2 & 2 & 0
\end{array}
$$

$\begin{array}{rrrr}128 & -4 & 1 & -1 \\ 4 & -4 & 2 & 0 \\ 2 & -4 & 0 & -1 \\ 0 & -2 & 2 & 0\end{array}$

A partir das matrizes atribuições de bits e da seqüência "zigzag", para bloco $4 \times 4$, gera-se os vetores "run-lenght1" e "run-lenght2", dados por:

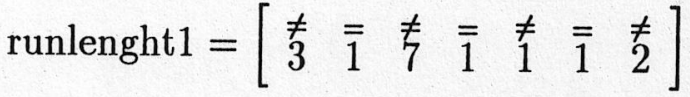

$$
\begin{aligned}
& \text { runlenght } 2=\left[\begin{array}{cccccc}
\neq & \overline{\overline{1}} & \neq & \overline{\overline{1}} & \neq & \overline{\overline{1}} \\
9 & \overline{1} & 2 & 1 & 2 & 1
\end{array}\right]
\end{aligned}
$$

Portanto, será aplicado o código de Huffman ao seguinte vetor:

$$
\left[\begin{array}{rrrrrrrrrrrrr}
107 & -12 & -4 & 4 & -1 & 2 & 4 & 0 & -2 & -1 & 1 & -2 & 1 \\
128 & -22 & -1 & 1 & -1 & -17 & 8 & -2 & 2 & -2 & 2 & -2 & 2 \\
118 & 4 & -7 & -7 & 7 & -1 & -2 & 3 & 2 & -4 & -2 & -1 & 1 \\
128 & -4 & 4 & 2 & -4 & 1 & -1 & 2 & -4 & -2 & 0 & -1 & 2
\end{array}\right]
$$

$\mathrm{Na}$ recepção, o vetor descomprimido pelo código de Huffman é recuperado através do mapa de classificação e dos vetores "runlenghts". Aplica-se a IFDCT chegando aos seguintes valores de pixels:

$$
\begin{array}{llllllll}
49 & 44 & 50 & 52 & 48 & 62 & 76 & 67 \\
52 & 50 & 53 & 58 & 46 & 62 & 80 & 62 \\
43 & 51 & 60 & 57 & 47 & 58 & 79 & 69 \\
46 & 57 & 63 & 64 & 55 & 64 & 75 & 67 \\
49 & 52 & 52 & 58 & 62 & 64 & 69 & 80 \\
57 & 54 & 49 & 57 & 64 & 64 & 64 & 62 \\
65 & 59 & 62 & 66 & 62 & 59 & 59 & 61 \\
80 & 64 & 56 & 57 & 59 & 64 & 62 & 61
\end{array}
$$


Com uma diferença entre os valores originais de:

$\begin{array}{llllllll}0 & 1 & 0 & 2 & 3 & 8 & 4 & 4 \\ 1 & 1 & 1 & 1 & 6 & 8 & 7 & 6 \\ 0 & 0 & 1 & 1 & 6 & 4 & 4 & 4 \\ 2 & 1 & 1 & 2 & 8 & 2 & 6 & 7 \\ 0 & 0 & 0 & 1 & 4 & 5 & 7 & 8 \\ 0 & 1 & 0 & 2 & 4 & 0 & 4 & 1 \\ 1 & 0 & 2 & 0 & 2 & 5 & 2 & 3 \\ 1 & 0 & 1 & 1 & 3 & 4 & 2 & 3\end{array}$

Pode-se notar que o erro é bem maior para os pixels pertencentes ao grupo2, ou seja, para os valores de pixels que são associados o-número 1 no vetor mapa de classificação.

\subsection{Discussão de Resultados}

Com a finalidade de avaliar o desempenho do módulo de compressão por transformada foram realizadas uma série de simulações computacionais. Cada ima- gem foi analisada com as seguintes razões médias, em bits/pixel:

1. $p_{1}=2.0$ e $p_{2}=2.5$;

2. $p_{1}=1.5$ e $p_{2}=2.0$;

3. $p_{1}=1.0$ e $p_{2}=0.5$.

As imagens reconstruídas avaliadas para as razões acima, bem como as imagens diferenças, estão nas figuras (4.4) a (4.7). Os resultados do MSE e SNR são dadas na tabela (4.2), assim como as razões de compressão, em bits/pixel, estão sumarizadas na tabela (4.3).

Analisando a qualidade subjetiva das imagens reconstruídas e das imagens diferenças nota-se que o efeito de blocos é a causa principal para a degradação, principalmente nas bordas com grandes contrastes.

Este efeito pode ser comprovado objetivamente pelo MSE e $S N R$, conforme tabela (4.2). Por exemplo, a imagem brasilia que apresenta regiões com grandes contrastes tem o resultado mais sofrível, $26.24 \mathrm{~dB}$, para $p_{1}=2.0$ e $p_{2}=2.5$, enquanto que para as imagens jor256s e cps5, que são mais suaves ocorre uma melhoria de até $4.19 \mathrm{~dB}$. 
Tabela 4.2: Resultados do MSE e SNR para as imaǵens em estudo.

\begin{tabular}{|c|c|c|c|c|c|c|}
\hline \multirow{3}{*}{ Imagem } & \multicolumn{3}{|c|}{ MSE } & \multicolumn{3}{|c|}{ SNR $(\mathrm{dB})$} \\
\hline & \multicolumn{3}{|c|}{ Razão Média $\left(p_{1}\right.$ e $\left.p_{2}\right)$} & \multicolumn{3}{|c|}{ Razão Média $\left(p_{1}\right.$ e $\left.p_{2}\right)$} \\
\hline & 2.5 & $\begin{array}{ll}1.5 & 2.0\end{array}$ & $1.0 \quad 0.5$ & 2.5 & 1.52 .0 & $1.0 \quad 0.5$ \\
\hline jor256s & 14.6 & 21.8 & 37.7 & 30.43 & 28.69 & 26.31 \\
\hline agmat3 & 77.5 & 116.0 & 164.3 & 29.23 & 27.48 & 25.97 \\
\hline $\operatorname{cps} 5$ & 59.4 & 84.8 & 148.7 & 30.39 & 28.84 & 26.40 \\
\hline brasília & 38.3 & 50.9 & 159.5 & 26.24 & 25.00 & 20.04 \\
\hline
\end{tabular}

Tabela 4.3: Resultados da razão de compressão, em bits/pixel, para as imagens em estudo.

\begin{tabular}{|c|c|c|c|c|c|c|c|}
\hline \multirow{3}{*}{ Imagem } & \multicolumn{7}{|c|}{ Razão de Compressão (bits/pixel) } \\
\hline & \multicolumn{6}{|c|}{ Razão Média $\left(p_{1}\right.$ e $\left.p_{2}\right)$} & \multirow{2}{*}{$\begin{array}{l}\text { média das } \\
\text { razões }\end{array}$} \\
\hline & 2.0 & 2.5 & 1.5 & 2.0 & 1.0 & 0.5 & \\
\hline jor256s & \multicolumn{2}{|c|}{4.31} & \multicolumn{2}{|c|}{.24} & & 3.87 \\
\hline agmat3 & \multicolumn{2}{|c|}{5.10} & & & \multicolumn{2}{|c|}{3.90} & 4.67 \\
\hline $\operatorname{cps} 5$ & \multicolumn{2}{|c|}{5.46} & & & \multicolumn{2}{|c|}{3.04} & 4.60 \\
\hline brasília & \multicolumn{2}{|c|}{5.79} & & & \multicolumn{2}{|c|}{2.88} & 4.77 \\
\hline
\end{tabular}

De acordo com o exposto acima, necessita-se de mais bits/pixel para comprimir a imagem brasília, uma média de $4.77 \mathrm{bits} /$ pixel, ao passo que para a jor256s necessita-se de $3.87 \mathrm{bits} / \mathrm{pixel}$, como mostra a tabela (4.3). 

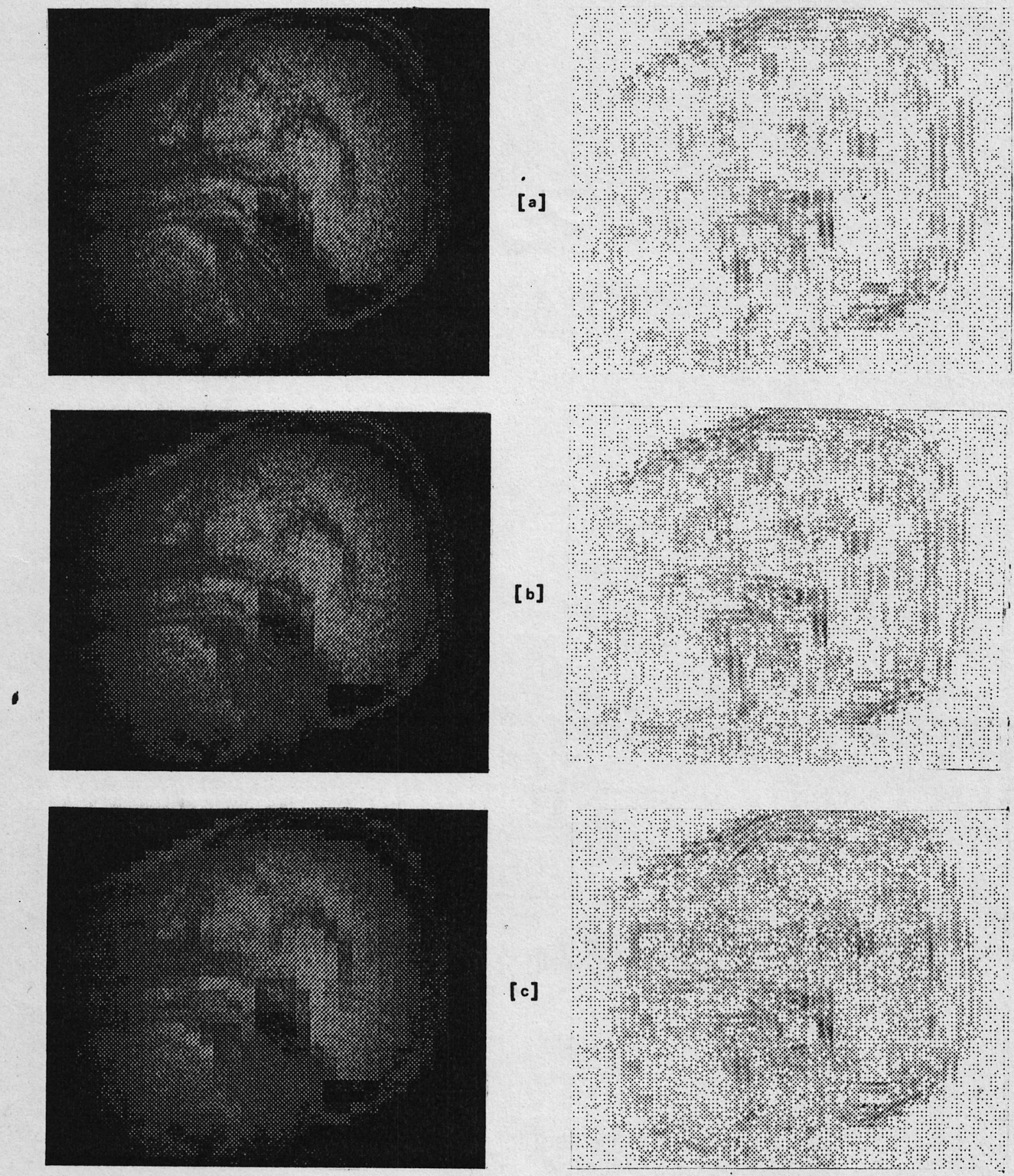

Figura 4.4: Resultados da compressão da imagem jor256s para as seguintes razões médias: (a) $p_{1}=2.0$ e $p_{2}=2.5 ;$ (b) $p_{1}=1.5$ e $p_{2}=2.0$;

(c) $p_{1}=1.0$ e $p_{2}=0.5$. 


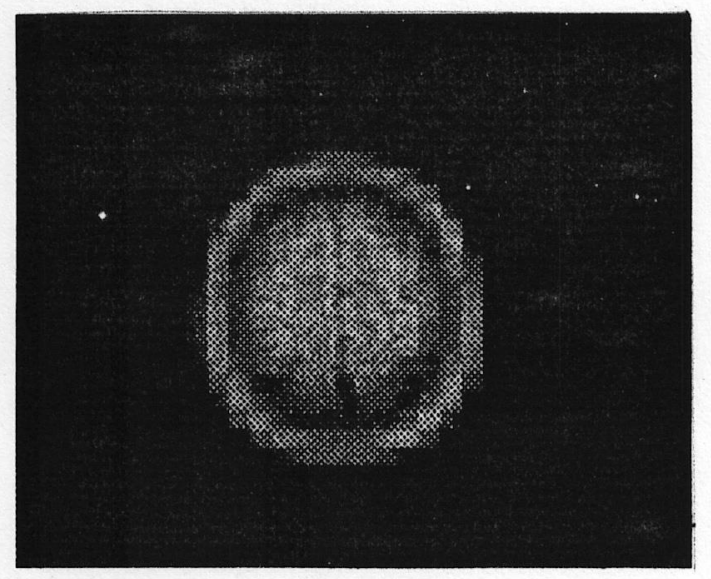

[a]
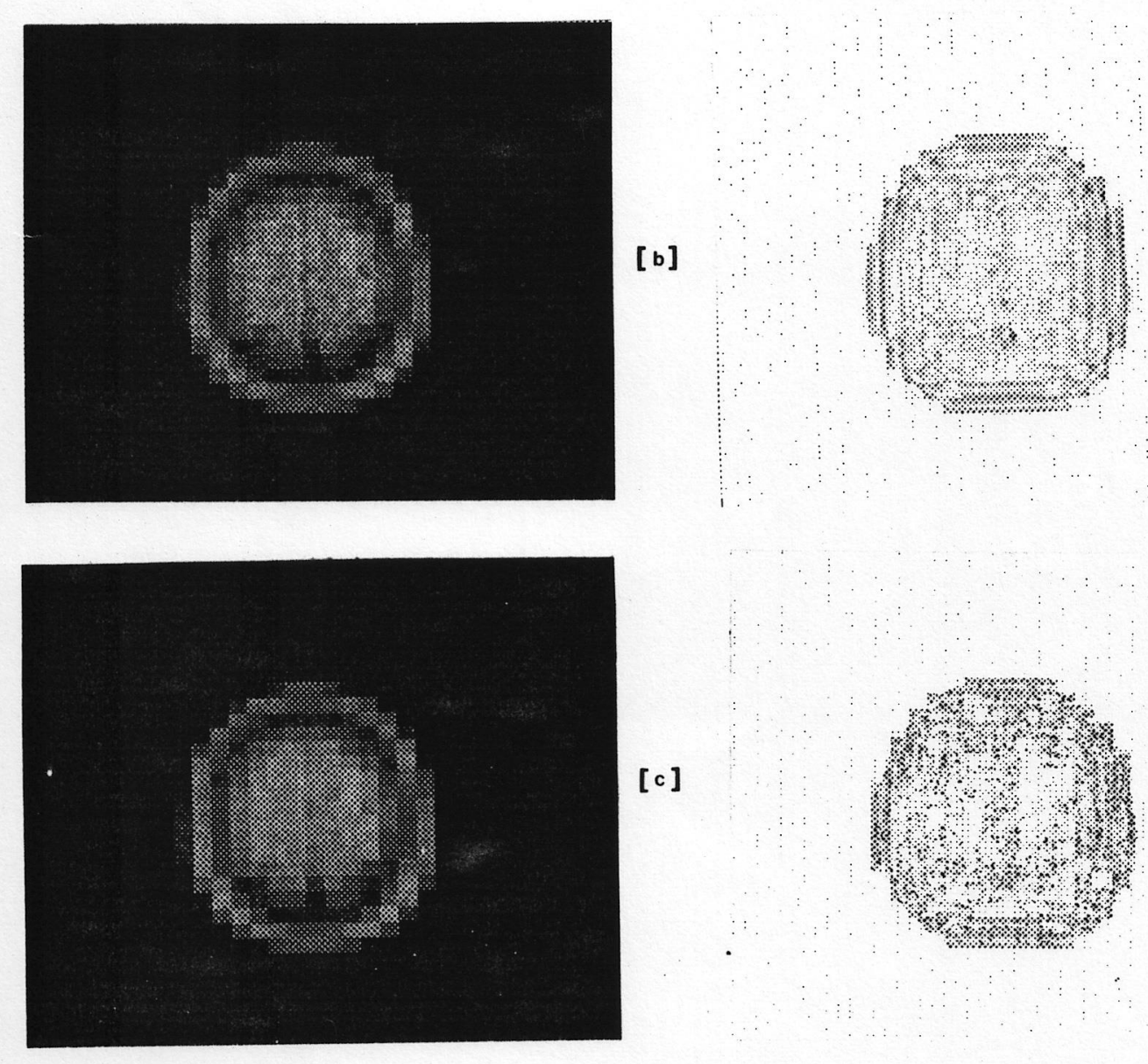

Figura 4.5: Resultados da compressão da imagem agmat3 para as seguintes razões médias: (a) $p_{1}=2.0$ e $p_{2}=2.5 ; \quad$ (b) $p_{1}=1.5$ e $p_{2}=2.0 ; \quad$ (c) $p_{1}=1.0$ e $p_{2}=0.5$. 

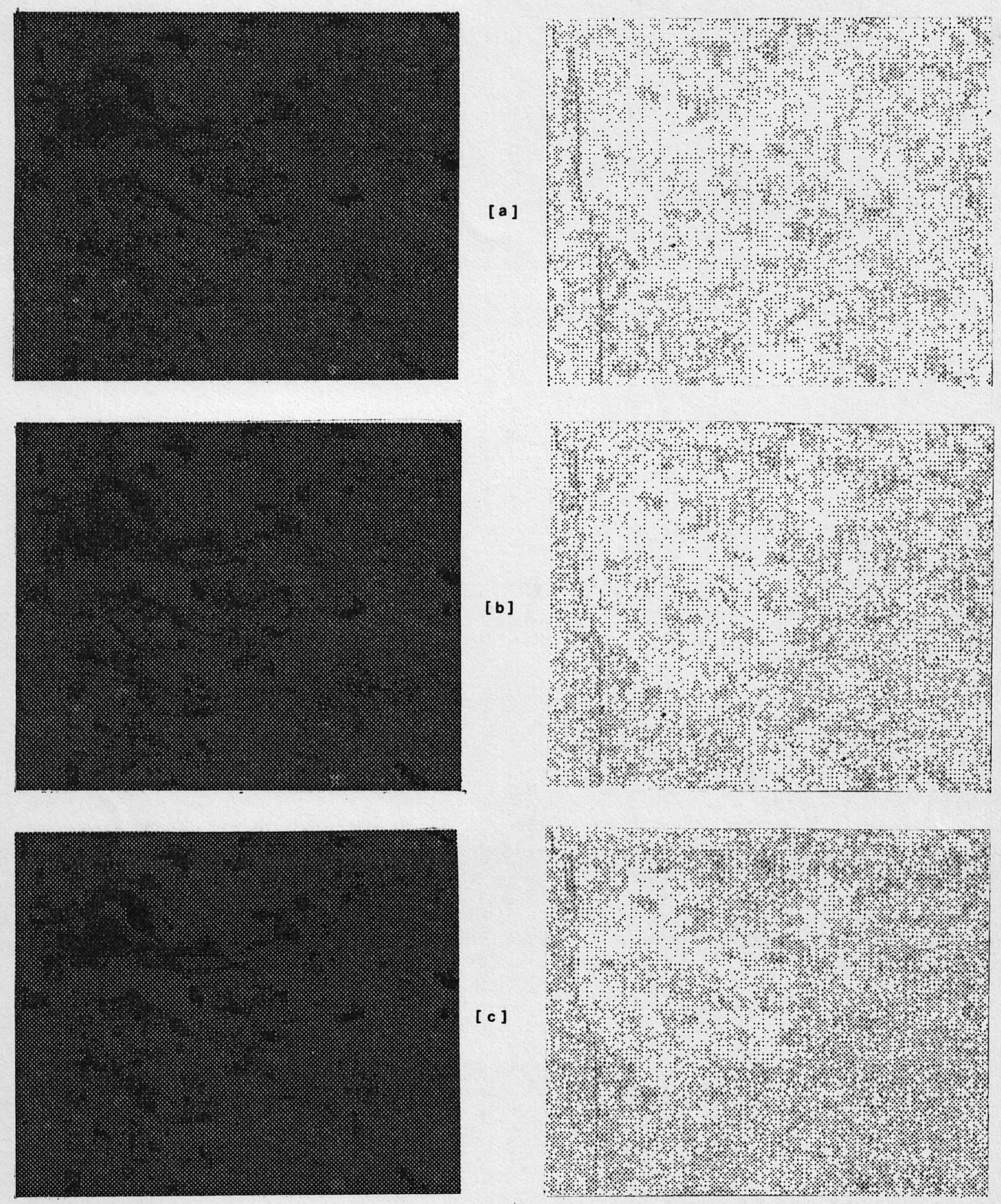

Figura 4.6: Resultados da compressão da imagem cps5 para as seguintes razões médias: (a) $p_{1}=2.0$ e $p_{2}=2.5$;

(b) $p_{1}=1.5$ e $p_{2}=2.0$;

(c) $p_{1}=1.0$ e $p_{2}=0.5$. 

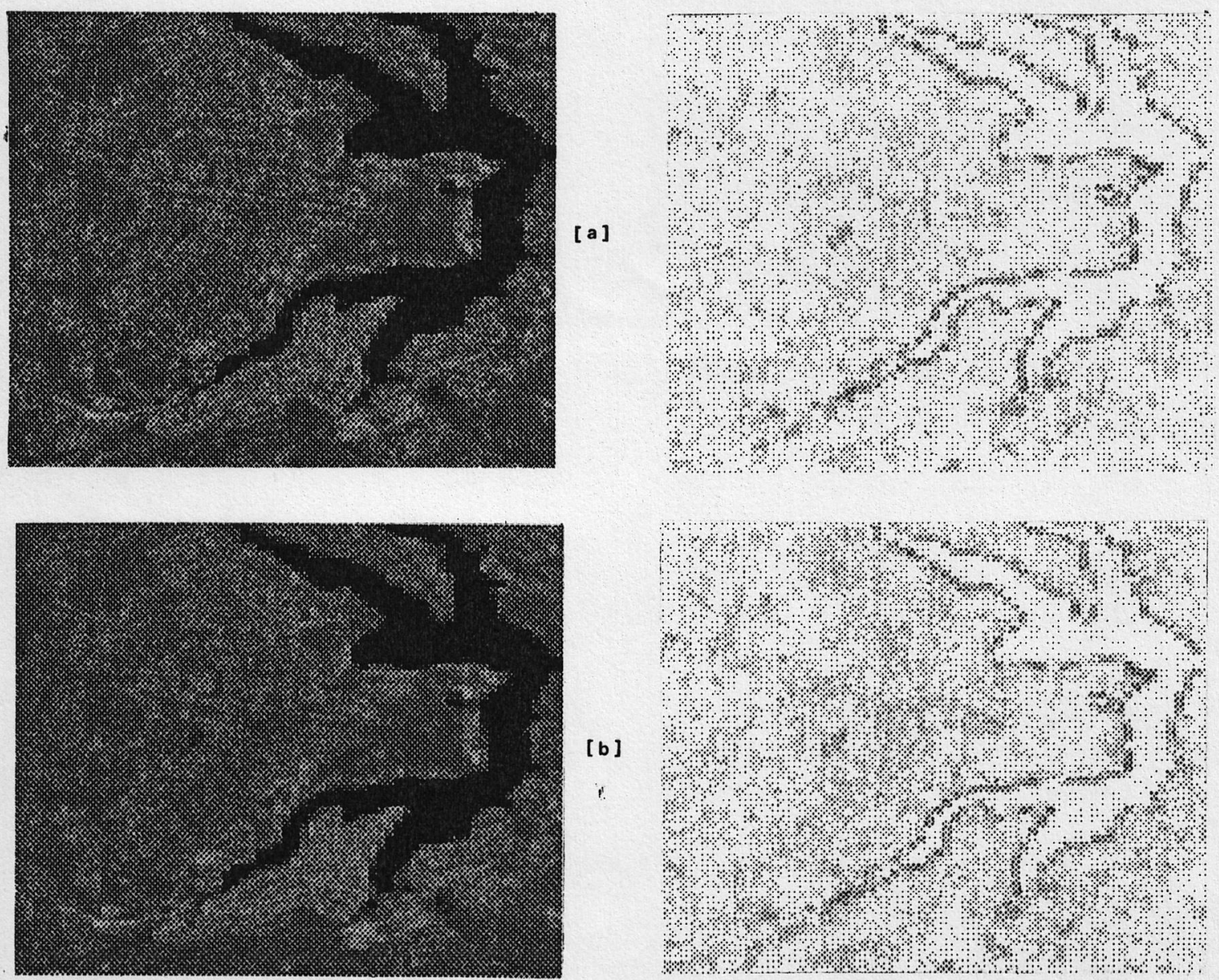

[b]
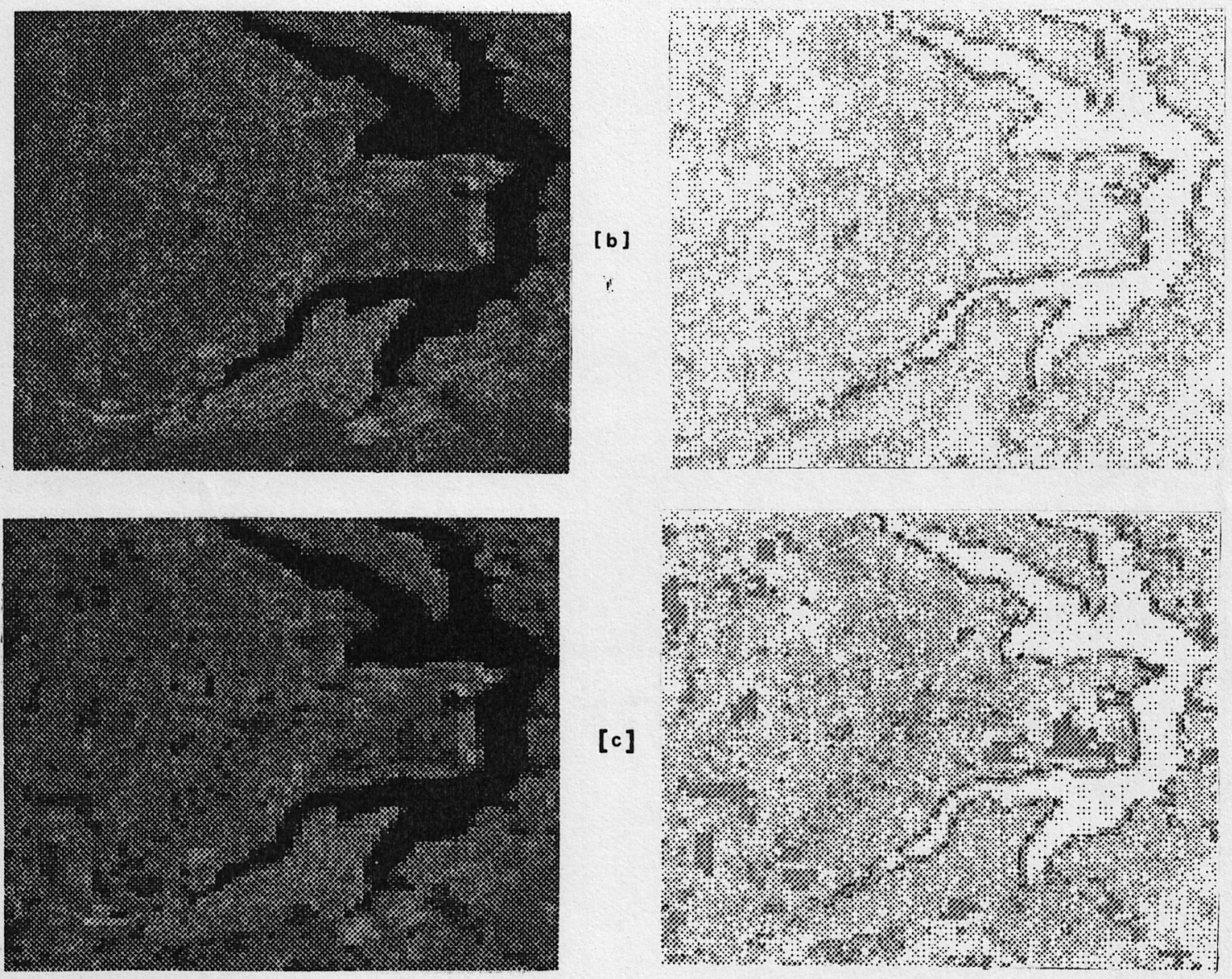

Figura 4.7: Resultados da compressão da imagem brasília para as seguintes razões médias: (a) $p_{1}=2.0$ e $p_{2}=2.5$;

(b) $p_{1}=1.5$ e $p_{2}=2.0$

(c) $p_{1}=1.0$ e $p_{2}=0.5$. 


\subsection{Conclusões e Trabalhos Futuros}

Este trabalho apresentou uma técnica de codificação por transformada no qual a FDCT foi a transformada escolhida, a quantização foi realizada com atribuição de bit gerada a partir das variâncias das imagens e o código de Huffman utilizado para associar uma palavra de comprimento variável aos coeficientes quantizados.

Os aspectos mais relevantes nesta técnica foram a utilização de uma rotina FFT para a obtenção da FDCT e principalmente a geração de atribuições de bits dependentes da atividade da imagem. Assim, para uma dada razão média de bits/pixel, determinou-se uma atribuição de bit específica.

Com esta maneira de efetuar a quantização acredita-se que os resultados obtidos foram satisfatórios, embora tenham permanecidos os efeitos de blocos neste processo "adaptativo" de codificação. Isto era de se esperar uma vez que nenhuma mudança fundamental foi realizada no módulo estudade que estivesse voltado para este problema.

Existem muitos aspectos neste módulo de compressão que necessitam de pesquisas adicionais a fim de melhorar seu desempenho. Dentre estes aspectos podese citar:

- Analisar uma função densidade de probabilidade que modele melhor o tipo de imagem em estudo, aumentando o desempenho das atribuição de bits.

- Estudar alguma outra técnica que possa ser utilizada antes da aplicação da transformada, como um pré processamento.

- Estudar outros códigos, além do código de Huffman, uma vez que este necessita se conhecer a freqüência de cada coeficiente, ocorrendo duas leituras ao arquivo. Fazer uma comparação com código aritmético ou outro código adaptativo. 


\section{Bibliografia}

[1] AHAMED, N.; NATARAJAN, T.; RAO, K.R. Discrete Cosine Transform. IEEE Trans. on Computers, p. 90-3, january 1974.

[2] C PROGRAMMING - CUA and DATA COMPRESSION. Dr. Dobb's Journal, p. 135-42, 162-3, february 1991.

[3] CHEN, W.H.; SMITH, C.H.; FRALICK, S.C. A Fast Computational Algorithm for the Discrete Cosine Transform. IEEE Trans. on Commun., v. COM-25, n. 9, p. 1004-9, september 1977.

[4] CHO, N.I.; LEE, S.U. Fast Algorithm and Implementation of 2-D Discrete Cosine Transform. IEEE Trans. on Circuits and Systems, v. 38, n.3, march 1991.

[5] CLARKE, R.J. Transform Coding of Images. Academic Press, 1990. (Microelectronics and Signal Processing Series).

[6] FARRELLE, P.M. Recursive Block Coding for Image Data Compression. New York, Springer-Verlag, 1990.

[7] FOX, B. Discrete Optimization Via Marginal Analysis. Management Sci.. v. 13, p. 201-16, november 1966.

[8] GEUS, P.L. Approaches to Live Image Transmission Between Workstations Over Limited-Bandwidth Networks. Ph.D. Thesis - Univ. of Manchester, may 1990.

[9] GIMLETT, T.I. Use of Activity Classes in Adaptive Transform Image. IEEE Trans. on Commun., v. COM-23, n. 7, p. 785-6, july 1975.

[10] GONZALEZ, R.C.; WINTZ, P. Digital Image Processing. Addison-Wesley , 2 ed., 1987. 
[11] HEALY, D.J.; MITCHELL, D.R. Digital Video Bandwidth Compression Using Block Truncation Coding. IEEE Trans. on Commun., v. COM29, p. 1809-23, december 1981.

[12] HUANG, T.S. Coding of Two-Tone Images. IEEE Trans. on Commun., v. COM-25, n. 11, november 1977.

[13] HUFFMAN, D.A. A Method for the Construction of Minimum-Redundancy Codes. Proc. of the IRE, v. 40, n. 9, p. 1098-101, september 1952.

[14] JAIN, A.K. Advances in Mathematical Models for Image Processing. Proc. on the IEEE, v. 69 , p. 502-28, may 1981.

[15] JAIN, A.K. Image Data Compression: A Review. Proc. on the IEEE, v. 69, n. 3, p. 349-89, march 1981.

[16] KRETZ, F. Subjectively Optimal Quantization of Pictures. IEEE Trans. on Commun., v. COM-23, p. 1288-92, november 1975.

[17] KRUGER, A. Block Truncation Compression. Dr. Dobb's Journal. p. 48,50,53-55,104,106; april 1992.

[18] LANGDON JR., G.G. An Introduction to Arithmetic Coding. IBM Journal Res. Develop., v. 28, n. 2, p. 135-49, march 1984.

[19] LINDE, Y.; BUZO, A.; GRAY, R.M. An Algorithm for Vector Quantizer Design. IEEE Trans. on Commun., v. COM-28, n. 1, p. 84-95, january 1980.

[20] MAKHOUL, J. A Fast Cosine Transform in One and Two Dimensions. IEEE Trans. on Acoustics, Speech and Signal Processing, v. ASSP-28, n. 1, p. 27-34, february 1980 .

[21] MASCARENHAS, N.D.A.; VELASCO, F.R.D. Processamento Digital de Imagens. In: EBAI-Escola Brasileiro-Argentina de Informática, 4, Universidad Católica de Santiago Del Estero, Termas de Rio Hondo, Argentina, 2 ed., january 1989.

[22] NARASIMHA, M.; PETERSON, A.M. On the Computation of the Discrete Cosine Transform. IEEE Trans. on Commun., v. COM-26, n. 6, p. 934-6, june 1978.

[23] NASRABADI, N.M.; KING, R.A. Image Coding Using Vector Quantization: A Review. IEEE Trans. on Commun., v. 36, n. 8, p. 957-71, august 1988. 
[24] NETRAVALI, A.N.; HASKELL, B.G. Digital Picture - Representation and Compression. New York, Plenum Press, 1988.

[25] NETRAVALI, A.N.; PRASADA, B. Adaptive Quantization of Picture Signals using Spatial Masking. Proc. of the IEEE, v. 65, p. 536-48, april 1977.

[26] PIRSCH, P. Block Coding of Color Video Signals. In: Proceedings of National Telecommunications Conference, 1977, p. 10.5.1-10.5.5.

[27] PRATT, W.K. Digital Image Processing. New York, John Wiley, 1978.

[28] PRESS, W.H.; FLANNERY, B.P.; TEUKOLSKY, S.A.; VETTERLING, W.T. Numerical Recipes in C - The Art of Scientific Computing. Cambridge, University Press, 1988.

[29] ROBERTS, L.G. Picture Coding Using Pseudo-Random Noise. IRE Trans. Inf. Theory, v. IT-8, p. 145-54, february 1962.

[30] SCHILDT, H. C Completo e Total. 2 ed. Osborne/McGraw-Hill, 1991.

[31] SHANNON, C.E. A Mathematical Theory of Communication. Bell. Syst. Tech. J., v. 27, p. $379-423 ; 623-59,1948$.

[32] SUN, M.-T; CHEN, T.-C.; GOTTLIEB, A.M. VLSI Implementation of a $16 \times 16$ Discrete Cosine Transform. Trans. on Circuits and Systems, v. 36 , n. 4 , april 1989 .

[33] WALLACE, G.K. The JPEG Still-Picture Compression Standard. Commun. of the $A C M$, v. 34, n. 4, p. 31-44, april 1991.

[34] WITTEN, I.H.; NEAL, R.M.; CLEARY, J.G. Arithmetic Coding for Data Compression. Commun. of the $A C M$, v. 30 , n. 6, p. 520-40, june 1987. 